\title{
Relapse of Orthodontically Corrected Deep Bites in Accordance with Growth Pattern
}

by

Derek Pollard, D.M.D.

\begin{abstract}
A thesis submitted to the Faculty of Graduate Studies of
The University of Manitoba

in partial fulfillment of the requirements for the degree of
\end{abstract}

MASTER OF SCIENCE

Department of Preventive Dental Science

University of Manitoba

Winnipeg

COPYRIGHT @ 2011 by Derek Pollard 


\section{University of Manitoba}

\section{Faculty of Graduate Studies}

The following certify that they have read the Master's thesis entitled:

"Relapse of orthodontically corrected deep bites in accordance with growth pattern"

Submitted by

\section{Dr. Derek Richard Pollard}

In partial fulfillment of the requirements for the degree of

Master of Science

(Orthodontics)

Dr. Sercan Akyalcin (Supervisor), DDS, PhD

Department of Preventive Dental Science

Dr. William A. Wiltshire (Internal Examiner), BChD, BChD(HONS), MDent, $\mathrm{MChD}($ Orth), DSc(Odont), FRCD(C)

Department Head of Preventive Dental Sciences

Dr. Wellington Rody Jr. (Internal Examiner), DDS, MS

Department of Preventive Dental Sciences

Dr. Noriko Boorberg (External Examiner), DDS, MEd

Department of Restorative Dentistry 


\begin{abstract}
RELAPSE OF ORTHODONTICALLY CORRECTED DEEP BITES IN ACCORDANCE WITH GROWTH PATTERN
\end{abstract}

OBJECTIVES: (1) Compare the relapse of corrected deep bites in three groups of patients separated by facial type (2) Determine the associations of various parameters influencing deep bite relapse.

METHODS: 60 patients treated at the University of Washington were included, all with initial overbites $>50 \%$. Patients were grouped according to initial Y-axis, MPA, and LFH values. Data was collected from casts and cephalometric radiographs at three time points: pre-treatment, post-treatment, and ten years post-retention.

RESULTS: Dolicocephalic subjects showed the least amount of deep bite relapse $(0.1 \pm$ $1.1 \mathrm{~mm})$, while brachycephalic $(1.2 \pm 0.9 \mathrm{~mm})$ and mesocephalic $(1.4 \pm 1.3 \mathrm{~mm})$ subjects experienced significant relapse $(\mathrm{p}<0.05)$. Intergroup comparisons revealed that the brachycephalic group had significantly more post-retention change in overbite, N-ANS, interincisal angle, and L1-MP than the dolicocephalic group $(\mathrm{p}<0.05)$.

CONCLUSIONS: Orthodontists should consider overcorrection of overbite in brachycephalic and mesocephalic patients presenting with overbites $>50 \%$. 


\section{ACKNOWLEDGEMENTS}

I would like to sincerely thank the following individuals who have helped me in one way or another throughout my graduate studies:

- The University of Washington for allowing me to use their long-term postretention data base

- My committee members - Drs. Sercan Akyalcin, William Wiltshire, Wellington Rody, and Noriko Boorberg

- Dr. Anne-Marie Bollen from the University of Washington

- My statistician Brenden Dufault

- The Manitoba Graduate Scholarship (MGS) for financial assistance

- My classmates Dr. Jared Rykiss and Dr. Xiem Phan

- My parents Rick and Sandra

- My wife Courtney 


\section{TABLE OF CONTENTS}

Page Number

TITLE PAGE I I

COMMITTEE CERTIFICATION II

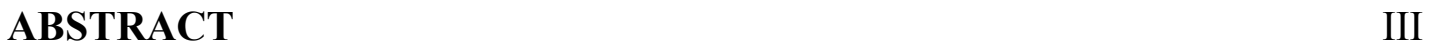

ACKNOWLEDGEMENTS IV IV I

TABLE OF CONTENTS V V

LIST OF FIGURES VII

LIST OF TABLES X X

CHAPTER 1 - INTRODUCTION

$\begin{array}{lll}1.1 & \text { Introduction } & 2\end{array}$

1.2 Review of the Literature 4

1.2.1 Normal Overbite 4

1.2.2 Measurement of Overbite 6

1.2.3 Overbite Correction 8

1.2.4 Overbite Relapse 9

1.2.5 Possible Reasons for Overbite Relapse 11

$\begin{array}{lll}1.3 & \text { Purpose of this Study } & 16\end{array}$

$\begin{array}{lll}1.4 & \text { Thesis Statement } & 17\end{array}$

CHAPTER 2 - SUBJECTS AND METHODS 18

$\begin{array}{lll}2.1 & \text { Sample Selection } & 19\end{array}$

2.2 Cephalometric Analysis 21

2.2.1 Landmark Definitions $\quad 23$

2.2.2 Angular Cephalometric Measurements 27 
2.3 Plaster Model Analysis

2.3.1 Plaster Model Measurements

2.4 Formation of Groups According to Facial Type

2.5 Statistical Analysis

3.1 Measurement Reliability

3.2 Total Overbite Correction and Relapse

3.3 Brachycephalic Group

3.4 Mesocephalic Group

3.5 Dolicocephalic Group $\quad 55$

3.6 Summary of Significant Intergroup Differences 58

3.7 Intergroup Changes for Each Variable 61

CHAPTER 4 - DISCUSSION 93

4.1 Evaluation of Group Facial Type Characteristics 94

4.2 Evaluation of Overbite Relapse 96

4.3 Possible Reasons for Intergroup Relapse Differences 98

4.3.1 Amount of Deep Bite Correction 98

4.3.2 Incisal Angulation Changes 99

$\begin{array}{lll}\text { 4.3.3 Incisal Position Changes } & 102\end{array}$

$\begin{array}{ll}\text { 4.3.4 Growth Pattern } & 104\end{array}$

4.4 Limitations of the Study 111

CHAPTER 5 - CONCLUSIONS 113

LIST OF REFERENCES 114 


\section{LIST OF FIGURES}

Page Number

Figure 1. Cephalometric points used in the study

Figure 2. SNA

Figure 3. SNB

Figure 4. ANB

Figure 5. MPA

Figure 6. $\quad$ Y-axis

Figure $7 . \quad$ LFH

Figure 8. FMA

Figure 9. OP-SN

Figure 10. U1-SN

Figure 11. L1-MP

Figure 12. Interincisal Angle

Figure 13. U1-PP (mm)

Figure 14. U4-PP and U5-PP (mm)

Figure 15. U6-PP (mm)

Figure 16. L1-MP (mm)

Figure 17. L4-MP and L5-MP (mm)

Figure 18. L6-MP (mm)

Figure 19. Anterior Face Height

Figure 20. Posterior Face Height

Figure 21. Upper Face Height 
Figure 22. Lower Anterior Face Height 38

Figure 23. Y-axis comparison for the three groups 61

Figure 24. MPA comparison for the three groups 62

Figure 25. LFH comparison for the three groups 63

Figure 26. SNA comparison for the three groups 64

Figure 27. SNB comparison for the three groups 65

Figure 28. ANB comparison for the three groups 66

Figure 29. FMA comparison for the three groups 67

Figure 30. AFH comparison for the three groups 68

$\begin{array}{lll}\text { Figure 31. PFH comparison for the three groups } & 69\end{array}$

$\begin{array}{lll}\text { Figure 32. UAFH comparison for the three groups } & 70\end{array}$

Figure 33. LAFH comparison for the three groups 71

Figure 34. OP-SN comparison for the three groups 72

Figure 35. U1-SN comparison for the three groups 73

$\begin{array}{lll}\text { Figure 36. L1-MP comparison for the three groups } & 74\end{array}$

Figure 37. Interincisal Angle comparison for the three groups 75

Figure 38. U1-PP (mm) comparison for the three groups 76

Figure 39. U4-PP (mm) comparison for the three groups 77

Figure 40. U5-PP (mm) comparison for the three groups 78

Figure 41. U6-PP (mm) comparison for the three groups 79

Figure 42. L1-MP (mm) comparison for the three groups 80

Figure 43. L4-MP (mm) comparison for the three groups 81

Figure 44. L5-MP (mm) comparison for the three groups 82

Figure 45. L6-MP (mm) comparison for the three groups 83 
Figure 46. Overjet comparison for the three groups 84

Figure 47. Overbite ( $\mathrm{mm})$ comparison for the three groups 85

Figure 48. Overbite (\%) comparison for the three groups 86

Figure 49. Curve of Spee comparison for the three groups 87

Figure 50. Lower Incisor Irregularity comparison for the three groups $\quad 88$

Figure 51. Lower Intercanine Width comparison for the three groups 89

Figure 52. Lower Intermolar Width comparison for the three groups 90

Figure 53. Upper Intercanine Width comparison for the three groups 91

Figure 54. Upper Intermolar Width comparison for the three groups 92 


\section{LIST OF TABLES}

Page Number

Table 1. Retention appliances used within each group 20

Table 2. Gender and skeletal patterns for the three groups 44

Table 3. Mean values for each of the three groups 44

Table 4. Data for the Brachycephalic Group $\quad 50$

Table 5. Data for the Mesocephalic Group 53

Table 6. Data for the Dolicocephalic Group 56

Table 7. Significant intergroup changes during orthodontic treatment $\quad 59$

Table 8. Significant intergroup changes during post-retention period $\quad 60$ 


\section{CHAPTER 1}

\section{INTRODUCTION}

\section{Page Number}

$\begin{array}{lll}1.1 & \text { Introduction } & 2\end{array}$

1.2 Review of the Literature 4

1.2.1 Normal Overbite 4

1.2.2 Measurement of Overbite 6

$\begin{array}{lll}\text { 1.2.3 Overbite Correction } & 8\end{array}$

1.2.4 Overbite Relapse 9

1.2.5 Possible Reasons for Overbite Relapse 11

$\begin{array}{lll}1.3 & \text { Purpose of this Study } & 16\end{array}$

1.4 Thesis Statement 17 


\subsection{INTRODUCTION}

There have been many studies that have attempted to identify how the dentition, dentoalveolar and skeletal bone, and facial soft tissues respond immediately following orthodontic treatment, as well as during the years that follow the removal of retention appliances (Simons \& Joondeph, 1973; Little, Riedel \& Årtun, 1988; Little, 1990; Harris, Gardner \& Vaden, 1999; Miao \& Liu, 2002; Lyotard, Hans, Nelson et al, 2010; Park, Boley, Alexander et al, 2010). A detailed review of the literature on this topic is beyond the scope of this literature review, but some of the most frequently cited papers on this subject are from Little's body of research performed at the University of Washington, Seattle, Washington. For example, one of his most significant findings was the almost certainty of post-treatment decrease in mandibular intercanine width, even in the absence of expansion during orthodontic treatment (Little, 1990). Although the causes of relapse remain uncertain and controversial, the one certainty is that post-orthodontic changes are multi-factorial in nature, and appear to involve a combination of dental relapse, continued growth, and normal aging (Little, Riedel \& Årtun, 1988; Little, 1990).

One of the most common problems faced by orthodontists is a deep overbite malocclusion. The National Health and Nutrition Examination Survey (NHANES III) estimated that over $50 \%$ of the US population had overbites greater than $3 \mathrm{~mm}$, with almost $8 \%$ being severe ( $\geq 6 \mathrm{~mm}$ ) (Brunelle, Bhat $\&$ Lipton, 1996). If left untreated, this can cause direct periodontal tissue trauma and dental attrition, which can lead to further periodontal breakdown (Daniels \& Richmond, 2000). It is also considered to be one of the most challenging to correct, specifically because of its high tendency for post-orthodontic 
relapse (Engel, Damerell, McAlpine et al, 1980; Berg, 1983; Dake \& Sinclair, 1989; Hirschfelder \& Hertrich, 1990; Hirschfelder \& Fleischer-Peters, 1992; Canut \& Arias, 1999; Kim \& Little, 1999; Al-Buraiki, Sadowsky \& Schneider, 2005; Schutz-Fransson, Bjerklin \& Lindsten, 2006; Ferrazzini, 2008; Preston, Maggard, Lampasso et al, 2008). To avoid or minimize such tendencies requires the clinician to be cognisant of certain morphological characteristics of patients predisposed to greater amounts of overbite relapse. Various characteristics have been researched and implicated, including relapse in the Curve of Spee (De Praeter, Dermaut, Martens et al, 2002; Preston, Maggard, Lampasso et al, 2008), relapse of the interincisal angle (Binda, Kuijpers-Jagtman, Maertens et al, 1994), pressure from the lips (Lapatki, Mager, Schulte-Moenting et al, 2002; Lapatki, Klatt, Schulte-Moenting et al, 2004), and facial type with corresponding musculature (Engel, Damerell, McAlpine et al, 1980; Berg, 1983; Ingervall \& Bitsanis, 1987; Liu, Xu, Yang et al, 2005). Accordingly, if certain patients can be identified as high-risk overbite relapse candidates, treatment mechanics and retention strategies may need to be enhanced in these individuals to achieve the most stable outcome. 


\subsection{REVIEW OF THE LITERATURE}

\subsubsection{Normal Overbite}

In order to determine what constitutes a deep overbite malocclusion, one first must be able to clearly define a normal overbite. Many different values for "normal" or "average" overbite have been defined in the literature. For instance, some authors prefer to use a certain percentage of clinical crown coverage of the mandibular incisors. Examples of this include: $15-60 \%$ of the clinical crown length of the lower incisor (Moorrees, 1959), $20 \%$ of the clinical crown length of the lower incisor (Neff, 1949), lower incisors occlude with the middle third (Baume, 1950) or incisal third (Strang \& Thompson, 1958) of the upper central incisors, overlap of up to half of the crowns of the lower incisors (Foster \& Day, 1974), and overlap in the middle third of the crowns of the lower incisors (Haynes, 1972).

Conversely, other researchers have chosen to ignore the clinical crown length of the mandibular incisors and focus on the amount of vertical incisal overlap measured in millimetres. Examples of this include: 0-3 mm (Brunelle, Bhat \& Lipton, 1996), 0-4 mm (Bjork, 1953), 0.5-4 mm (Kim, 1974), 1-4 mm (Ceylan \& Eröz, 2001), 2-4 mm (Kinaan, 1986), and 2.5-6.5 mm (Prakash \& Margolis, 1952)

Although most researchers use a numerical value for normal overbite as seen above, Engelman (1966) suggested that overbite should not be considered abnormal unless function is impeded, abrasion of teeth is induced, or the dental or gingival health is in 
danger. Thus, it is apparent that there is no universal consensus regarding what can be considered a normal overbite. Strang \& Thompson (1958) and Engelman (1966) stated that the distinction between a normal and an abnormal overbite is not clear, and normal overbite may vary depending on age, racial background, tooth shape, and facial type. 


\subsubsection{Measurement of Overbite}

Similar to most dentofacial landmarks and measurements, dental overbite can be measured in a variety of ways. The most commonly used method is to clinically measure the degree of overbite intraorally with a periodontal probe. This technique is an easy and efficient method making it ideal for daily private practice use, but it is not precise enough for research purposes. In the literature, most researchers opt to measure overbite more precisely from either dental casts or cephalometric radiographs.

When choosing to measure overbite from dental casts, a technique originally developed by Moorrees (1959) is most frequently used. It involves placing a fine pencil mark on the labial surface of the mandibular incisors denoting the projection of the incisal edge of the maxillary central incisors. Moorrees suggested that the pencil be held in such a position that the upper side of the cone produced by sharpening is parallel with the occlusal plane. Haynes (1972) altered this original technique by recommending that clinicians and researchers use Frankfurt Horizontal as the reference plane.

When measuring overbite on cephalometric radiographs, most researchers measure the linear distance between the incisal tips of upper and lower incisors perpendicular to a particular reference line. The Occlusal Plane is the most common reference line (Bjork, 1953; Kim, 1974; Lowe, 1980; Beckmann, Kuitert, Prahl-Andersen et al, 1998; Ceylan \& Eröz, 2001), although Palatal Plane (Bergersen, 1988), Nasion-Sella plane (Isaacson, Isaacson, Speidel et al, 1971), Facial Plane (Nasion-Pogonion) (Prakash \& Margolis, 
1952), and Nasion-Menton plane (Nahoum, Horowitz \& Benedicto, 1972) have also been utilized.

Once the desired technique for measuring overbite has been determined, researchers also have the option of reporting overbite in either a millimetre value or a percentage. Neff (1949) strongly supported the latter, indicating that a percentage is the only way to have an accurate representation of overbite regardless of tooth length. Some have also suggested measuring overbite as part of the length of the upper central incisor crown (Strang \& Thompson, 1958). 


\subsubsection{Overbite Correction}

Orthodontic correction of an anterior deep bite malocclusion can be achieved by intrusion and/or proclination of the anterior teeth, extrusion of the posterior teeth, or a combination of these. When looking at the literature, it appears that the latter might be the closest to the truth. For instance, Parker, Nanda \& Currier (1995) found that the correction of deep overbite in their sample of 132 deep bite cases primarily affected the proclination of incisors and the extrusion of molars, while lower incisor intrusion occurred in only $35 \%$ of the cases. Bernstein, Preston \& Lampasso (2007) observed that most levelling of the Curve of Spee in their sample was accomplished by the extrusion of the premolars, although some incisor intrusion was observed as well. Finally, Otto, Anholm \& Engel (1980) analysed deep-bite cases treated using Bioprogressive technique and reported that the majority were corrected by a combination of lower incisor intrusion and incisor proclination. 


\subsubsection{Overbite Relapse}

Once the deep bite is corrected, some amount of relapse can be expected and has been shown numerous times in the literature. For example, deep bite cases treated using the Ricketts technique showed an average intrusion of $3 \mathrm{~mm}$, followed by an average relapse of $1 \mathrm{~mm}$ (Engel, Damerell, McAlpine et al, 1980). In another study by Dake \& Sinclair (1989), subjects treated by Tweed mechanics demonstrated $0.8 \mathrm{~mm}$ (20\%) of overbite relapse, compared to $1.4 \mathrm{~mm}$ (34\%) for the Ricketts group. Berg (1983) observed a mean overbite reduction of $49.2 \%$ during treatment, which relapsed $18.8 \%$ post-treatment. When related to pre-treatment situation, the mean relapse was $9.2 \%$. Hirschfelder \& Hertrich (1990) reported a mean relapse in overbite of $1.7 \mathrm{~mm}$ in $93.3 \%$ of their 49 deep bite subjects. In another study, Hirschfelder \& Fleischer-Peters (1992) analysed the stability of deep bite correction in 60 patients treated with functional appliances. Posttreatment deepening of the overbite $(>0.8 \mathrm{~mm})$ was found in $54.2 \%$ of the subjects. Schutz-Fransson, Bjerklin \& Lindsten (2006) observed a mean relapse of $0.8 \mathrm{~mm}, 11$ years after treatment in the deep bite group, while the untreated control group underwent a bite opening of $0.7 \mathrm{~mm}$ during the same time period.

Kim \& Little (1999) analyzed 62 patients with Class II Division 2 malocclusions and observed an average overbite improvement of $3.5 \mathrm{~mm}$ during treatment, followed by an average relapse of $1.4 \mathrm{~mm}$. Kim and Little's study revealed more relapse than most studies have reported, most likely because of the long duration of the post-retention phase. The mean post-retention duration in this study was 15 years, with the minimum being 8.6 years. In a similar study, Canut \& Arias (1999) observed a mean overbite 
correction of $3.5 \pm 1.8 \mathrm{~mm}$ in 30 Class II division 2 subjects during active orthodontic treatment, which relapsed $0.9 \pm 1.2 \mathrm{~mm}$ during the post-retention period $($ mean duration $=$ 7 years). Preston, Maggard, Lampasso et al (2008) found a statistically significant, but clinically insignificant, amount of relapse after levelling the Curve of Spee (COS) in deep bite patients. They also concluded that patients whose Curves of Spee were not completely level post-treatment had a greater incidence and magnitude of COS relapse, and indirectly deep bite relapse, than did those who were completely levelled. Ferrazzini (2008) showed remarkable stability of most dental variables measured, including overbite, in a 37 patient sample treated for their Class II division 2 malocclusions after 20 years. Al-Buraiki, Sadowsky \& Schneider (2005) studied 25 subjects with deep overbite of at least $4 \mathrm{~mm}$ (mean overbite $=5.9 \mathrm{~mm}$ ) that were treated with cervical headgear and intrusion mechanics and found that overbite increased by $0.7 \mathrm{~mm}$, or $17 \%$, during the post-treatment period. 


\subsubsection{Possible Reasons for Overbite Relapse}

From the studies cited in the previous section, it is readily apparent that stabilization of a corrected deep overbite malocclusion is a major orthodontic concern. Rather than advising overcorrection in all patients presenting with this common dental problem, many investigators have attempted to identify dentofacial characteristics that predispose a patient to greater amounts of deep bite relapse. For instance, De Praeter, Dermaut, Martens et al (2002) analyzed 149 patients (57 males, 92 females; mean age $=12.8)$ who were on average 6.7 years post-retention and found a mild correlation between the amount of relapse of the Curve of Spee and the relapse of the irregularity index, overjet, and overbite. The highest correlation was found for the amount of overbite relapse, indicating that the relapse of the Curve of Spee is associated with a deepening of the bite post-retention $(r=0.36)$. However, only about $13 \%$ of the relapse of the Curve of Spee was due to the deepening of the bite.

The literature also indicates that the interincisal angle may play a significant role in the relapse in overbite post-retention. In a sample of 44 Class II division 2 subjects, Binda, Kuijpers-Jagtman, Maertens et al (1994) reported a $6.3^{\circ}$ relapse in this angle during the 5year post-retention period. This increase in the interincisal angle was significantly correlated $(r=0.6)$ with the increase in overbite also observed during the same 5-year span. To counteract this tendency, the authors recommended an extended retention period with a bite relieving appliance that also retains the inclination of the upper anterior teeth. This may contribute to long-term stability. On the other hand, Simons \& Joondeph (1973) 
did not find a correlation between the interincisal angle established following orthodontic treatment and post-retention changes in overbite.

The soft tissues surrounding the oral cavity, specifically the lips, have also been implicated as a cause of the increased amounts of relapse of deep overbite. Lapatki, Klatt, Schulte-Monting et al (2004) found an average relapse of $20 \%$ of the total correction of the anterior linguoversion and deep bite, with the relapse tendency being greater in patients with maxillary extractions, cases requiring large changes to upper incisor inclination, and patients with a high post-treatment lip line (i.e. amount the lower lip covers the upper incisors). Thus, an increased amount of deep bite relapse can be expected in patients whose lip line is not reduced to a maximum of $3 \mathrm{~mm}$ after orthodontic treatment. Similar findings were found by Lapatki, Baustert, Schulte-Monting et al (2006), in which the authors stated that the achievement of physiological relationships between upper incisors and lower lip should be regarded as one of the most important objectives when correcting deep bite.

One of the most important morphological characteristics relevant to the amount of relapse appears to be the growth pattern and corresponding facial type of the individual patient. For instance, Simons \& Joondeph (1973) concluded that significant vertical mandibular growth during and following treatment was correlated with overbite stability, while lack of mandibular growth or growth in a more horizontal direction was associated with overbite relapse. Engel, Damerell, McAlpine et al (1980) found that the greatest amount of relapse in treated deep-bite cases was in those with brachycephalic patterns with short lower anterior facial height and low mandibular plane angle. Engel, Damerell, McAlpine 
et al (1980) also found that patients with a higher than average mandibular arc showed the least opening during treatment and the greatest closing after treatment. In fact, the cases that presented with increased mandibular arcs (an indication of a true brachycephalic pattern) that opened during treatment averaged more than $100 \%$ relapse of the facial axis. Berg (1983) revealed that both treatment changes and post-treatment relapse were greater in seven Class II division 2 cases, which are typically characterized by a more brachycephalic facial type, than those found in nineteen Class II division 1 cases.

Liu, Xu, Yang et al (2005) found that after orthodontic treatment, the hyperdivergent group (MP-SN $>40^{\circ} ; \mathrm{N}=10$ ) exhibited extrusion of both upper and lower molars as well as a decrease in ANB angle reflecting a tendency to change from skeletal Class II to Class I. In the vertical dimension, the ratio of Articulare-Gonion/ANS-Menton increased in this group, revealing that the ramus showed great growth potential during the treatment stage and maintained the inclination of the mandibular plane. In contrast, the hypodivergent group (MP $<29^{\circ} ; \mathrm{N}=9$ ) only showed extrusion of the lower molars after treatment. In the post-retention stage, the change of overbite in the hyperdivergent group was mainly due to lingual inclination of the upper incisors during the treatment stage and in the hypodivergent group it was due to the molar extrusion during treatment. To summarize Liu's findings, the stability of the overbite didn't show any statistically significant difference between the two groups during the follow-up stage ( $>2$ years). Also, the relapse of the overbite was correlated with changes of teeth during the treatment and follow-up stages. 
A patient's facial type is strongly associated with facial musculature, which most likely also influences overbite. Gedrange, Hietschold, Haase et al (2005) determined that the deep overbite group had significantly higher muscle densities in the medial pterygoid, masseter, and genioglossus muscles in comparison to open bite patients. Significant differences of muscle cross-section were measured in the masseter between patients with retroclined maxillary incisors and with an open bite. Therefore, the results of this study showed a correlation between different jaw positions and masticatory muscles.

Another interesting experiment by Ingervall \& Bitsanis (1987) also showed the importance of the mandibular muscles in the determination of facial type and facial growth. They analysed thirteen long-faced children and had the subjects chew a tough chewing material daily for one year. Results showed that bite force and muscle activity during maximal bite both increased over the experimental period. More importantly, facial growth was characterized by anterior mandibular rotation in nine out of the twelve cases with a mean decrease of $2.5^{\circ}$. The authors suggested that this value is considerably greater than would be expected during normal growth. Harris, Gardner \& Vaden (1999) observed a similar rotation of the mandible in their sample of 28 subjects that were followed up for a mean of 14.4 years post orthodontic treatment. This counter clockwise rotation was evident by increases seen over time in facial height index (i.e. PFH/AFH ratio) coupled with decreases in FMA and occlusal plane angle. The authors suggested that continued horizontal growth, significant ramus growth, and mandibular border remodelling are the reason for the observed rotation. Whatever the cause of the rotation, the direction and amount thereof could potentially lead to an overclosed situation resulting in an increase in overbite. 
Kim \& Little (1999) determined that initial overbite was the most important factor in predicting post-retention overbite since initial overbite was positively correlated with post-retention overbite. Maxillary and mandibular incisors which were very upright before orthodontic treatment tended to have deeper initial overbite and showed a tendency to return to their original relationship by the post-retention stage. The authors also hypothesized that more favourable growth in the vertical direction might contribute to the maintenance of the overbite correction. 


\subsection{PURPOSE OF THIS STUDY}

This study was undertaken to evaluate and compare the amount of relapse of orthodontically corrected anterior deep bite cases, as well as to evaluate the morphologic changes according to growth type. 


\subsection{THESIS STATEMENT}

Null Hypothesis \#1:

There is no difference in the amount of relapse of deep overbite between the brachycephalic, mesocephalic, and dolicocephalic subjects.

Null Hypothesis \#2:

Overbite relapse is independent of other dentoalveolar and craniofacial changes. 


\section{CHAPTER 2}

\section{SUBJECTS AND METHODS}

Page Number

$\begin{array}{lll}2.1 & \text { Sample Selection } & 19\end{array}$

$\begin{array}{lll}2.2 & \text { Cephalometric Analysis } & 21\end{array}$

$\begin{array}{ll}\text { 2.2.1 Landmark Definitions } & 23\end{array}$

2.2.2 Angular Cephalometric Measurements 27

2.2.3 Linear Cephalometric Measurements 33

2.3 Plaster Model Analysis $\quad 39$

2.3.1 Plaster Model Measurements $\quad 40$

2.4 Formation of Groups According to Facial Type 43

2.5 Statistical Analysis 45 


\subsection{SAMPLE SELECTION}

The sample for the present study was drawn from an archived collection of over 1000 treated patients in the long-term post-retention database at the University of Washington (Seattle, Washington) Graduate Orthodontic Clinic. Cases were selected based on meeting all the following criteria: they had pre-treatment (T1), post-treatment (T2), and long-term post-retention (T3) records (models, lateral cephalometric and panoramic radiographs) of sufficient quality to allow for accurate landmark identification, they were at least 11 years old at the start of orthodontic treatment and were in the permanent dentition, they were at least 10 years post-retention at T3, they were treated nonextraction with full fixed orthodontic appliances, and they presented with incisor overbites of $50 \%$ or greater as measured on the initial (T1) study models. This initial overbite assessment for inclusion into the study was done visually on the pre-treatment casts. If it was discovered that a particular subject did not have the necessary $50 \%$ or greater overbite during accurate measurement of overbite, the subject was excluded from the study. Included subjects also had to demonstrate overbite correction during orthodontic treatment. Accordingly, overbite had to be less than $50 \%$ at T2. The quality of the treated result was not considered in the selection process. Two subjects whom had prior growth modification were included in the sample.

The final sample consisted of the records of 60 Caucasian patients (30 males, 30 females), which included 34 subjects presenting with an initial Class 1 skeletal pattern $(\mathrm{ANB}=0$ $\left.4^{\circ}\right), 25$ subjects with a Class 2 pattern $\left(\mathrm{ANB}>4^{\circ}\right.$ ), and 1 subject with a mild Class 3 pattern $\left(\mathrm{ANB}<0^{\circ}\right)$. Although specific information on orthodontic techniques and 
mechanics utilized during each subjects' treatment was not available, all underwent routine edgewise orthodontics followed by a minimum of two years in retention. Information on the type of retention used for each case was also difficult to collect due to incomplete records, but the majority of cases that had this information either used an upper removable Hawley retainer combined with a lower fixed lingual 3-3 retainer or upper and lower Hawley retainers (Table 1). The lower fixed 3-3 retainers consisted of banded lower canines joined together by a lingual stainless steel wire. Upper bite plates were incorporated into the retainers in only three cases ( 2 mesocephalic subjects and 1 dolicocephalic subject).

Table 1. Retention appliances used within each group

\begin{tabular}{|c|c|c|c|c|}
\hline \multirow{2}{*}{ Group } & \multirow{2}{*}{$\mathrm{N}$} & Upper Hawley, & Upper \& Lower & Retention not \\
\cline { 3 - 5 } & & Lower fixed 3-3 & Hawleys & specified \\
\hline Mesocephalic & 28 & 11 & 8 & 9 \\
\hline Brachycephalic & 16 & 6 & 2 & 8 \\
\hline Dolicocephalic & 16 & 9 & 5 & 2 \\
\hline
\end{tabular}




\subsection{CEPHALOMETRIC ANALYSIS}

The cephalometric radiographs, along with a translucent calibration ruler, were individually scanned into Dolphin imaging software (Dolphin Imaging, California, USA). The following standard cephalometric landmarks were identified on each radiograph: Sella (S), Nasion (N), Porion (Po), Orbitale (Or), Anterior Nasal Spine (ANS), Posterior Nasal Spine (PNS), A point (A), B point (B), Gonion (Go), Menton (Me), Pogonion (Pog), Gnathion (Gn), Protuberance Menti (PM), Xi point (Xi), upper incisal tip (U1), upper incisor root apex (UR), upper first premolar cusp tip (U4), upper second premolar cusp tip (U5) upper first molar mesial cusp tip (U6), lower incisal tip (L1), lower incisal root apex (LR), lower first premolar cusp tip (L4), lower second premolar cusp tip (L5), and lower first molar mesial cusp tip (L6) (see figure 2.2.1). All bilateral structures were located on a line or point midway between the right and left images. Due to the age and subsequent deterioration of the radiographs, no soft tissue landmarks could be consistently and reliably identified and as a result, none were included in the cephalometric analysis for the study. 
Figure 1. Cephalometric points used in the study

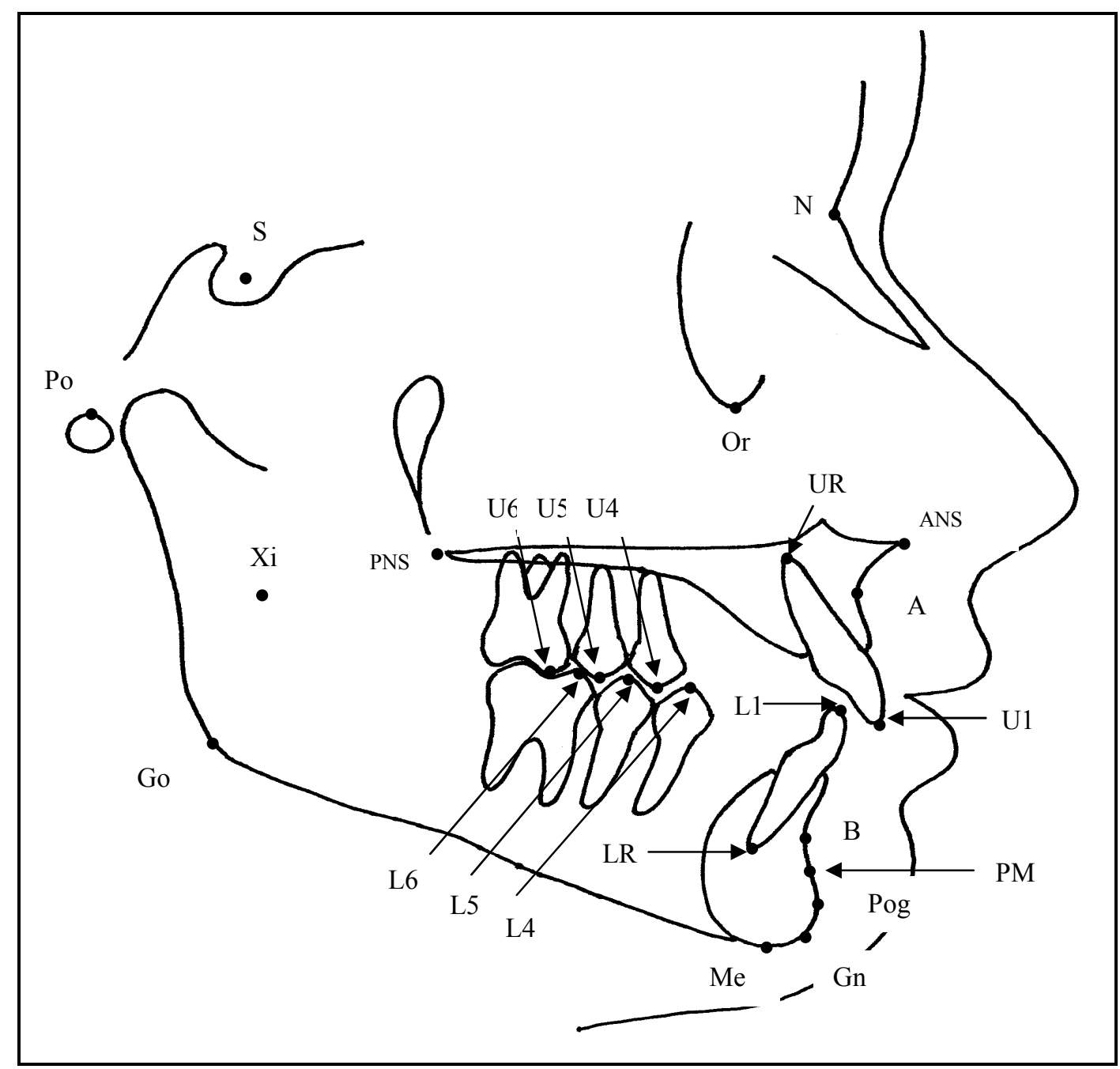

To determine the intra-examiner cephalometric analysis error, the records were first assigned random numbers, which made it possible for one investigator (D.P.) to examine them blindly. Once the initial cephalometric analysis was complete, five subjects were randomly selected from the original sample one month later and their cephalometric radiographs were re-measured by the same operator (D.P.), without reference to the previous measurements. 


\subsubsection{Landmark Definitions:}

The following cephalometric landmarks were located on each lateral cephalogram:

Sella (S): the geometric center of the pituitary fossa (sella turcica) in the midsagittal plane; determined by inspection on the lateral cephalogram (Downs, 1948).

Nasion (N): the most anterior point on the frontonasal suture (Broadbent, Broadbent, \& Golden, 1975).

Porion (Po): the most superiorly positioned point of the external auditory meatus located by using the ear rods (anatomical porion).

Orbitale (Or): the lowest point on the inferior rim of the orbit.

Anterior Nasal Spine (ANS): the most anterior point on the sharp bony process of the maxilla at the lower margin of the anterior nasal aperature (Broadbent, Broadbent, \& Golden, 1975).

Posterior Nasal Spine (PNS): the most posterior point on the bony spine of the palatine bone constituting the hard palate (Broadbent, Broadbent, \& Golden, 1975). 
A point (A): the most posterior midline point in the concavity between prosthion (the most anterior inferior point on the alveolar bone overlying the maxillary incisors) and ANS.

B point (B): the most posterior midline point in the concavity between infradentale (the most anterior superior point on the alveolar bone overlying the mandibular incisors) and pogonion.

Gonion (Go): constructed point on the curvature of the angle of the mandible located by bisecting the angle formed by lines tangent to the posterior ramus and the inferior border of the mandible.

Menton (Me): the most inferior point on the mandibular symphysis in the median plane (Broadbent, Broadbent, \& Golden, 1975).

Pogonion (Pog): the most anterior point on the mandibular symphysis in the median plane (Broadbent, Broadbent, \& Golden, 1975).

Gnathion (Gn): the most anterior inferior point on the mandibular symphysis in the median plane; determined anatomically by inspection, not cephalometrically (Broadbent, Broadbent, \& Golden, 1975).

Protuberance Menti (PM): the point on the mandibular symphysis where the curvature of the anterior border changes from concave to convex (Ricketts, 1981). 
Xi point (Xi): a constructed point located at the geometric center of the mandibular ramus; derived by bisecting vertical height and the horizontal depth of the ramus (Ricketts, 1981)

Upper Incisal Tip (U1): the incisal tip of the most labially positioned maxillary central incisor.

Upper Incisor Root Apex (UR): the root tip of the most labially positioned maxillary central incisor (Riolo, Moyers, McNamara et al, 1974). If the root was not fully formed, the midpoint of the growing root tip was used.

Upper First Premolar Cusp Tip (U4): the cusp tip of the maxillary first bicuspid.

Upper Second Premolar Cusp Tip (U5): the cusp tip of the maxillary second bicuspid.

Upper First Molar Mesial Cusp Tip (U6): the mesial cusp tip of the maxillary first molar.

Lower Incisal Tip (L1): the incisal tip of the most labially positioned mandibular incisor.

Lower Incisal Root Apex (LR): the root tip of the most labially positioned mandibular incisor (Riolo, Moyers, McNamara et al, 1974). If the root was not fully formed, the midpoint of the growing root tip was used. 
Lower First Premolar Cusp Tip (L4): the cusp tip of the mandibular first bicuspid.

Lower Second Premolar Cusp Tip (L5): the cusp tip of the mandibular second bicuspid.

Lower First Molar Mesial Cusp Tip (L6): the mesial cusp tip of the mandibular first molar. 


\subsubsection{Angular Cephalometric Measurements}

The following angular measurements were obtained on each lateral cephalogram:

SNA: The acute angle formed by the intersection of a line from Sella (S) to Nasion (N) and a line from Nasion $(\mathrm{N})$ to A point $(\mathrm{A})$. The average value for SNA is $82^{\circ} \pm 2^{\circ}$.

Figure 2. SNA

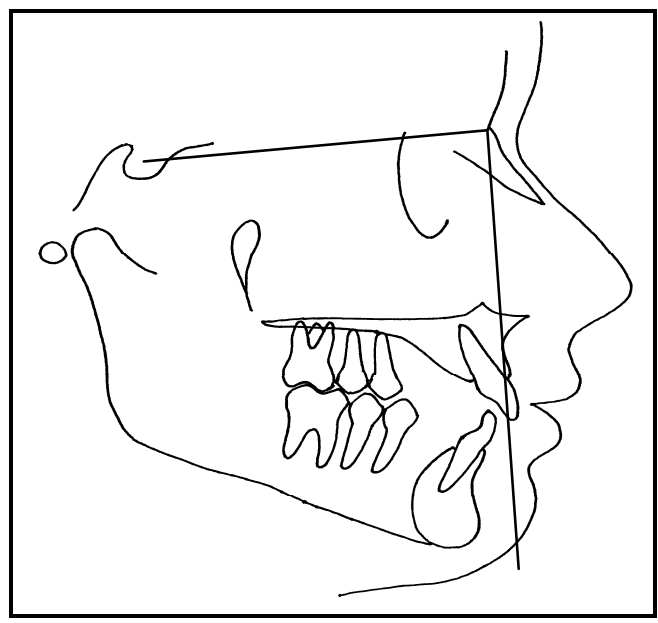

SNB: The acute angle formed by the intersection of a line from Sella (S) to Nasion (N) and a line from Nasion (N) to B point (B). The average value for SNB is $80^{\circ} \pm 2^{\circ}$.

Figure 3. $\quad$ SNB

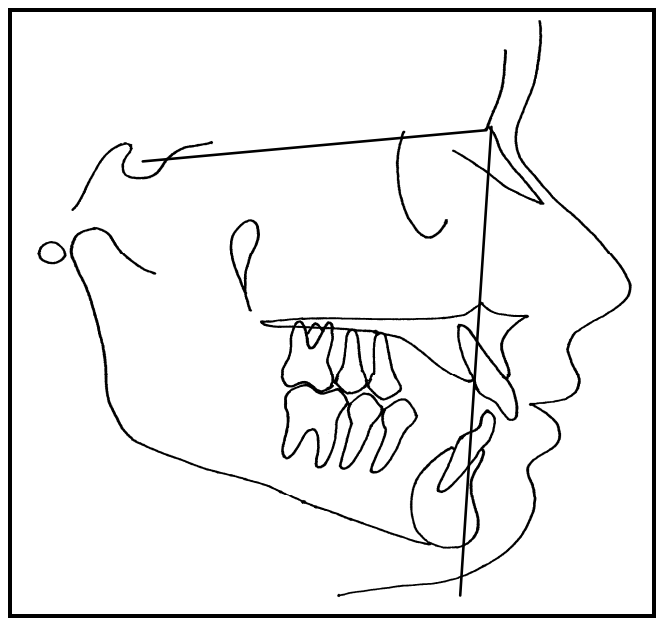


ANB: This is measured as the difference between the SNA and SNB angles (SNA$\mathrm{SNB}=\mathrm{ANB})$. The average value for $\mathrm{ANB}$ is $2^{\circ} \pm 2^{\circ}$.

Figure 4. ANB

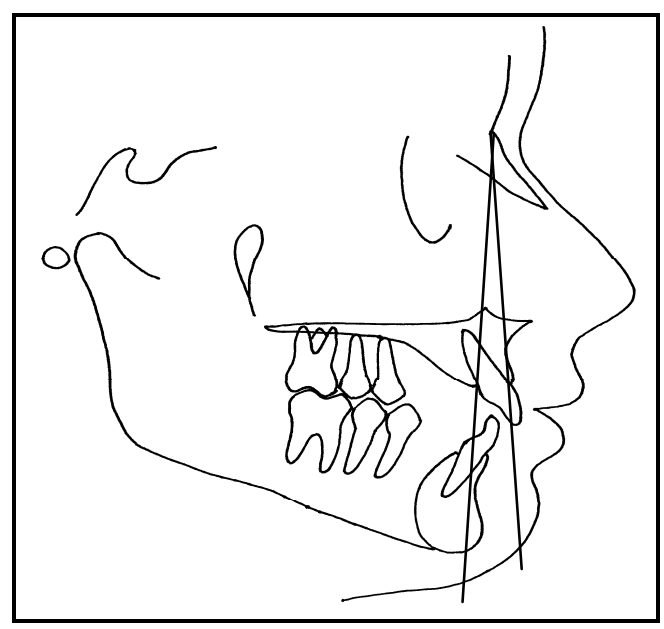

Mandibular Plane Angle (MPA): The acute angle formed by the intersection of a line from Sella $(\mathrm{S})$ to Nasion $(\mathrm{N})$ and a line from Gonion (Go) to Gnathion (Gn). The average value for MPA is $32^{\circ} \pm 2^{\circ}$.

Figure 5. MPA

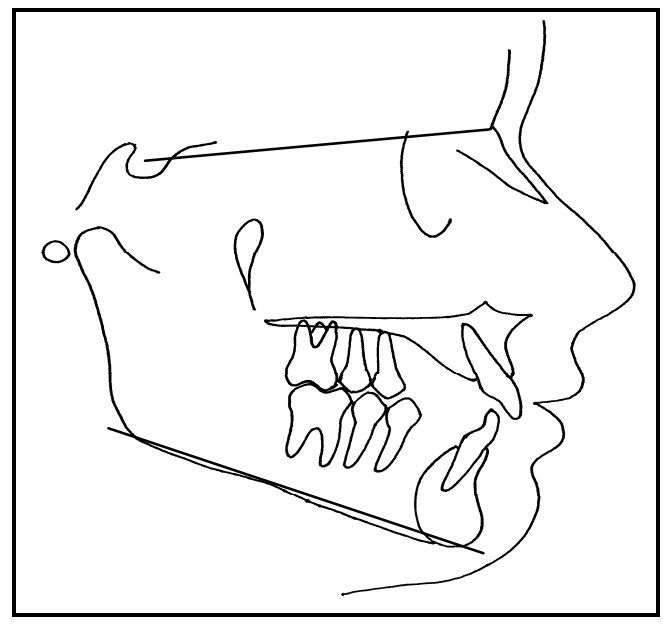


Y-axis: The acute angle formed by the intersection of a line from Sella (S) to Gnathion $(\mathrm{Gn})$ and a line from Sella $(\mathrm{S})$ to Nasion $(\mathrm{N})$. The average value for $\mathrm{Y}$-axis is $66^{\circ} \pm 2^{\circ}$.

Figure 6. $\quad \mathrm{Y}$-axis

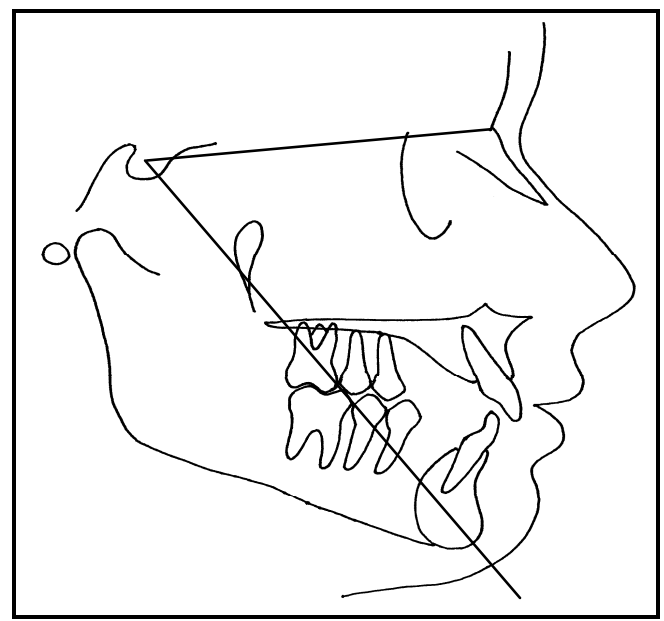

Lower Facial Height - Ricketts' (LFH): The acute angle formed by the Corpus Axis (line from $\mathrm{Xi}$ to $\mathrm{PM}$ ) and a line from Xi to ANS. The average value is $44^{\circ} \pm 3^{\circ}$ (Ricketts, 1981).

Figure $7 . \quad$ LFH

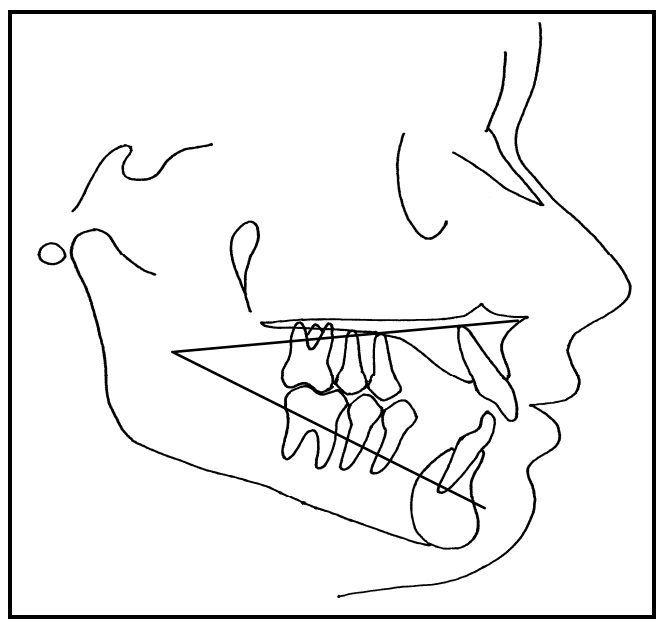


FMA (FH-MP): The acute angle formed by the intersection of a line from Porion (Pr) to Orbitale (Or), which is also known as Frankfurt Horizontal (FH), and a line from Gonion (Go) to Menton (Me), which is also known as Mandibular Plane (MP). The average value for FMA is $25^{\circ} \pm 5^{\circ}$.

Figure 8. FMA

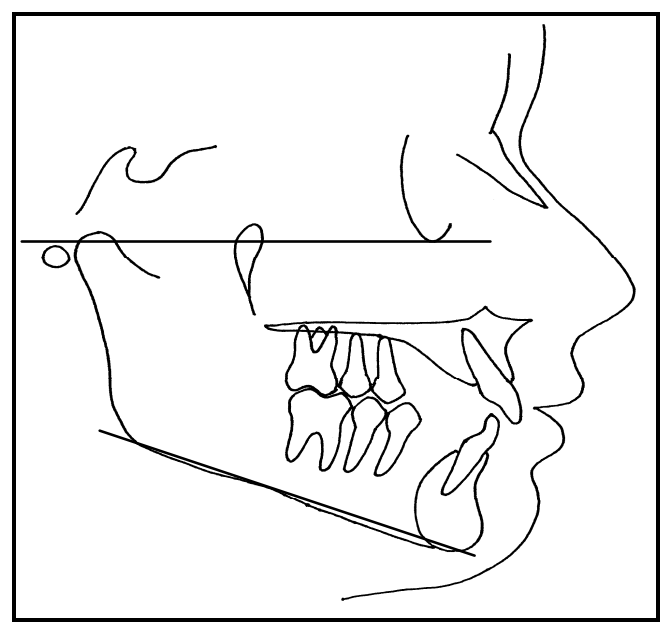

Occlusal Plane Angle (OP-SN): The acute angle formed by the intersection of a line through the overlapping cusps of the first premolars and first molars (Occlusal Plane) and a line from Sella (S) to Nasion (N). The average value for OP-SN is $14^{\circ} \pm 5$.

Figure 9. OP-SN

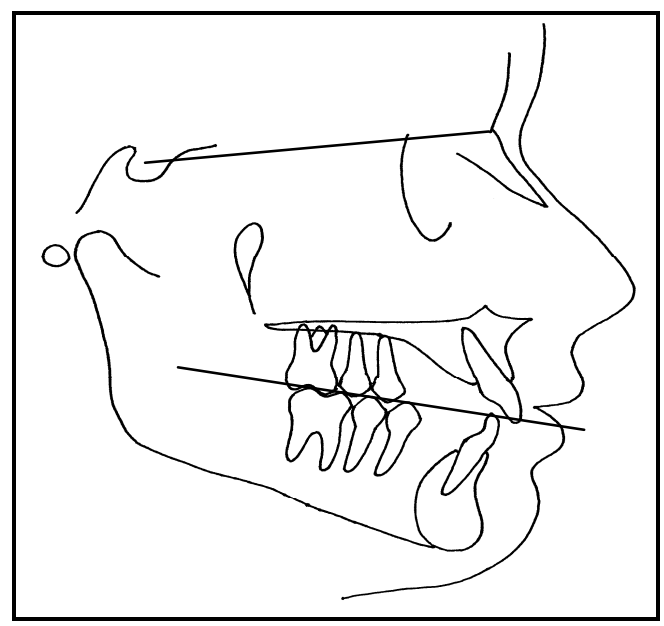


Upper Incisor Angle (U1-SN): The angle formed by the intersection of a line from the upper incisal tip (U1) to the upper incisal root apex (UR) and a line from Sella (S) to Nasion $(\mathrm{N})$. The average value for $\mathrm{U} 1-\mathrm{SN}$ is $104^{\circ} \pm 2^{\circ}$.

Figure 10. U1-SN

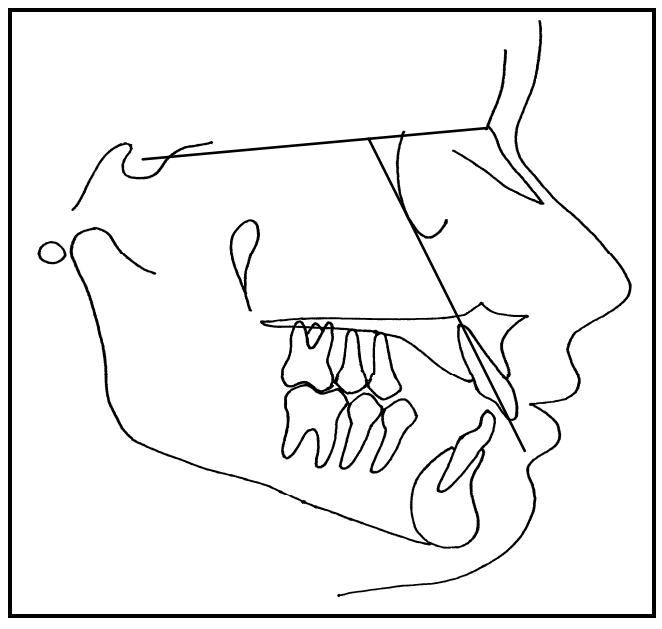

Lower Incisor Angle (L1-MP): The angle formed by the intersection of a line from the lower incisal tip (L1) to the lower incisal root apex (LR) and a line from Gonion (Go) to Gnathion (Gn), also known as Mandibular Plane (MP). The average value for L1-MP is $88^{\circ} \pm 4^{\circ}$

Figure 11. L1-MP

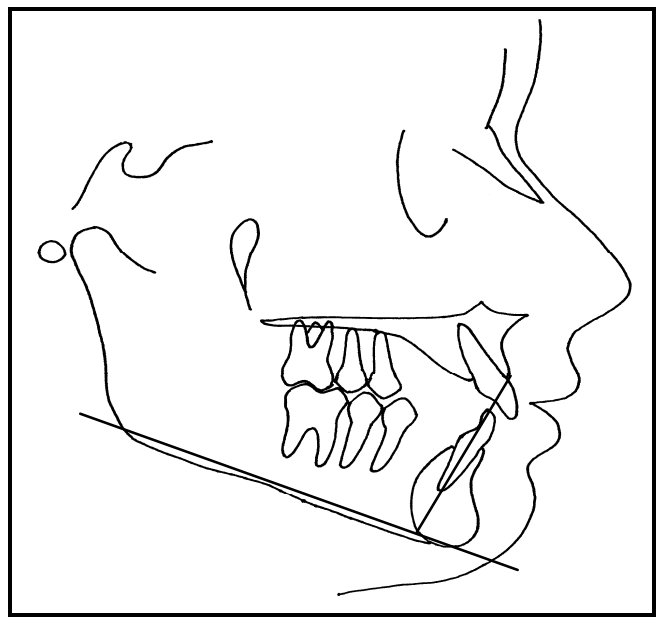


Interincisal Angle (U1-L1): The angle formed by the intersection of a line from the upper incisal tip (U1) to the upper incisal root apex (UR) and a line from the lower incisal tip (L1) to the lower incisal root apex (LR). The average value for Interincisal Angle is $131^{\circ} \pm 2^{\circ}$

Figure 12. Interincisal Angle

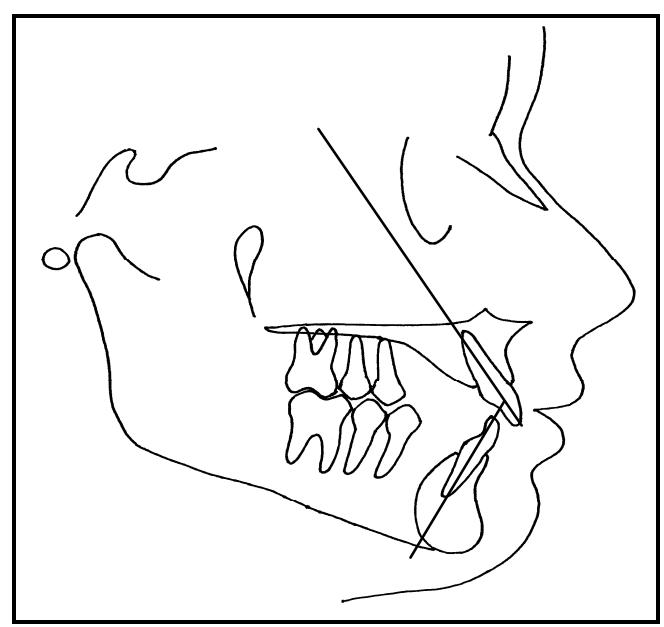




\subsubsection{Linear Cephalometric Measurements}

The following linear measurements were obtained on each lateral cephalogram:

Upper Incisor Position (U1-PP, mm): The linear distance from the incisal tip of the maxillary incisor (U1) to Palatal Plane (ANS-PNS), measured perpendicular to Palatal Plane. The average values are $33 \pm 3 \mathrm{~mm}$ for adult males and $30 \pm 3 \mathrm{~mm}$ for adult females (Riolo, Moyers, McNamara et al, 1974).

Figure 13. U1-PP

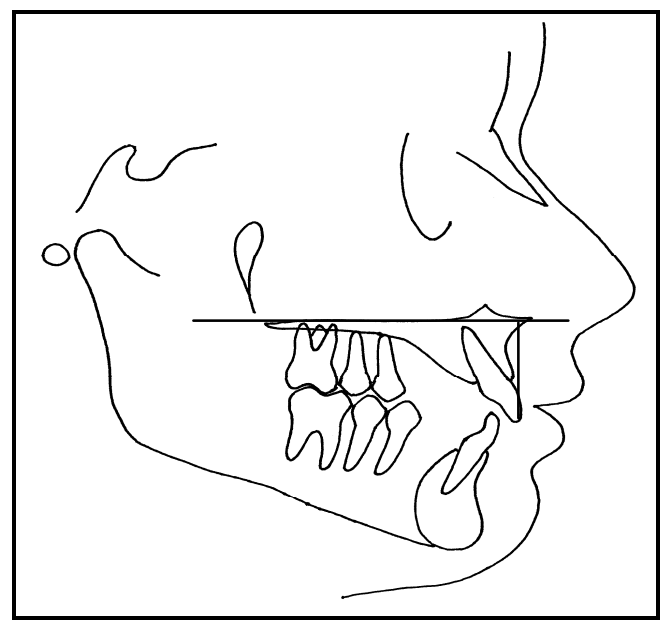


Upper Premolar Positions (U4-PP and U5-PP, mm): The linear distances from the cusp tips of the maxillary premolars (U4 and U5) to Palatal Plane (ANS-PNS), measured perpendicular to Palatal Plane.

Figure 14. U4-PP and U5-PP

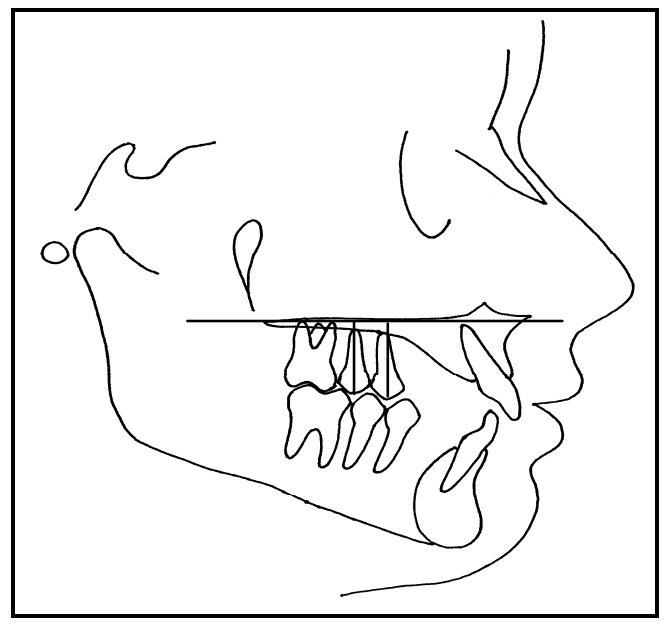

Upper First Molar Position (U6-PP, mm): The linear distance from the mesial cusp tip of the maxillary first molar (U6) to Palatal Plane (ANS-PNS), measured perpendicular to Palatal Plane. The average values are $28 \pm 3 \mathrm{~mm}$ for adult males and $25 \pm 2 \mathrm{~mm}$ for adult females (Riolo, Moyers, McNamara et al, 1974).

Figure 15. U6-PP

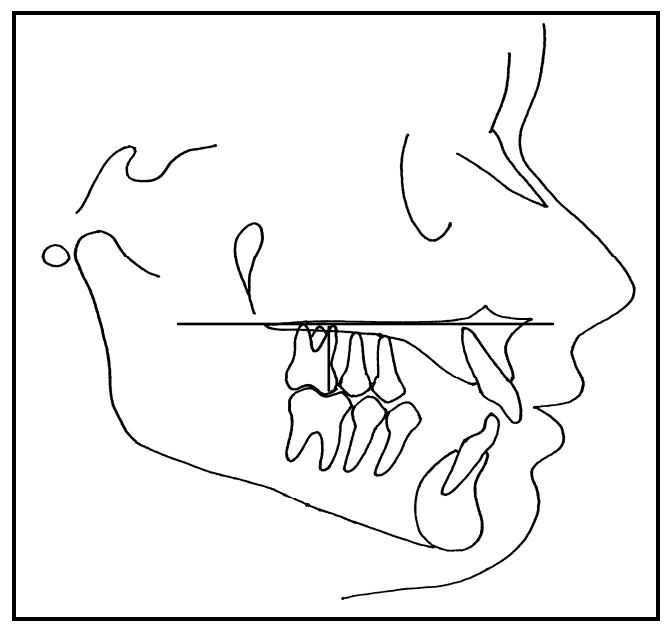


Lower Incisor Position (L1-MP, mm): The linear distance from the incisal tip of the mandibular incisor (L1) to Mandibular Plane (MP), measured perpendicular to Mandibular Plane. The average values are $49 \pm 3 \mathrm{~mm}$ for adult males and $42 \pm 3 \mathrm{~mm}$ for adult females (Riolo, Moyers, McNamara et al, 1974).

Figure 16. L1-MP

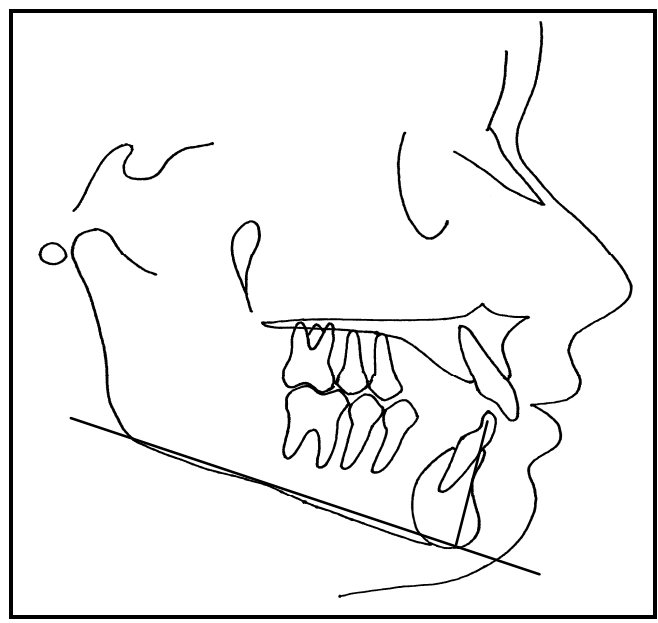

Lower Premolar Positions (L4-MP and L5-MP, mm): The linear distances from the cusp tips of the mandibular premolars (L4 and L5) to Mandibular Plane (MP), measured perpendicular to Mandibular Plane.

Figure 17. L4-MP and L5-MP

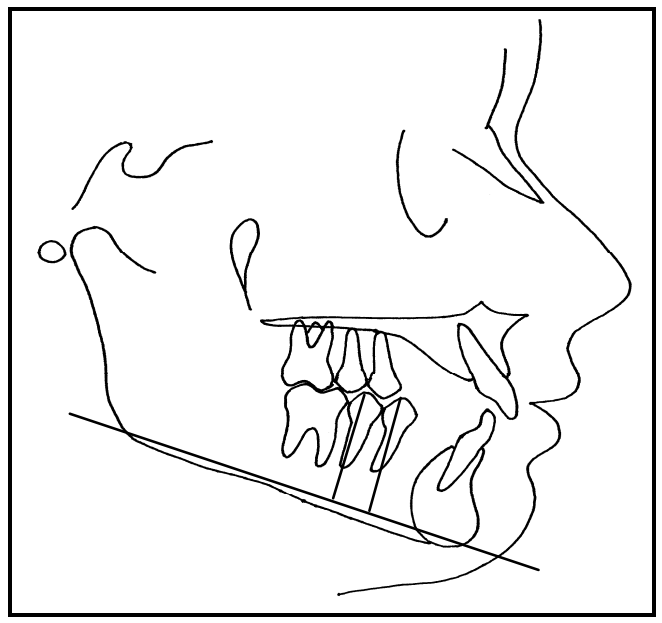


Lower First Molar Position (L6-MP, mm): The linear distance from the mesial cusp tip of the mandibular first molar (L6) to Mandibular Plane (MP), measured perpendicular to Mandibular Plane. The average values are $38 \pm 3 \mathrm{~mm}$ for adult males and $33 \pm 3 \mathrm{~mm}$ for adult females (Riolo, Moyers, McNamara et al, 1974).

Figure 18. L6-MP

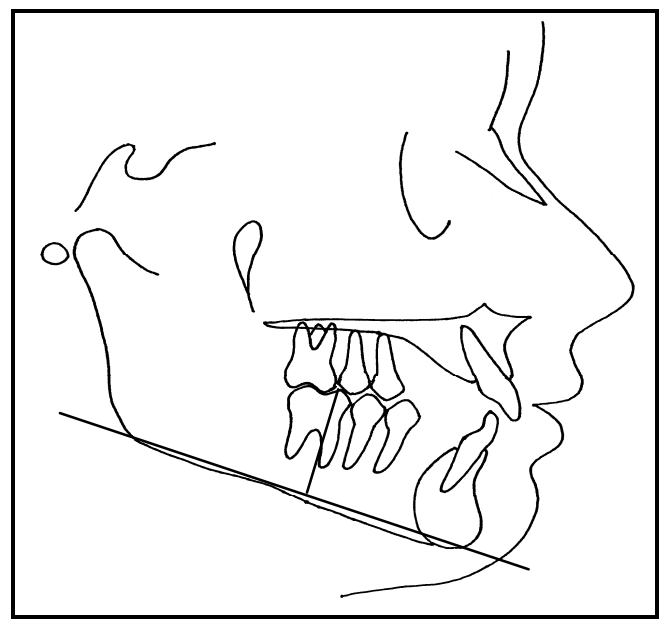

Upper Anterior Face Height (N-Me): The linear distance from Nasion (N) to Menton (Me). The average value is $137 \pm 8 \mathrm{~mm}$ for an adult male and $123 \pm 5 \mathrm{~mm}$ for an adult female (Riolo, Moyers, McNamara et al, 1974).

Figure 19. Anterior Face Height

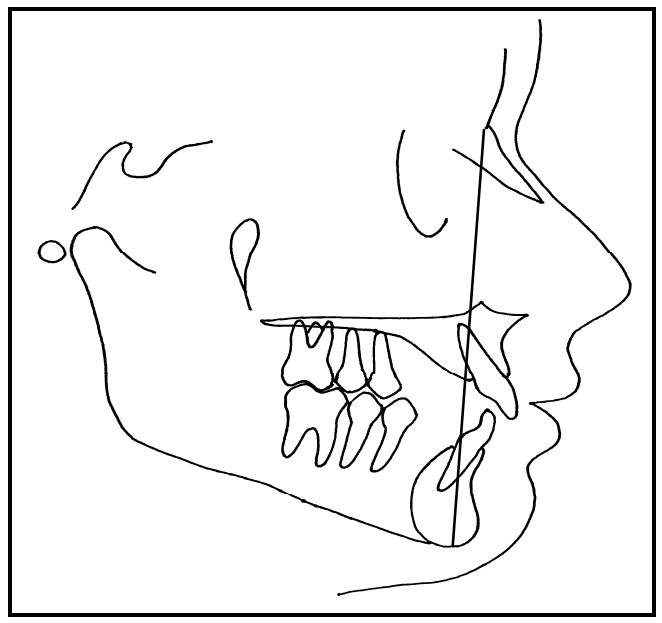


Posterior Face Height (S-Go): The linear distance from Sella (S) to Gonion (Go). The average value for an adult male is $88 \pm 6 \mathrm{~mm}$, while the average value for an adult female is $79 \pm 4 \mathrm{~mm}$ (Riolo, Moyers, McNamara et al, 1974).

Figure 20. Posterior Face Height

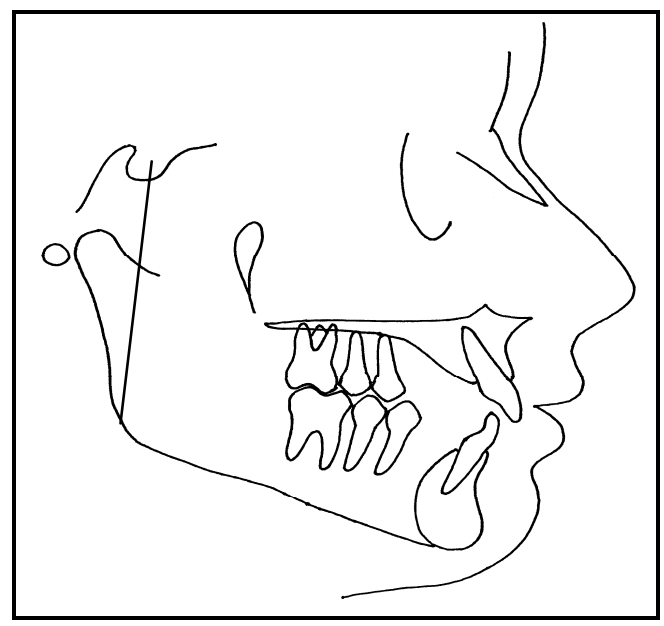

Upper Face Height (N-ANS): The linear distance from Nasion (N) to Anterior Nasal Spine (ANS). The average value is $52.0 \mathrm{~mm}$.

Figure 21. Upper Face Height

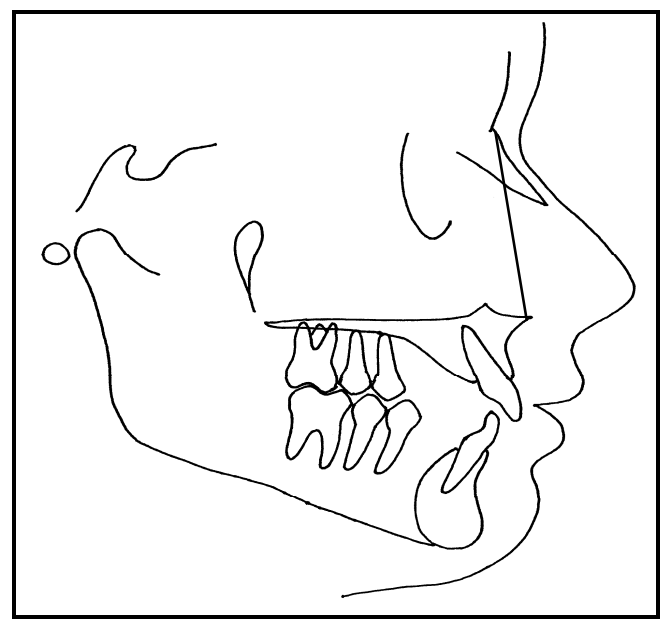


Lower Anterior Face Height (ANS-Me): The linear distance from Anterior Nasal Spine (ANS) to Menton (Me). The average value is $63.0 \mathrm{~mm}$, but depends largely on the size and age of an individual.

Figure 22. Lower Anterior Face Height

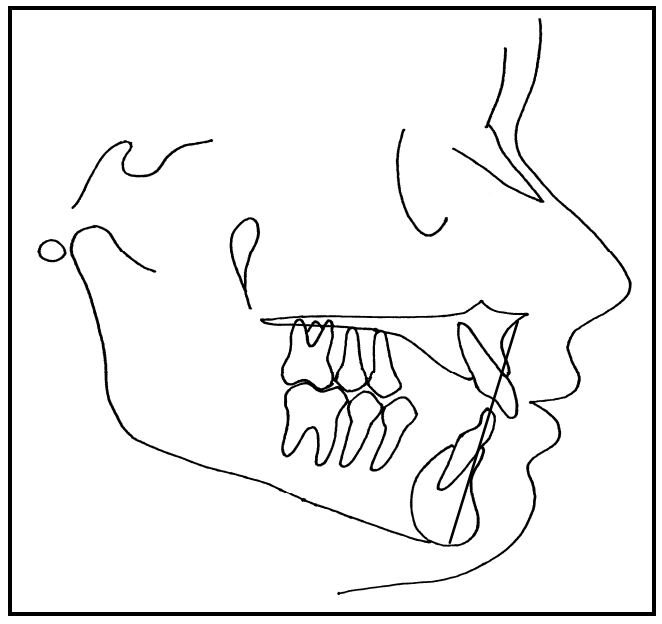




\subsection{PLASTER MODEL ANALYSIS}

Plaster models for each time point were verified to ensure that the dates they were taken matched the dates of the corresponding cephalometric radiographs. Once this was confirmed, each set of models was carefully inspected for damage. If there were any broken or chipped teeth that would be used in any of the measurements described below, the subject was excluded from the study.

To determine the intra-examiner cast measurement error, the same five subjects who were randomly selected from the original sample for the cephalometric error calculation were uuencoded and their models retrieved and re-measured by the same operator (D.P.) three days later, without reference to the previous measurements. 


\subsubsection{Plaster Model Measurements}

The following measurements were performed on the plaster models:

Overbite (mm): the amount of vertical incisor overlap, measured as a linear distance from the maxillary central incisors to the mandibular incisors. First, the incisal edges of the right and left maxillary central incisors were projected onto the labial surface of the mandibular incisors using a mechanical pencil. The pencil's lead was oriented parallel to the functional occlusal plane and was extended so that it contacted both the incisal edge and the labial surface simultaneously. Next, the distance from these two pencil markings (i.e. one for each upper central incisor) to the mandibular incisal edges was measured with the Boley gauge to the nearest $0.1 \mathrm{~mm}$, holding the gauge parallel to the labial surface of the lower incisors. If there was a discrepancy in overbite between the two measurements of up to $2 \mathrm{~mm}$, the greater of the two measurements was recorded. If this discrepancy was greater than $2 \mathrm{~mm}$, the tooth that was deemed to be more malpositioned in relation to the other maxillary anterior teeth was excluded.

Overbite (\%): The amount of vertical incisor overlap, measured as a percentage of lower incisor clinical crown coverage by the maxillary central incisors. To calculate this, the 'overbite (mm)' value, as described above, was divided by the clinical crown length of the mandibular central incisor used. To measure clinical crown length, the Boley gauge was held parallel to the labial surface of the lower incisor and the distance from the most gingival position of the clinical crown to the incisal edge was measured to the nearest 0.1 $\mathrm{mm}$. 
Overjet: The amount of horizontal incisor overlap, measured from the labial surface of the mandibular incisors to the labial surface of the incisal edge of the maxillary incisors. To accurately determine this value, a compass with two sharp and pointed arms was used, with one arm being placed on the incisal edge (labial surface) of a maxillary central incisor and the other placed on the most labial surface of its corresponding mandibular incisor. This distance measured by the compass was then transferred to a Boley gauge and recorded to the nearest $0.1 \mathrm{~mm}$. Overjet values for both the right and left upper central incisors were determined. If there was a discrepancy in overjet between the two values of up to $2 \mathrm{~mm}$, the greater measurement of the two was recorded. If this discrepancy was greater than $2 \mathrm{~mm}$, the tooth that was deemed to be more malpositioned in relation to the other maxillary anterior teeth was excluded.

Maxillary and mandibular intercanine widths: Measured from canine cusp tip to canine cusp tip for each arch. A Boley gauge was used and measurements were taken to the nearest $0.1 \mathrm{~mm}$. When there was visible canine cusp wear that made landmark identification difficult, the cusp tip was approximated by locating the center of the attrition pattern, marking this spot with a mechanical pencil, and measuring from this point. If canine crown restorations were present, the cusp tip of the restoration was taken as the natural anatomical cusp tip.

Maxillary and mandibular intermolar widths: Measured from the first molar central fossa on one side to the first molar central fossa on the opposite side for each arch. A Boley gauge was used and measurements were taken to the nearest $0.1 \mathrm{~mm}$. When 
occlusal restorations that covered the central fossa were present on the first molars (i.e. full coverage crowns, inlays, onlays, occlusal amalgams, occlusal composites, etc.), the best approximation of its location was determined by locating the center point of the mesiobuccal, distobuccal, and mesiolingual cusps for the maxillary molars or all four cusps for the mandibular molars, marking this spot with a mechanical pencil, and measuring from this point.

Irregularity Index: The sum of the linear distances between adjacent anatomic contact points of the mandibular incisors, as described by Little (1975).

Curve of Spee: Measured by placing a metal ruler from the most posterior mandibular tooth to the incisors and measuring the deepest part of the arc. If mandibular premolars and/or canines were still erupting and not yet in occlusion, they were excluded in the measurement and the next highest value that was in occlusion was recorded. Both the right and left quadrants were measured and the higher of the two values was recorded as the Curve of Spee. 


\subsection{FORMATION OF GROUPS ACCORDING TO FACIAL TYPE}

After data collection was completed, subjects were grouped according to their initial facial type (mesocephalic, brachycephalic, and dolicocephalic) based on their pretreatment (T1) cephalometric values for three commonly used variables for the assessment of facial type: Y-axis, Mandibular Plane Angle (MPA), and Ricketts' Lower Facial Height (LFH). These variables were described previously in this chapter.

The ranges for Y-axis, MPA, and LFH that determined what group a particular subject would be categorized into were determined by increasing the range around the average values until the groups had proportional representation. The mesocephalic group was chosen to be those with an MPA between $29-35^{\circ}$, Y-axis between $63-69^{\circ}$, and LFH between $44-50^{\circ}$. The dolicocephalic group included those with an MPA greater than $35^{\circ}$, Y-axis greater than $69^{\circ}$, and LFH greater than $50^{\circ}$. Finally, the brachycephalic group consisted of those with an MPA less than $29^{\circ}$, Y-axis less than $63^{\circ}$, and LFH less than $44^{\circ}$. Since the majority of subjects failed to have all three variables placing them in a particular group, it was arbitrarily decided that if they had two out of three variables in a group, this would suffice. These ranges yielded fairly equal groups: 28 mesocephalic subjects, 16 brachycephalic subjects, and 16 dolicocephalic subjects. Four subjects were eliminated because of poor radiographs that could not be adequately analyzed and one subject was eliminated because she could not be placed in a particular group (Tables $2 \&$ 3). 
Table 2. Gender and skeletal patterns for the three groups

\begin{tabular}{|c|c|c|c|c|c|c|}
\hline \multirow{2}{*}{ Group } & \multirow{2}{*}{$N$} & \multicolumn{2}{|c|}{ Gender distribution } & \multicolumn{3}{c|}{ Skeletal pattern } \\
\cline { 3 - 7 } & & Males & Females & Class 1 & Class II & Class III \\
\hline Mesocephalic & 28 & 13 & 15 & 18 & 10 & 0 \\
\hline Brachycephalic & 16 & 10 & 6 & 8 & 7 & 1 \\
\hline Dolicocephalic & 16 & 7 & 9 & 8 & 8 & 0 \\
\hline
\end{tabular}

Table 3. Mean values for each of the three groups

\begin{tabular}{|c|c|c|c|c|c|c|}
\hline Group & Mean & Mean & Mean & Mean & Mean & Mean post- \\
& (y) & MPA & Y-axis & LAFH & time (m) & retention time \\
\hline Mesocephalic & 13.4 & 32.5 & 66.3 & 42.5 & 30 & 12.9 \\
\hline Brachycephalic & 14.0 & 26.5 & 64.1 & 38.8 & 26 & 13.0 \\
\hline Dolicocephalic & 13.5 & 37.8 & 70.5 & 45.6 & 32 & 15.0 \\
\hline
\end{tabular}

$\mathrm{y}=$ years $; \mathrm{m}=$ months 


\subsection{STATISTICAL ANALYSIS}

Two completely different statistical outputs were performed for the present study. The first was a mixed effects model (repeated measures design) that was used to determine how each variable changed over time for the three groups without assessing the change of a variable through time. This statistical method is similar to a regular regression model except more powerful since it accounts for the correlation between measurements made on the same subject through time. This allowed us to observe whether there are differences between groups at each time point, between time points within each group, and between the slopes of the curves for each group through time.

Analysis of Variance (ANOVA) was then used to compare the mean differences between the time points (i.e. T2-T1, T3-T2, and T3-T1) for the three groups. Both the changes during orthodontic treatment (T2-T1) and changes post-retention (T3-T2) were of particular interest for this study. ANOVA was then followed by pair-wise bivariate contrasts in the form of t-tests, which contain their own p-values. So for each variable, an overall ANOVA p-value and a matrix of p-values pertaining to the post-hoc t-tests was determined, with a $\mathrm{p}$ value of $<0.05$ considered statistically significant. 


\section{CHAPTER 3}

\section{RESULTS}

Page Number

3.1 Measurement Reliability $\quad 47$

3.2 Total Overbite Correction and Relapse 48

3.3 Brachycephalic Group $\quad 49$

3.4 Mesocephalic Group $\quad 52$

3.5 Dolicocephalic Group $\quad 55$

3.6 Summary of Significant Intergroup Differences 58

3.7 Intergroup Changes for Each Variable 61 


\subsection{MEASUREMENT RELIABILITY}

Re-measurements were made one month after the original measurements by the same individual investigator (D.P.) to ensure measurement accuracy and subsequently evaluated statistically using the Wilcoxon nonparametric test. No significant differences were found for any of the parameters $(\mathrm{p}>0.05)$ and measurement accuracy, reliability, and repeatability was confirmed. 


\subsection{TOTAL OVERBITE CORRECTION AND RELAPSE}

The mean overbite correction from orthodontic treatment for the entire sample, irrespective of facial type, was $2.7 \pm 1.4 \mathrm{~mm}$. After the long-term follow-up period of approximately ten years, the mean relapse for the sample was $0.98 \pm 1.2 \mathrm{~mm}$ with a range from $-1.4 \mathrm{~mm}$ to $4 \mathrm{~mm}$. When measured as a percentage of mandibular clinical crown coverage, overbite was orthodontically corrected by a mean amount of $38.1 \pm 20.0 \%$, which then showed a mean relapse of $11.0 \pm 17.0 \%$ during the post-retention period. 


\subsection{BRACHYCEPHALIC GROUP}

Although the present study was most interested in changes during the post-retention period (T3-T2), it is also interesting to analyse the difference in changes that occurred during orthodontic treatment (T2-T1) for each group. Within the brachycephalic group, significant increases $(\mathrm{p}<0.05)$ during treatment were observed in SNB $\left(+0.8^{\circ}\right)$, Ricketts' lower face height $\left(+1.6^{\circ}\right)$, anterior face height $(+6 \mathrm{~mm})$, posterior face height $(+5.2 \mathrm{~mm})$, upper face height $(+2 \mathrm{~mm})$, lower anterior face height $(+3.7 \mathrm{~mm})$, lower incisor angulation $\left(+4.4^{\circ}\right)$, maxillary posterior tooth position $(\mathrm{U} 4=+1.4 \mathrm{~mm}, \mathrm{U} 5=+1.5 \mathrm{~mm}$,

$\mathrm{U} 6=+1.6 \mathrm{~mm}$ ), mandibular posterior tooth position ( $\mathrm{L} 4=+2.3 \mathrm{~mm}, \mathrm{~L} 5=+2.7 \mathrm{~mm}, \mathrm{~L} 6=+2.6$ $\mathrm{mm})$, maxillary intercanine width $(+1.5 \mathrm{~mm})$, and maxillary intermolar width $(+1.3 \mathrm{~mm})$. Conversely, SNA $\left(-0.7^{\circ}\right)$, ANB $\left(-1.5^{\circ}\right)$, overjet $(-2.6 \mathrm{~mm})$, curve of Spee $(-1.8 \mathrm{~mm})$, and mandibular irregularity index $(-2.4 \mathrm{~mm})$ all decreased significantly $(\mathrm{p}<0.05)$. Mean overbite was also significantly reduced $(\mathrm{p}<0.05)$ from $5.8 \mathrm{~mm}(81 \%)$ to $2.6 \mathrm{~mm}$ (35.2\%), resulting in a mean correction of $3.2 \pm 0.3 \mathrm{~mm}$, or $45.9 \pm 4.9 \%$.

After ten years post-retention, anterior face height $(+2.5 \mathrm{~mm})$, posterior face height $(+3.9$ $\mathrm{mm})$, lower face height $(+2.2 \mathrm{~mm})$, maxillary second premolar position $(+0.8 \mathrm{~mm})$, maxillary first molar position $(+1.0 \mathrm{~mm})$, and mandibular posterior tooth position (L4=+1.5 mm, L5=+1.8 mm, L6=+1.8 mm) continued to increase significantly $(\mathrm{p}<0.05)$ as they did during treatment. There were also significant increases $(\mathrm{p}<0.05)$ in maxillary $(\mathrm{U} 1=+1.6 \mathrm{~mm})$ and mandibular $(\mathrm{L} 1=+1.6 \mathrm{~mm})$ incisor positions, relative to palatal plane and mandibular plane respectively, which were held in place during treatment. Maxillary first premolar position $(+0.7 \mathrm{~mm})$ increased as well, but it was not statistically significant. 
Significant amounts of relapse $(\mathrm{p}<0.05)$ were observed for lower incisor angulation $(-$ $\left.4.2^{\circ}\right)$, inter-incisal angle $\left(+8.0^{\circ}\right)$, Curve of Spee $(+0.6 \mathrm{~mm})$, and mandibular irregularity index $(+1.8 \mathrm{~mm})$. Overbite also relapsed significantly $(\mathrm{p}<0.05)$ and returned to its original deep bite condition, as the mean went from $2.6 \mathrm{~mm}(35.2 \%)$ at debond to $3.7 \mathrm{~mm}$ $(48.2 \%)$ at $\mathrm{T} 3$, resulting in a relapse of $1.2 \pm 0.3 \mathrm{~mm}$, or $13 \pm 3.9 \%$. Mandibular plane angle $\left(-1.6^{\circ}\right)$ and mandibular intercanine width $(-1.2 \mathrm{~mm})$ decreased significantly $(\mathrm{p}<$ 0.05) during this time period. Y-axis, known to be a stable angle, did not change significantly during treatment or after the ten year post-retention follow-up.

Table 4. Data for the Brachycephalic Group

\begin{tabular}{|c|c|c|c|c|c|c|c|c|c|c|c|c|}
\hline \multirow{2}{*}{ Brachycephalic } & \multicolumn{2}{|c|}{ T1 } & \multicolumn{2}{|c|}{ T2 } & \multicolumn{2}{|c|}{ T3 } & \multicolumn{3}{|c|}{ T2-T1 } & \multicolumn{3}{|c|}{ T3-T2 } \\
\hline & Mean & SE & Mean & SE & Mean & SE & Mean & SE & $\mathbf{P}$ & Mean & SE & $\bar{P}$ \\
\hline SNA & 82.5 & 0.7 & 81.7 & 0.8 & 81.9 & 0.8 & 0.7 & 0.3 & $*$ & -0.2 & 0.3 & \\
\hline SNB & 78.7 & 0.6 & 79.5 & 0.6 & 79.6 & 0.7 & -0.8 & 0.2 & * & -0.2 & 0.3 & \\
\hline ANB & 3.8 & 0.5 & 2.3 & 0.5 & 2.3 & 0.5 & 1.5 & 0.3 & * & 0 & 0.4 & \\
\hline MPA & 26.5 & 0.5 & 26.4 & 0.7 & 24.8 & 0.8 & 0.1 & 0.4 & & 1.6 & 0.6 & * \\
\hline Y-axis & 64.1 & 0.5 & 64.3 & 0.5 & 63.7 & 0.5 & $\begin{array}{l}-0.3 \\
\end{array}$ & 0.3 & & 0.6 & 0.3 & \\
\hline LFH & 38.8 & 0.8 & 40.3 & 0.8 & 40 & 0.9 & -1.6 & 0.4 & $*$ & 0.3 & 0.4 & \\
\hline FMA & 20.1 & 0.9 & 20.6 & 0.8 & 19 & 0.9 & -0.5 & 0.6 & & 1.6 & 0.8 & \\
\hline $\mathrm{Na}-\mathrm{Me}$ & 113.5 & 1.5 & 119.5 & 1.9 & 122.1 & 2.1 & -6 & 1 & $*$ & -2.5 & 0.9 & * \\
\hline S-Go & 80.4 & 1.3 & 85.6 & 1.6 & 89.5 & 2 & -5.2 & 0.8 & * & -3.9 & 1 & * \\
\hline N-ANS & 53.3 & 0.8 & 55.3 & 1 & 55.7 & 0.9 & -2 & 0.6 & * & $\begin{array}{l}-0.3 \\
\end{array}$ & 0.5 & \\
\hline ANS-Me & 61.4 & 1.1 & 65.1 & 1.3 & 67.3 & 1.6 & -3.7 & 0.6 & $*$ & -2.2 & 0.8 & * \\
\hline OP-SN & 12.3 & 0.9 & 13.9 & 0.9 & 13.8 & 0.9 & -1.6 & 1 & & 0.1 & 0.7 & \\
\hline U1-SN & 99.1 & 2.4 & 101.4 & 1.5 & 99.1 & 1.7 & -2.3 & 2.6 & & 2.4 & 1.4 & \\
\hline L1-MP & 92.8 & 1.8 & 97.1 & 1.8 & 93 & 1.8 & -4.4 & 1.5 & $*$ & 4.2 & 1.5 & * \\
\hline U1-L1 & 141.8 & 3.4 & 135.2 & 2.1 & 143.2 & 2.4 & 6.6 & 3.4 & & -8 & 2 & * \\
\hline U1-PP (mm) & 27.1 & 0.6 & 27.3 & 0.7 & 28.9 & 0.8 & -0.2 & 0.4 & & -1.6 & 0.5 & * \\
\hline U4-PP (mm) & 23.3 & 0.6 & 24.8 & 0.6 & 25.4 & 0.6 & -1.4 & 0.4 & * & -0.7 & 0.4 & \\
\hline
\end{tabular}




\begin{tabular}{|l|c|c|c|c|c|c|c|c|c|c|c|c|}
\hline U5-PP (mm) & 22.3 & 0.7 & 23.8 & 0.7 & 24.6 & 0.7 & -1.5 & 0.4 & $*$ & -0.8 & 0.4 & $*$ \\
\hline U6-PP (mm) & 20.8 & 0.6 & 22.4 & 0.6 & 23.3 & 0.6 & -1.6 & 0.4 & $*$ & -1 & 0.4 & $*$ \\
\hline L1-GoGn (mm) & 39.3 & 0.9 & 39.1 & 0.9 & 40.6 & 0.9 & 0.3 & 0.4 & & -1.6 & 0.4 & $*$ \\
\hline L4-GoGn (mm) & 33.7 & 0.9 & 36.1 & 0.9 & 37.6 & 0.9 & -2.3 & 0.4 & $*$ & -1.5 & 0.4 & $*$ \\
\hline L5-GoGn (mm) & 31.5 & 0.8 & 34.2 & 0.8 & 35.9 & 0.8 & -2.7 & 0.4 & $*$ & -1.8 & 0.4 & $*$ \\
\hline L6-GoGn (mm) & 29.6 & 0.7 & 32.2 & 0.8 & 34.1 & 1 & -2.6 & 0.4 & $*$ & -1.8 & 0.4 & $*$ \\
\hline Overbite (mm) & 5.8 & 0.3 & 2.6 & 0.2 & 3.7 & 0.3 & 3.2 & 0.3 & $*$ & -1.2 & 0.3 & $*$ \\
\hline Overbite (\%) & 81 & 5.2 & 35.2 & 3.1 & 48.2 & 4.3 & 45.9 & 4.9 & $*$ & -13 & 3.9 & $*$ \\
\hline Overjet & 5.3 & 0.6 & 2.7 & 0.2 & 3.1 & 0.2 & 2.6 & 0.6 & $*$ & -0.4 & 0.2 & \\
\hline Curve of Spee & 2.7 & 0.2 & 0.9 & 0.2 & 1.5 & 0.2 & 1.8 & 0.3 & $*$ & -0.6 & 0.2 & $*$ \\
\hline Md intercanine width & 26 & 0.5 & 26.7 & 0.3 & 25.5 & 0.4 & -0.7 & 0.4 & & 1.2 & 0.2 & $*$ \\
\hline Md intermolar width & 41.2 & 0.5 & 41.6 & 0.5 & 41.5 & 0.5 & -0.4 & 0.4 & & 0.2 & 0.2 & \\
\hline Max intercanine width & 33.9 & 0.6 & 35.4 & 0.6 & 35.1 & 0.6 & -1.5 & 0.6 & $*$ & 0.3 & 0.3 & \\
\hline Max intermolar width & 46.5 & 0.5 & 47.9 & 0.5 & 47.7 & 0.5 & -1.3 & 0.5 & $*$ & 0.2 & 0.2 & $*$ \\
\hline Md Irregularity Index & 3.7 & 0.6 & 1.3 & 0.2 & 3.1 & 0.5 & 2.4 & 0.6 & $*$ & -1.8 & 0.5 & $*$ \\
\hline
\end{tabular}

$*=\mathrm{p}<0.05, \mathrm{SE}=$ standard error 


\subsection{MESOCEPHALIC GROUP}

The following measurements in the mesocephalic group increased significantly $(p<0.05)$ during treatment: $Y$-axis $\left(+0.8^{\circ}\right)$, Ricketts' lower face height $\left(+1.5^{\circ}\right)$, anterior face height $(+5.8 \mathrm{~mm})$, posterior face height $(+4.6 \mathrm{~mm})$, upper face height $(+2.1 \mathrm{~mm})$, lower anterior face height $(+3.6 \mathrm{~mm})$, occlusal plane angle $\left(+2.0^{\circ}\right)$, lower incisor angulation $\left(+3.3^{\circ}\right)$, maxillary posterior tooth position (U4=+1.4 mm, U5=+1.3 mm, U6=+1.4 mm), mandibular posterior tooth position ( $\mathrm{L} 4=+2.5 \mathrm{~mm}, \mathrm{~L} 5=+2.7 \mathrm{~mm}, \mathrm{~L} 6=+2.4 \mathrm{~mm}$ ), maxillary intermolar width $(+1.2 \mathrm{~mm})$, and mandibular intermolar width $(+1.0 \mathrm{~mm})$.

Conversely, the following decreased significantly $(\mathrm{p}<0.05)$ during treatment: SNA ($\left.0.9^{\circ}\right)$, ANB $\left(-0.9^{\circ}\right)$, overjet $(-2.9 \mathrm{~mm})$, Curve of Spee $(-1.2 \mathrm{~mm})$, and mandibular irregularity index $(-2.1 \mathrm{~mm})$. Overbite was also decreased significantly $(\mathrm{p}<0.05)$ during treatment $(-2.6 \pm 0.3 \mathrm{~mm}$, or $37.1 \pm 3.7 \%)$, from an initial value of $5.0 \mathrm{~mm}(69.4 \%)$ to 2.4 $\mathrm{mm}(32.3 \%)$.

Between T2 and T3, the following variables continued to increase significantly $(\mathrm{p}<$ 0.05): anterior face height $(+4.2 \mathrm{~mm})$, posterior face height $(+4.8 \mathrm{~mm})$, upper face height $(+1.4 \mathrm{~mm})$, lower face height $(+2.7 \mathrm{~mm})$, maxillary posterior tooth position (U4=+1.4 $\mathrm{mm}, \mathrm{U} 5=+1.4 \mathrm{~mm}, \mathrm{U} 6=+1.7 \mathrm{~mm})$, and mandibular posterior tooth position $(\mathrm{L} 4=+2.1$ $\mathrm{mm}, \mathrm{L} 5=+2.0 \mathrm{~mm}, \mathrm{~L} 6=+2.2 \mathrm{~mm})$. In addition, maxillary $(\mathrm{U} 1=+2.0 \mathrm{~mm})$ and mandibular $(\mathrm{L} 1=+2.3 \mathrm{~mm})$ incisor positions, relative to palatal plane and mandibular plane respectively, also increased significantly $(\mathrm{p}<0.05)$. Significant relapse $(\mathrm{p}<0.05)$ occurred in the following variables: inter-incisal angle $\left(+4.2^{\circ}\right)$, overjet $(+0.5 \mathrm{~mm})$, curve of Spee $(+0.5 \mathrm{~mm})$, mandibular intercanine width $(-1.2 \mathrm{~mm})$, mandibular intermolar 
width $(-0.4 \mathrm{~mm})$, and mandibular irregularity index $(+1.9 \mathrm{~mm})$. Mean relapse of overbite for this group was statistically significant $(\mathrm{p}<0.05)$ at $1.4 \pm 0.2 \mathrm{~mm}$, or $16.4 \pm 3.0 \%$. Both maxillary intermolar and intercanine widths, which were expanded during orthodontic treatment $(+1.2 \mathrm{~mm}$ and $+0.9 \mathrm{~mm}$, respectively), did not relapse significantly after 10 years post-retention. Mandibular plane angle showed a significant decrease ($\left.1.5^{\circ}\right)(\mathrm{p}<0.05)$ during this same period.

Table 5. Data for the Mesocephalic Group

\begin{tabular}{|c|c|c|c|c|c|c|c|c|c|c|c|c|}
\hline \multirow{2}{*}{ Mesocephalic } & \multicolumn{2}{|c|}{ T1 } & \multicolumn{2}{|c|}{ T2 } & \multicolumn{2}{|c|}{ T3 } & \multicolumn{3}{|c|}{ T2-T1 } & \multicolumn{3}{|c|}{ T3-T2 } \\
\hline & Mean & SE & Mean & SE & Mean & SE & Mean & SE & $\mathbf{P}$ & Mean & SE & $\mathbf{P}$ \\
\hline SNA & 82 & 0.6 & 81.2 & 0.6 & 81 & 0.6 & 0.9 & 0.2 & * & 0.2 & 0.2 & \\
\hline SNB & 78 & 0.5 & 78.1 & 0.5 & 78.4 & 0.5 & -0.1 & 0.2 & & -0.3 & 0.3 & \\
\hline ANB & 4 & 0.4 & 3.1 & 0.3 & 2.6 & 0.4 & 0.9 & 0.2 & * & 0.4 & 0.3 & \\
\hline MPA & 32.5 & 0.4 & 32.8 & 0.5 & 31.2 & 0.6 & -0.3 & 0.3 & & 1.5 & 0.5 & * \\
\hline Y-axis & 66.3 & 0.4 & 67.1 & 0.4 & 66.8 & 0.4 & -0.8 & 0.2 & * & 0.3 & 0.2 & \\
\hline LFH & 42.5 & 0.6 & 43.9 & 0.6 & 43.6 & 0.7 & -1.5 & 0.3 & * & 0.3 & 0.3 & \\
\hline FMA & 25.1 & 0.7 & 25.3 & 0.6 & 24.1 & 0.7 & -0.2 & 0.5 & & 1.2 & 0.6 & \\
\hline $\mathrm{Na}-\mathrm{Me}$ & 114.2 & 1.1 & 120.1 & 1.4 & 124.3 & 1.6 & $\begin{array}{l}-5.8 \\
\end{array}$ & 0.8 & * & -4.2 & 0.7 & * \\
\hline S-Go & 74.7 & 1 & 79.3 & 1.2 & 84.1 & 1.5 & -4.6 & 0.6 & * & $\begin{array}{l}-4.8 \\
\end{array}$ & 0.7 & * \\
\hline N-ANS & 51.9 & 0.6 & 54 & 0.8 & 55.4 & 0.7 & -2.1 & 0.4 & * & -1.4 & 0.4 & * \\
\hline ANS-Me & 63.8 & 0.8 & 67.4 & 1 & 70.2 & 1.2 & -3.6 & 0.5 & * & -2.7 & 0.6 & * \\
\hline OP-SN & 14.6 & 0.7 & 16.6 & 0.7 & 15.7 & 0.7 & -2 & 0.7 & * & 0.9 & 0.5 & \\
\hline U1-SN & 101.6 & 1.8 & 101.4 & 1.1 & 100.4 & 1.3 & 0.3 & 2 & & 1 & 1 & \\
\hline L1-MP & 90.3 & 1.3 & 93.7 & 1.3 & 92.1 & 1.3 & -3.3 & 1.1 & * & 1.6 & 1.1 & \\
\hline U1-L1 & 135.7 & 2.6 & 132.2 & 1.6 & 136.4 & 1.8 & 3.4 & 2.5 & & -4.2 & 1.5 & * \\
\hline U1-PP (mm) & 28.3 & 0.4 & 28.6 & 0.5 & 30.6 & 0.6 & $\begin{array}{l}-0.3 \\
\end{array}$ & 0.3 & & -2 & 0.4 & * \\
\hline U4-PP (mm) & 24.1 & 0.5 & 25.5 & 0.5 & 26.9 & 0.5 & -1.4 & 0.3 & * & -1.4 & 0.3 & * \\
\hline U5-PP (mm) & 22.9 & 0.5 & 24.2 & 0.5 & 25.7 & 0.5 & $\begin{array}{l}-1.3 \\
\end{array}$ & 0.3 & * & -1.4 & 0.3 & * \\
\hline U6-PP (mm) & 21.1 & 0.5 & 22.4 & 0.5 & 24.1 & 0.5 & -1.4 & 0.3 & $*$ & -1.7 & 0.3 & $*$ \\
\hline L1-GoGn (mm) & 40 & 0.6 & 40.1 & 0.6 & 42.3 & 0.6 & -0.1 & 0.3 & & -2.3 & 0.3 & * \\
\hline
\end{tabular}




\begin{tabular}{|l|c|c|c|c|c|c|c|c|c|c|c|c|}
\hline L4-GoGn (mm) & 33.7 & 0.6 & 36.1 & 0.6 & 38.2 & 0.6 & -2.5 & 0.3 & $*$ & -2.1 & 0.3 & $*$ \\
\hline L5-GoGn (mm) & 31.2 & 0.6 & 33.9 & 0.6 & 35.9 & 0.6 & -2.7 & 0.3 & $*$ & -2 & 0.3 & $*$ \\
\hline L6-GoGn (mm) & 29.2 & 0.5 & 31.6 & 0.6 & 33.7 & 0.7 & -2.4 & 0.3 & $*$ & -2.2 & 0.3 & $*$ \\
\hline Overbite (mm) & 5 & 0.3 & 2.4 & 0.2 & 3.8 & 0.2 & 2.6 & 0.3 & $*$ & -1.4 & 0.2 & $*$ \\
\hline Overbite (\%) & 69.4 & 3.9 & 32.3 & 2.3 & 48.7 & 3.3 & 37.1 & 3.7 & $*$ & -16.4 & 3 & $*$ \\
\hline Overjet & 5.5 & 0.5 & 2.6 & 0.1 & 3 & 0.2 & 2.9 & 0.5 & $*$ & -0.5 & 0.2 & $*$ \\
\hline Curve of Spee & 2.5 & 0.2 & 1.3 & 0.1 & 1.8 & 0.1 & 1.2 & 0.2 & $*$ & -0.5 & 0.1 & $*$ \\
\hline Md intercanine width & 25.7 & 0.4 & 26.4 & 0.3 & 25.2 & 0.3 & -0.6 & 0.3 & & 1.2 & 0.2 & $*$ \\
\hline Md intermolar width & 40.2 & 0.4 & 41.3 & 0.4 & 40.9 & 0.4 & -1 & 0.3 & $*$ & 0.4 & 0.2 & $*$ \\
\hline Max intercanine width & 32.7 & 0.4 & 33.6 & 0.5 & 33.6 & 0.4 & -0.9 & 0.5 & & 0 & 0.2 & \\
\hline Max intermolar width & 45.9 & 0.4 & 47.1 & 0.4 & 47.1 & 0.4 & -1.2 & 0.4 & $*$ & 0 & 0.2 & \\
\hline Md Irregularity Index & 3.5 & 0.5 & 1.4 & 0.2 & 3.3 & 0.4 & 2.1 & 0.5 & $*$ & -1.9 & 0.4 & $*$ \\
\hline
\end{tabular}

$*=p<0.05, \mathrm{SE}=$ standard error 


\subsection{DOLICOCEPHALIC GROUP}

During the T1-T2 phase, dolicocephalic subjects showed significant increases $(p<0.05)$ in the following measurements: Y-axis $\left(+0.9^{\circ}\right)$, Ricketts' lower face height $\left(+1.4^{\circ}\right)$, anterior face height $(+6.1 \mathrm{~mm})$, posterior face height $(+3.9 \mathrm{~mm})$, upper face height $(+2.1$ $\mathrm{mm})$, lower anterior face height $(+3.9 \mathrm{~mm})$, maxillary posterior tooth position $(\mathrm{U} 4=+1.6$ $\mathrm{mm}, \mathrm{U} 5=+1.1 \mathrm{~mm}, \mathrm{U} 6=+1.5 \mathrm{~mm}$ ), mandibular posterior tooth position (L4=+2.8 $\mathrm{mm}$, L5 $=+3.2 \mathrm{~mm}, \mathrm{~L} 6=+2.4 \mathrm{~mm})$, and maxillary intermolar width $(+2.1 \mathrm{~mm})$. Similar to the other two groups, the upper (U1) and lower (L1) incisor positions were not changed significantly during orthodontic treatment. The following variables showed significant decreases $(\mathrm{p}<0.05)$ during this period: SNA $\left(-1.3^{\circ}\right)$, ANB $\left(-1.3^{\circ}\right)$, overbite $(-2.2 \pm 0.3$ $\mathrm{mm}, 32 \pm 4.9 \%)$, overjet $(-3.1 \mathrm{~mm})$, Curve of Spee $(1.1 \mathrm{~mm})$, and mandibular irregularity index $(2.3 \mathrm{~mm})$.

After ten years post-retention, anterior face height $(+3.7 \mathrm{~mm})$, posterior face height $(+3.6$ $\mathrm{mm})$, upper face height $(+2.0 \mathrm{~mm})$, and lower anterior face height $(+1.7 \mathrm{~mm})$ increased significantly $(\mathrm{p}<0.05)$, as did maxillary $(\mathrm{U} 4=+0.9 \mathrm{~mm}, \mathrm{U} 5=+1.3 \mathrm{~mm}, \mathrm{U} 6=+1.3 \mathrm{~mm})$ and mandibular ( $\mathrm{L} 4=+1.4 \mathrm{~mm}, \mathrm{~L} 5=+1.5 \mathrm{~mm}, \mathrm{~L} 6=+1.8 \mathrm{~mm}$ ) posterior tooth positions. As for the anterior teeth, the lower incisors extruded significantly $(+1.7 \mathrm{~mm})(\mathrm{p}<0.05)$ but the upper incisors did not. Significant relapse $(\mathrm{p}<0.05)$ was observed in overjet $(+0.5 \mathrm{~mm})$, curve of Spee $(+0.7 \mathrm{~mm})$, mandibular intercanine width $(-0.9 \mathrm{~mm})$, and mandibular irregularity index $(+2.3 \mathrm{~mm})$. Most importantly, there was no significant relapse observed in overbite $(+0.1 \pm 0.3 \mathrm{~mm}$ or $0.4 \pm 3.9 \%)$ during this time period for the dolicocephalic subjects. The correction from the pre-treatment mean value of $4.7 \mathrm{~mm}$ to $2.5 \mathrm{~mm}$ at 
debond was maintained over the post-retention period (2.6 $\mathrm{mm}$ at $\mathrm{T} 3)$. Inter-incisal angle also did not show any significant amount of relapse as it did in the brachycephalic and mesocephalic groups. Mandibular plane angle, which had a tendency to decrease in the other two groups, was also maintained in these patients during the long term follow-up period. Similar to the other groups, expansion of maxillary intermolar width during orthodontic treatment was stable and did not relapse significantly at T3.

Table 6. Data for the Dolicocephalic Group

\begin{tabular}{|c|c|c|c|c|c|c|c|c|c|c|c|c|}
\hline \multirow{2}{*}{ Dolicocephalic } & \multicolumn{2}{|c|}{ T1 } & \multicolumn{2}{|c|}{ T2 } & \multicolumn{2}{|c|}{ T3 } & \multicolumn{3}{|c|}{ T2-T1 } & \multicolumn{3}{|c|}{ T3-T2 } \\
\hline & Mean & SE & Mean & SE & Mean & $\mathbf{S E}$ & Mean & SE & $\mathbf{P}$ & Mean & SE & $\mathbf{P}$ \\
\hline SNA & 77.6 & 0.7 & 76.4 & 0.8 & 76.1 & 0.8 & 1.3 & 0.3 & $*$ & 0.3 & 0.3 & \\
\hline SNB & 73.4 & 0.6 & 73.4 & 0.6 & 73.3 & 0.7 & 0 & 0.2 & & 0.1 & 0.3 & \\
\hline ANB & 4.3 & 0.5 & 2.9 & 0.5 & 2.8 & 0.5 & 1.3 & 0.3 & $*$ & 0.2 & 0.4 & \\
\hline MPA & 37.8 & 0.5 & 38.5 & 0.7 & 37.6 & 0.8 & -0.7 & 0.4 & & 0.9 & 0.6 & \\
\hline Y-axis & 70.5 & 0.5 & 71.4 & 0.5 & 71.4 & 0.5 & -0.9 & 0.3 & $*$ & 0 & 0.3 & \\
\hline$\overline{\mathrm{LFH}}$ & 45.6 & 0.8 & 47.1 & 0.8 & 46.6 & 0.9 & -1.4 & 0.4 & $*$ & 0.5 & 0.4 & \\
\hline FMA & 27.5 & 0.9 & 28.7 & 0.8 & 27.4 & 0.9 & -1.2 & 0.6 & & 1.3 & 0.8 & \\
\hline Na-Me & 118.1 & 1.5 & 124.2 & 1.9 & 128 & 2.1 & -6.1 & 1 & $*$ & -3.7 & 0.9 & * \\
\hline S-Go & 72.3 & 1.3 & 76.2 & 1.6 & 79.8 & 2 & $\begin{array}{l}-3.9 \\
\end{array}$ & 0.8 & $*$ & -3.6 & 1 & * \\
\hline N-ANS & 53.4 & 0.8 & 55.4 & 1 & 57.4 & 0.9 & -2.1 & 0.6 & $*$ & -2 & 0.5 & * \\
\hline ANS-Me & 66.1 & 1.1 & 70 & 1.3 & 71.7 & 1.6 & -3.9 & 0.6 & $*$ & -1.7 & 0.8 & * \\
\hline OP-SN & 18.9 & 0.9 & 20.8 & 0.9 & 20 & 0.9 & -2 & 1 & & 0.9 & 0.7 & \\
\hline U1-SN & 98.4 & 2.4 & 96.7 & 1.5 & 97.4 & 1.7 & 1.7 & 2.6 & & -0.7 & 1.4 & \\
\hline L1-MP & 90.6 & 1.8 & 90.7 & 1.8 & 90.9 & 1.8 & -0.1 & 1.5 & & -0.3 & 1.5 & \\
\hline U1-L1 & 133.7 & 3.4 & 134.4 & 2.1 & 134.2 & 2.4 & $\begin{array}{l}-0.8 \\
\end{array}$ & 3.4 & & 0.2 & 2 & \\
\hline U1-PP (mm) & 29 & 0.6 & 29.5 & 0.7 & 30.2 & 0.8 & -0.5 & 0.4 & & -0.7 & 0.5 & \\
\hline U4-PP (mm) & 24.3 & 0.6 & 25.9 & 0.6 & 26.7 & 0.6 & -1.6 & 0.4 & $*$ & -0.9 & 0.4 & * \\
\hline U5-PP (mm) & 23 & 0.7 & 24.1 & 0.7 & 25.4 & 0.7 & -1.1 & 0.4 & $*$ & -1.3 & 0.4 & * \\
\hline U6-PP (mm) & 20.9 & 0.6 & 22.4 & 0.6 & 23.7 & 0.6 & -1.5 & 0.4 & $*$ & -1.3 & 0.4 & * \\
\hline L1-GoGn (mm) & 39.9 & 0.9 & 40.6 & 0.9 & 42.3 & 0.9 & -0.7 & 0.4 & & -1.7 & 0.4 & * \\
\hline
\end{tabular}




\begin{tabular}{|l|c|c|c|c|c|c|c|c|c|c|c|c|}
\hline L4-GoGn (mm) & 34 & 0.9 & 36.8 & 0.9 & 38.2 & 0.9 & -2.8 & 0.4 & $*$ & -1.4 & 0.4 & $*$ \\
\hline L5-GoGn (mm) & 31.1 & 0.8 & 34.3 & 0.8 & 35.8 & 0.8 & -3.2 & 0.4 & $*$ & -1.5 & 0.4 & $*$ \\
\hline L6-GoGn (mm) & 29.3 & 0.7 & 31.7 & 0.8 & 33.4 & 1 & -2.4 & 0.4 & $*$ & -1.8 & 0.4 & $*$ \\
\hline Overbite (mm) & 4.7 & 0.3 & 2.5 & 0.2 & 2.6 & 0.3 & 2.2 & 0.3 & $*$ & -0.1 & 0.3 & \\
\hline Overbite (\%) & 64.4 & 5.2 & 32.4 & 3.1 & 32.1 & 4.3 & 32 & 4.9 & $*$ & 0.4 & 3.9 & \\
\hline Overjet & 5.8 & 0.6 & 2.7 & 0.2 & 3.1 & 0.2 & 3.1 & 0.6 & $*$ & -0.5 & 0.2 & $*$ \\
\hline Curve of Spee & 2.1 & 0.2 & 1 & 0.2 & 1.7 & 0.2 & 1.1 & 0.3 & $*$ & -0.7 & 0.2 & $*$ \\
\hline Md intercanine width & 24.7 & 0.5 & 25.5 & 0.3 & 24.6 & 0.4 & -0.8 & 0.4 & & 0.9 & 0.2 & $*$ \\
\hline Md intermolar width & 41.1 & 0.5 & 41.6 & 0.5 & 41.6 & 0.5 & -0.5 & 0.4 & & 0 & 0.2 & \multirow{2}{*}{ (\%) } \\
\hline Max intercanine width & 32.7 & 0.6 & 33.6 & 0.6 & 33.2 & 0.6 & -0.9 & 0.6 & & 0.4 & 0.3 & \\
\hline Max intermolar width & 44.9 & 0.5 & 47 & 0.5 & 46.6 & 0.5 & -2.1 & 0.5 & $*$ & 0.3 & 0.3 & \\
\hline Md Irregularity Index & 3.5 & 0.6 & 1.2 & 0.2 & 3.5 & 0.5 & 2.3 & 0.6 & $*$ & -2.3 & 0.5 & $*$ \\
\hline
\end{tabular}

$*=\mathrm{p}<0.05, \mathrm{SE}=$ standard error 


\subsection{SUMMARY OF SIGNIFICANT INTERGROUP DIFFERENCES}

The only significant differences $(p<0.05)$ found between the three groups when analyzing the changes between $\mathrm{T} 1$ and $\mathrm{T} 2$ were in the SNB angle when comparing the brachycephalic group to both the dolicocephalic group and the mesocephalic group, and in overbite comparing brachycephalic and dolicocephalic groups. No significant differences were found between the dolicocephalic and mesocephalic groups for any variable measured.

Additionally, significant differences were also observed between the three groups when comparing the changes occurring between $\mathrm{T} 2$ and $\mathrm{T} 3$. When comparing the mesocephalic and dolicocephalic groups, the change in post-treatment upper incisor position (U1-PP) and overbite were significantly different $(\mathrm{p}<0.05)$. A comparison of T3-T2 results between brachycephalic and dolicocephalic groups revealed that upper face height $(\mathrm{N}-$ ANS), lower incisor angulation (L1-MP), inter-incisal angle, and overbite were all significantly different $(\mathrm{p}<0.05)$. No significant differences were found between brachycephalic and mesocephalic groups for this time period. 
Table 7. Significant changes between groups during orthodontic treatment (T2-T1)

\begin{tabular}{|c|c|c|c|}
\hline & brachy vs. dolicho & brachy vs. meso & dolicho vs. meso \\
\hline $\begin{array}{l}\text { SNA } \\
\end{array}$ & & & \\
\hline SNB & * & * & \\
\hline ANB & & & \\
\hline MPA & & & \\
\hline Y-axis & & & \\
\hline LFH & & & \\
\hline FMA & & & \\
\hline $\mathrm{Na}-\mathrm{Me}$ & & & \\
\hline S-Go & & & \\
\hline N-ANS & & & \\
\hline ANS-Me & & & \\
\hline OP-SN & & & \\
\hline U1-SN & & & \\
\hline L1-MP & & & \\
\hline Interincisal angle & & & \\
\hline U1-PP (mm) & & & \\
\hline U4-PP (mm) & & & \\
\hline U5-PP (mm) & & & \\
\hline U6-PP (mm) & & & \\
\hline L1-MP (mm) & & & \\
\hline L4-MP (mm) & & & \\
\hline L5-MP (mm) & & & \\
\hline L6-MP (mm) & & & \\
\hline Overbite & $*$ & & \\
\hline Overjet & & & \\
\hline Curve of Spee & & & \\
\hline Mand intercanine width & & & \\
\hline Mand intermolar width & & & \\
\hline Max intercanine width & & & \\
\hline Max intermolar width & & & \\
\hline Irregularity Index (mand) & & & \\
\hline
\end{tabular}

$* \mathrm{p}<0.05$ 
Table 8. Significant changes between groups during post-retention period (T3-T2)

\begin{tabular}{|c|c|c|c|}
\hline & Brachy vs. dolicho & brachy vs. meso & dolicho vs. meso \\
\hline SNA & & & \\
\hline SNB & & & \\
\hline ANB & & & \\
\hline MPA & & & \\
\hline Y-axis & & & \\
\hline LFH & & & \\
\hline FMA & & & \\
\hline $\mathrm{Na}-\mathrm{Me}$ & & & \\
\hline S-Go & & & \\
\hline N-ANS & $*$ & & \\
\hline ANS-Me & & & \\
\hline OP-SN & & & \\
\hline U1-SN & & & \\
\hline L1-MP & * & & \\
\hline Interincisal angle & $*$ & & \\
\hline $\mathrm{U} 1-\mathrm{PP}(\mathrm{mm})$ & & & $*$ \\
\hline U4-PP (mm) & & & \\
\hline U5-PP (mm) & & & \\
\hline U6-PP (mm) & & & \\
\hline L1-MP (mm) & & & \\
\hline L4-MP (mm) & & & \\
\hline L5-MP (mm) & & & \\
\hline L6-MP (mm) & & & \\
\hline Overbite & $*$ & & * \\
\hline Overjet & & & \\
\hline Curve of Spee & & & \\
\hline Mand intercanine width & & & \\
\hline Mand intermolar width & & & \\
\hline Max intercanine width & & & \\
\hline Max intermolar width & & & \\
\hline Irregularity Index (mand) & & & \\
\hline
\end{tabular}

$* \mathrm{p}<0.05$ 


\subsection{INTERGROUP CHANGES FOR EACH VARIABLE}

\section{Y-axis}

Before orthodontic treatment (T1), the mean Y-axis values for the brachycephalic $\left(64.1^{\circ}\right)$, mesocephalic $\left(66.3^{\circ}\right)$, and dolicocephalic $\left(70.5^{\circ}\right)$ groups differed significantly from each other $(\mathrm{p}<0.0001)$. There were no significant differences in $\mathrm{Y}$-axis changes between the groups during orthodontic treatment (T2-T1) or during the long-term follow up period $(\mathrm{T} 3-\mathrm{T} 2)(\mathrm{p}>0.05)$.

Figure 23. Y-axis comparison for the three groups

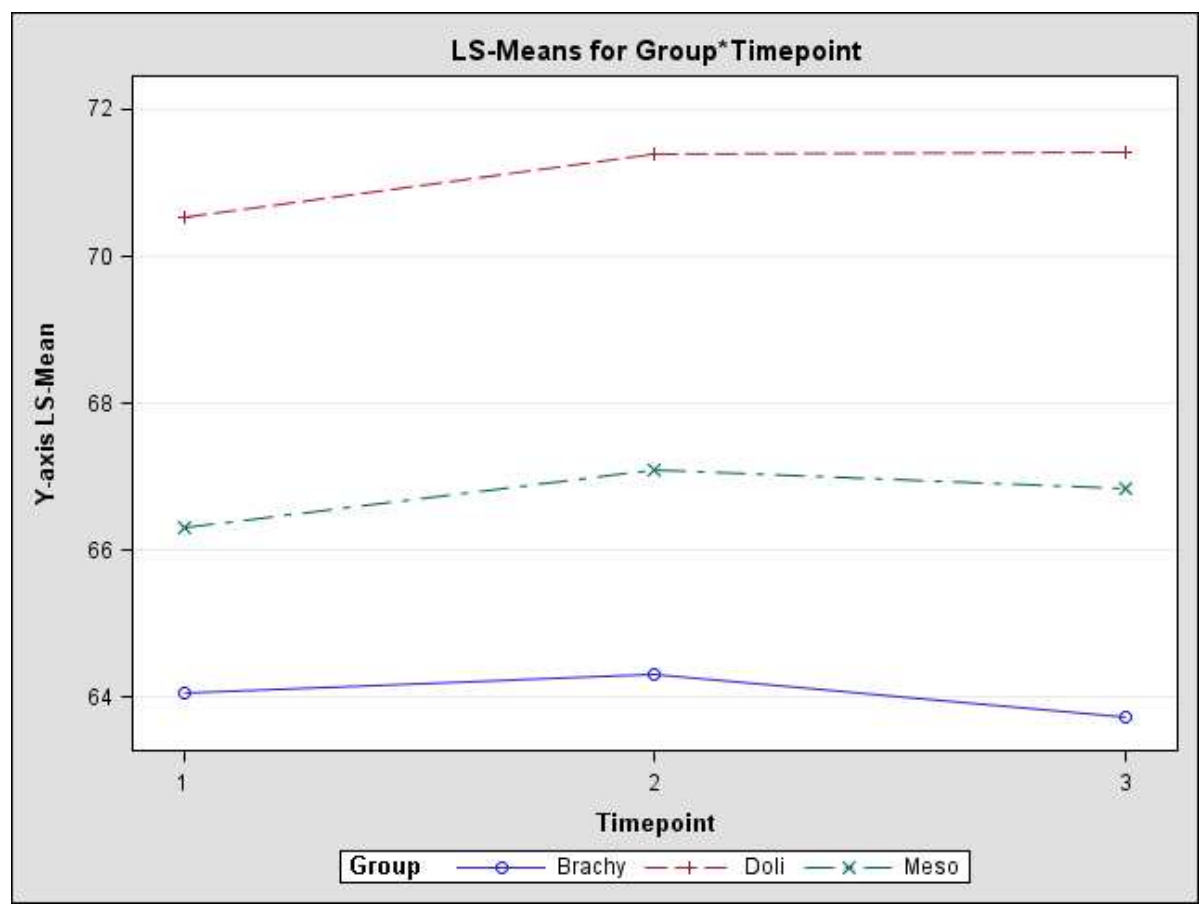




\section{Mandibular Plane Angle (MPA)}

Before orthodontic treatment (T1), the mean MPA values for the brachycephalic $\left(26.5^{\circ}\right)$, mesocephalic $\left(32.5^{\circ}\right)$, and dolicocephalic $\left(37.8^{\circ}\right)$ groups differed significantly from each other $(\mathrm{p}<0.0001)$. There were no significant differences in MPA changes between the groups during orthodontic treatment (T2-T1) or during the long-term follow up period $(\mathrm{T} 3-\mathrm{T} 2)(\mathrm{p}>0.05)$

Figure 24. MPA comparison for the three groups

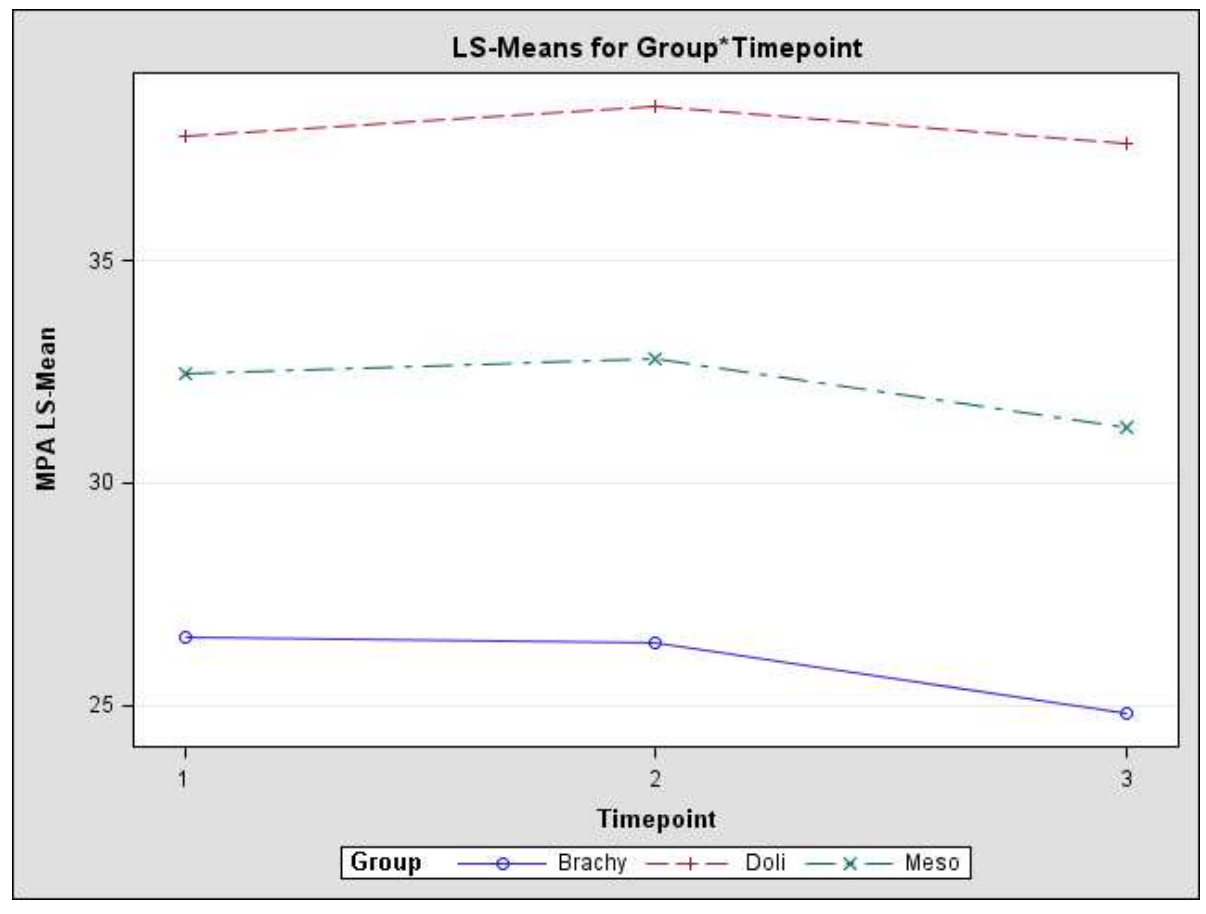




\section{Lower Anterior Face Height (LFH, Ricketts)}

Before orthodontic treatment (T1), the mean LFH values for the brachycephalic $\left(38.8^{\circ}\right)$, mesocephalic $\left(42.5^{\circ}\right)$, and dolicocephalic $\left(45.6^{\circ}\right)$ groups differed significantly from each other $(\mathrm{p}<0.005)$. There were no significant differences in MPA changes between the groups during orthodontic treatment (T2-T1) or during the long-term follow up period $(\mathrm{T} 3-\mathrm{T} 2)(\mathrm{p}>0.05)$.

Figure 25. LFH comparison for the three groups

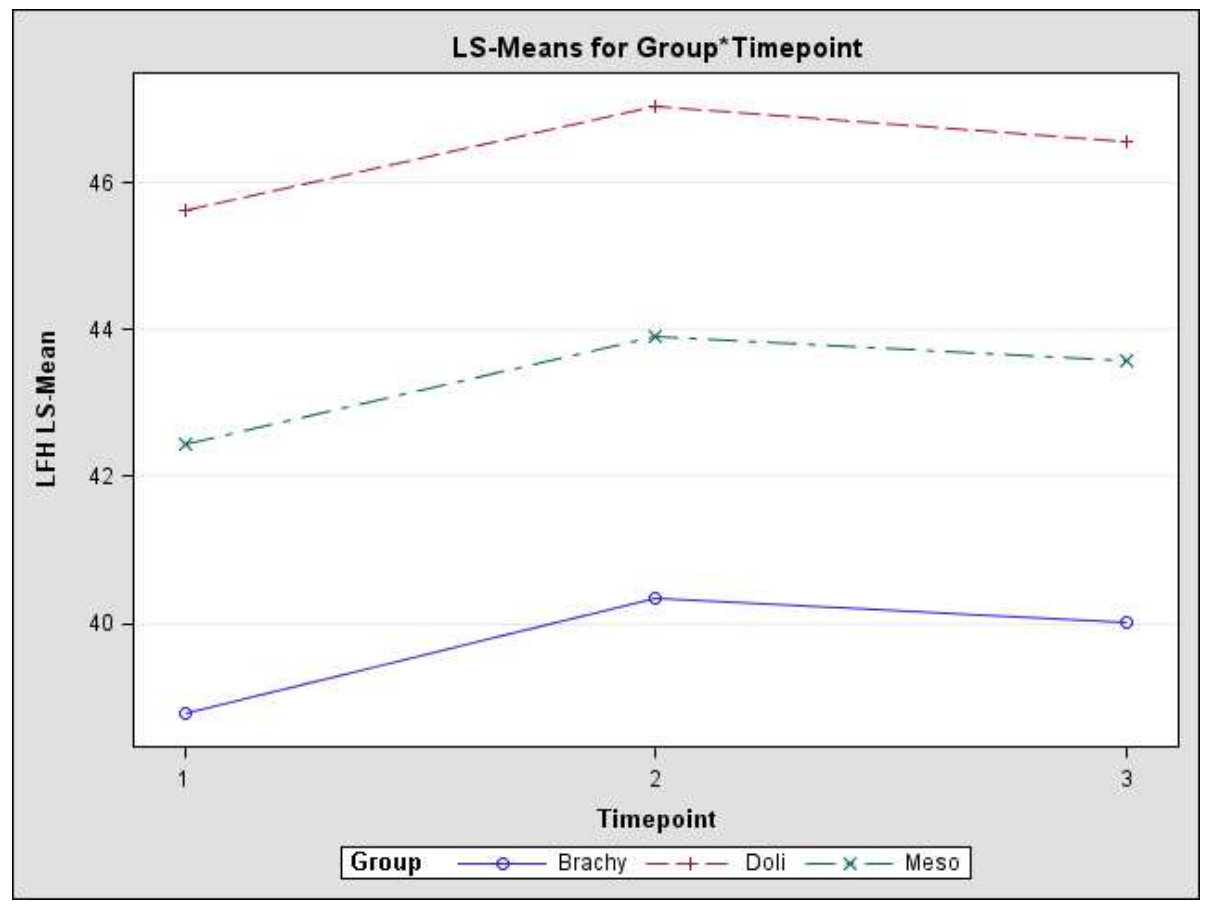




\section{Sella-Nasion-A point Angle (SNA)}

Before orthodontic treatment (T1), the mean SNA value for the dolicocephalic group $\left(77.6^{\circ}\right)$ differed significantly from the mean SNA value for both the mesocephalic $\left(82.0^{\circ}\right)$ and brachycephalic $\left(82.5^{\circ}\right)$ groups $(\mathrm{p}<0.0001)$. The latter two groups' mean SNA at T1 did not differ significantly. There were no significant differences in SNA changes between the groups during orthodontic treatment (T2-T1) or during the long-term follow up period $(\mathrm{T} 3-\mathrm{T} 2)(\mathrm{p}>0.05)$.

Figure 26. SNA comparison for the three groups

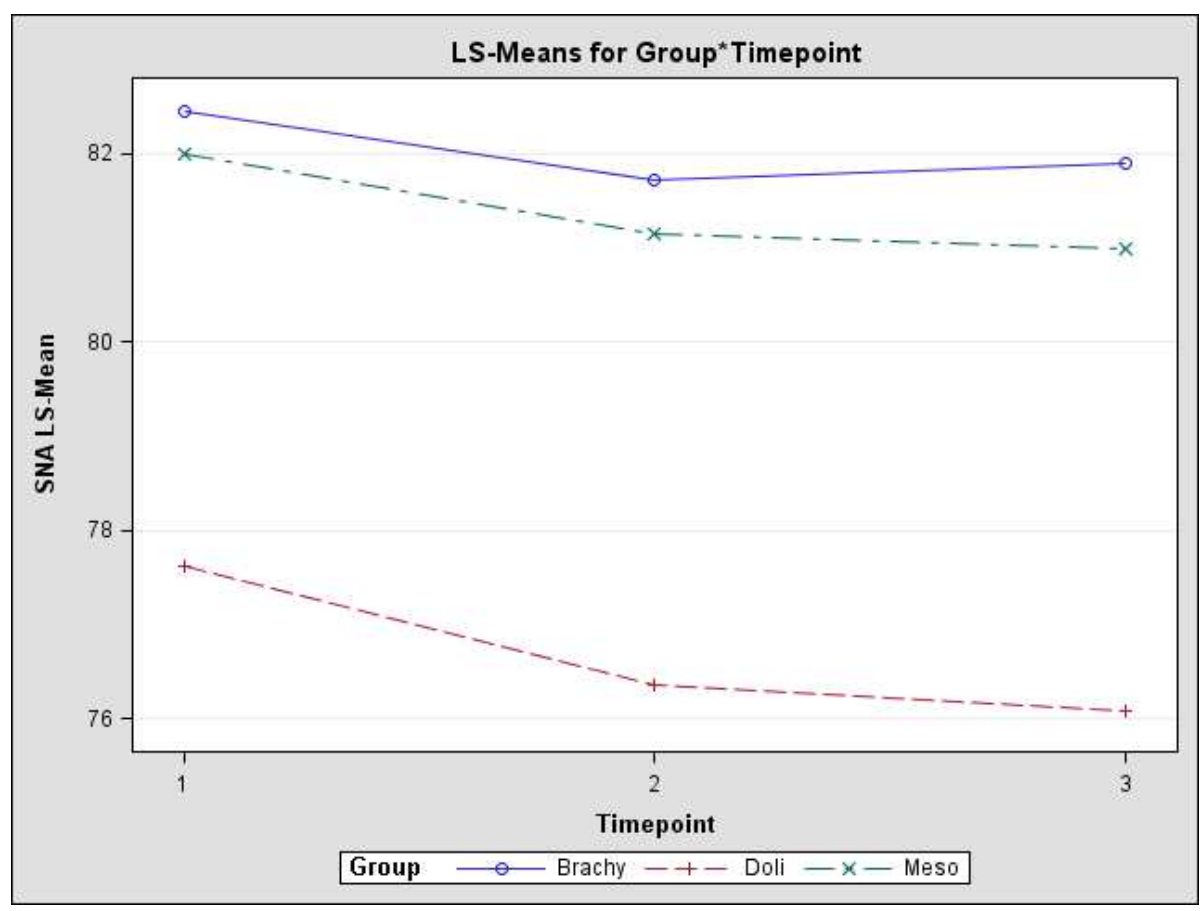




\section{Sella-Nasion-B point Angle (SNB)}

Before orthodontic treatment (T1), the mean SNB value for the dolicocephalic group $\left(73.4^{\circ}\right)$ differed significantly from the mean SNB value for both the mesocephalic $\left(78.0^{\circ}\right)$ and brachycephalic $\left(78.7^{\circ}\right)$ groups $(\mathrm{p}<0.0001)$. The latter two groups' mean SNB at T1 did not differ significantly $(\mathrm{p}>0.05)$. During orthodontic treatment $(\mathrm{T} 2-\mathrm{T} 1)$, the mean SNB for the brachycephalic group increased significantly more than both the mesocephalic $(p=0.0259)$ and dolicocephalic $(p=0.0301)$ groups. There were no significant differences in SNB changes between the groups during the long-term follow up period $(\mathrm{T} 3-\mathrm{T} 2)(\mathrm{p}>0.05)$.

Figure 27. SNB comparison for the three groups

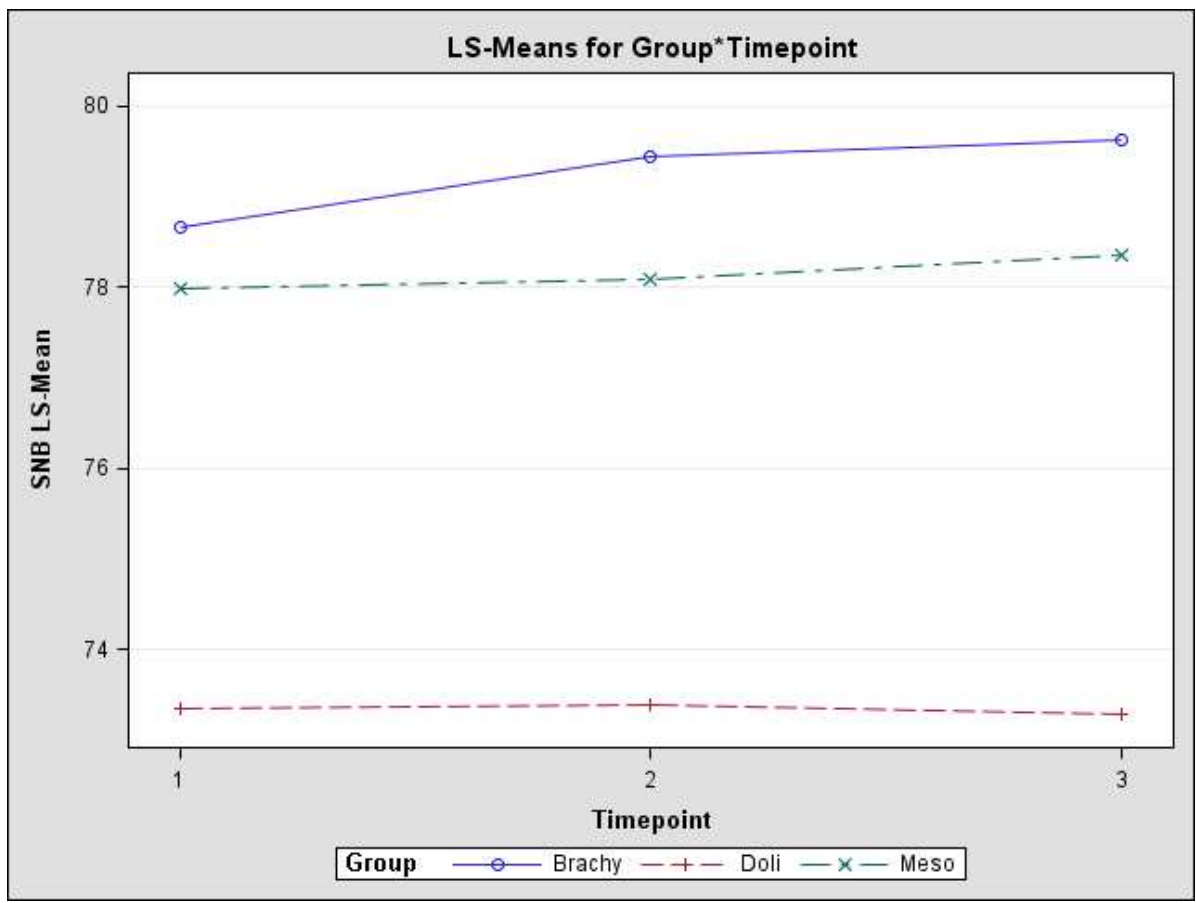




\section{A point-Nasion-B point Angle (ANB)}

Before orthodontic treatment (T1), the mean ANB values for the three groups were not significantly different $(\mathrm{p}>0.05)$. There were no significant differences in ANB changes between the groups during orthodontic treatment (T2-T1) or during the long-term follow up period (T3-T2) $(\mathrm{p}>0.05)$.

Figure 28. ANB comparison for the three groups

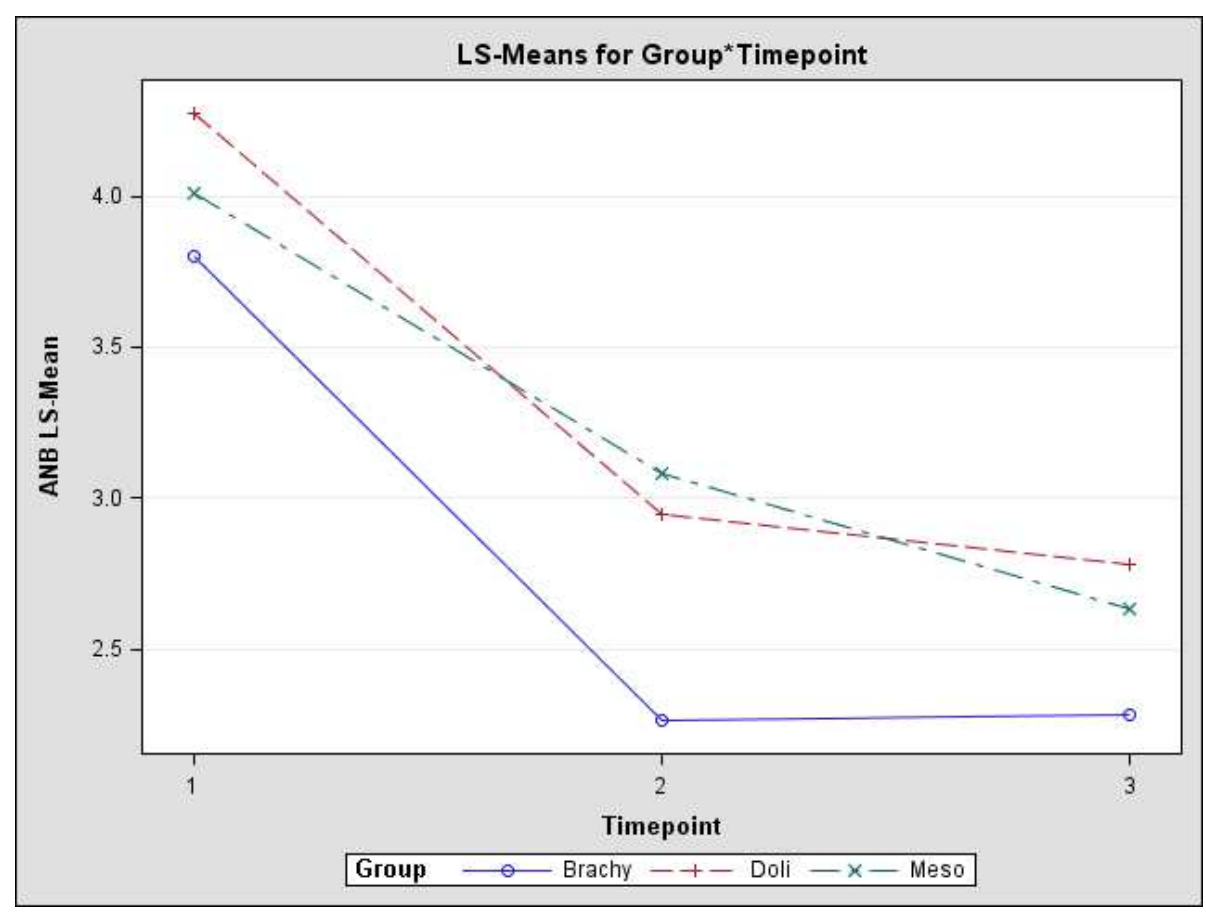




\section{Frankfort-Mandibular Plane Angle (FMA)}

Before orthodontic treatment (T1), the mean FMA values for the brachycephalic $\left(20.1^{\circ}\right)$, mesocephalic $\left(25.1^{\circ}\right)$, and dolicocephalic $\left(27.5^{\circ}\right)$ groups differed significantly from each other $(\mathrm{p}<0.05)$. There were no significant differences in SNA changes between the groups during orthodontic treatment (T2-T1) or during the long-term follow up period $(\mathrm{T} 3-\mathrm{T} 2)(\mathrm{p}>0.05)$

Figure 29. FMA comparison for the three groups

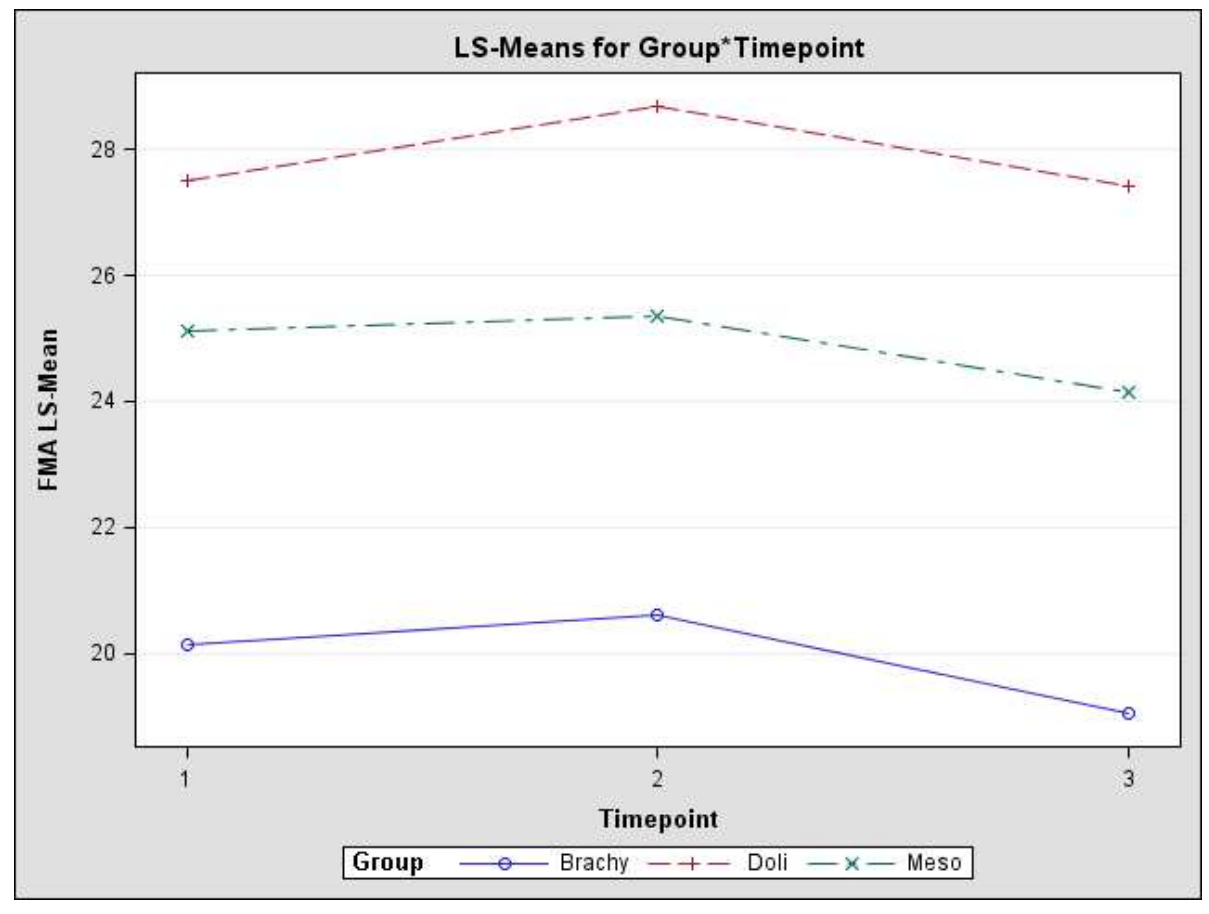




\section{Anterior Face Height (AFH, Nasion-Menton)}

Before orthodontic treatment (T1), the mean AFH value for the dolicocephalic group (118.1 mm) differed significantly from the mean AFH value for both the mesocephalic $(114.3 \mathrm{~mm})$ and brachycephalic $(113.5 \mathrm{~mm})$ groups $(\mathrm{p}<0.05)$. The latter two groups' mean AFH at $\mathrm{T} 1$ did not differ significantly $(\mathrm{p}>0.05)$. There were no significant differences in AFH changes between the groups during orthodontic treatment (T2-T1) or during the long-term follow up period (T3-T2) $(\mathrm{p}>0.05)$.

Figure 30. AFH comparison for the three groups

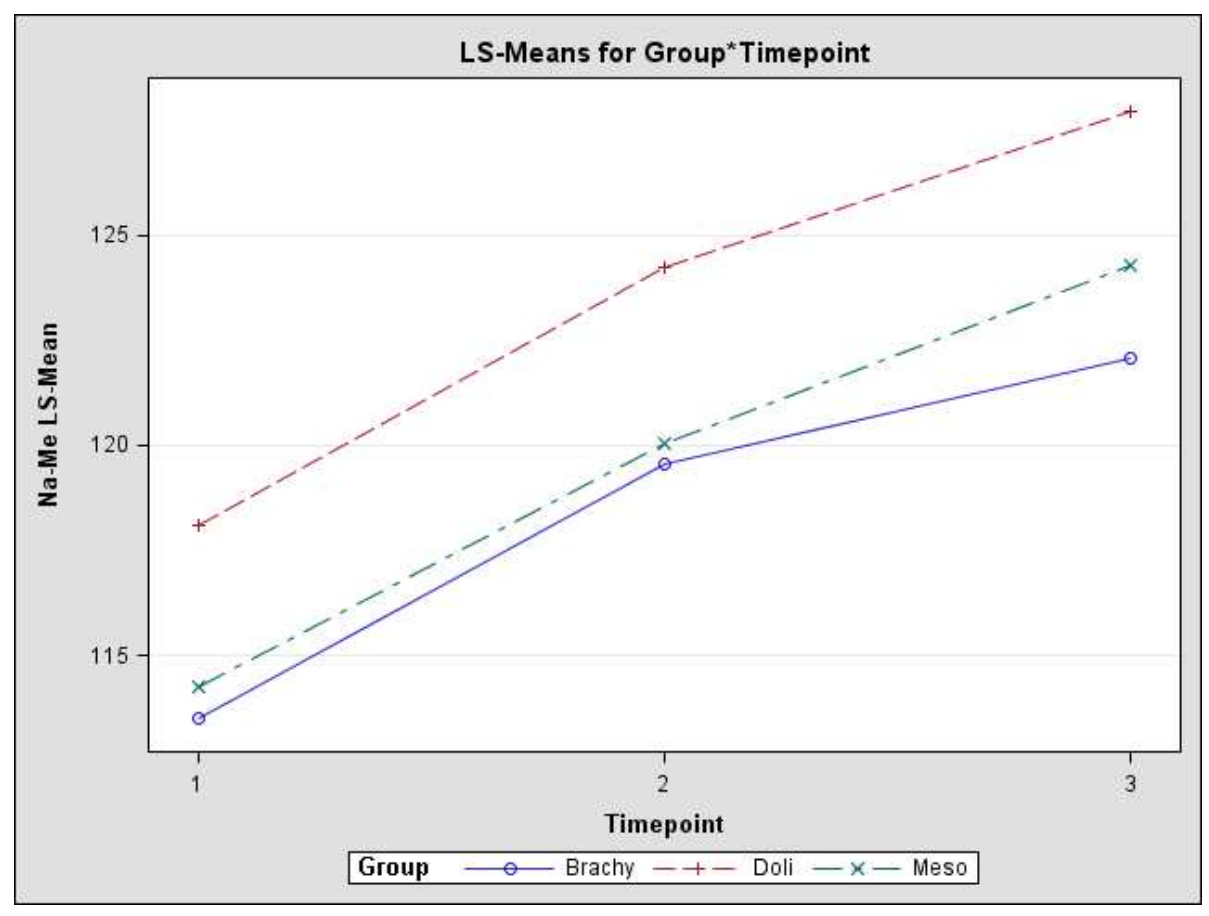




\section{Posterior Face Height (PFH, Sella-Gonion)}

Before orthodontic treatment (T1), the mean PFH value for the brachycephalic group (80.4 mm) differed significantly from the mean PFH value for both the mesocephalic $(74.7 \mathrm{~mm})$ and dolicocephalic $(72.3 \mathrm{~mm})$ groups $(\mathrm{p}<0.001)$. The latter two groups' mean PFH at T1 did not differ significantly $(\mathrm{p}>0.05)$. There were no significant differences in PFH changes between the groups during orthodontic treatment (T2-T1) or during the long-term follow up period (T3-T2) $(\mathrm{p}>0.05)$.

Figure 31. PFH comparison for the three groups

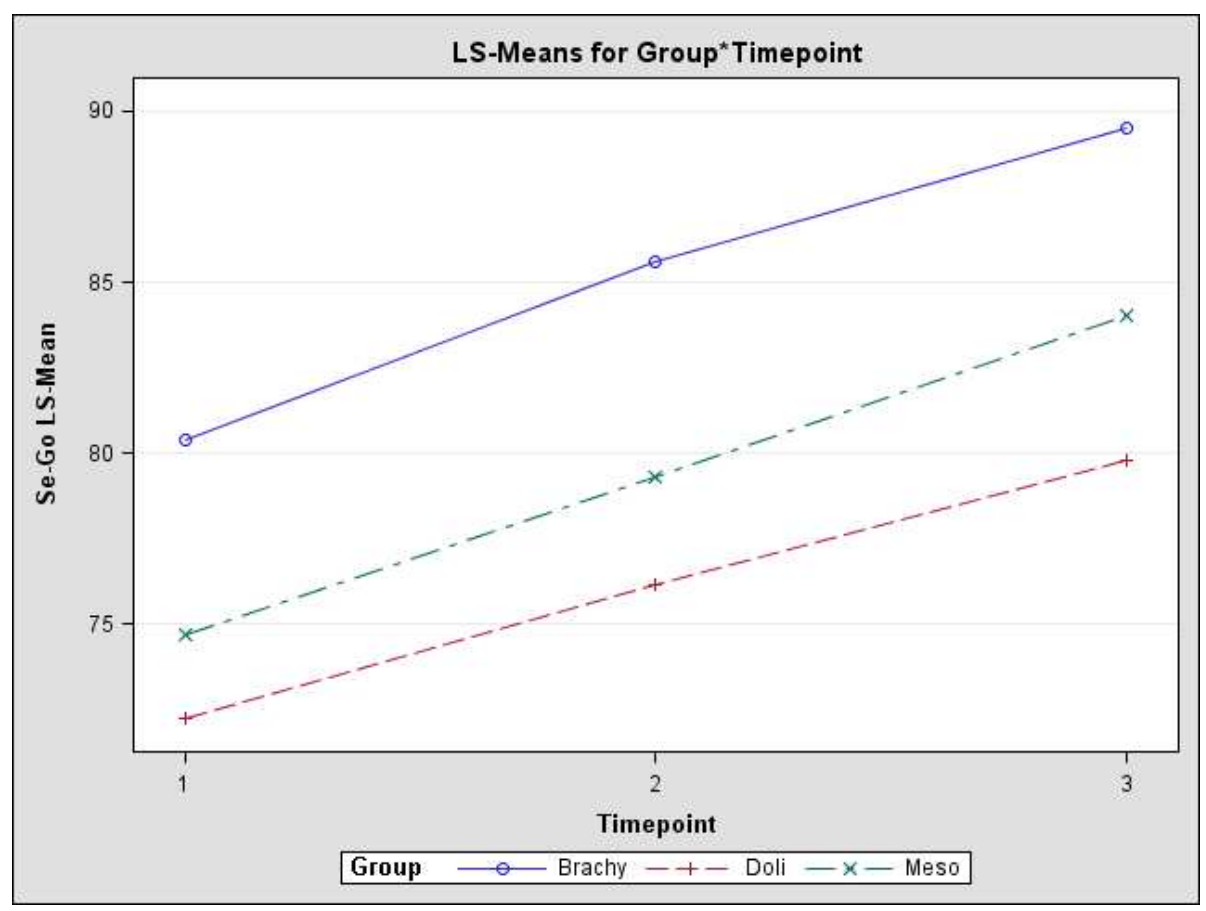




\section{Upper Anterior Face Height (UAFH, Nasion-ANS)}

Before orthodontic treatment (T1), the mean UAFH values for the three groups were not significantly different $(p>0.05)$. There were no significant differences in UAFH changes between the groups during orthodontic treatment $(\mathrm{T} 2-\mathrm{T} 1)(\mathrm{p}>0.05)$. However, during the long-term follow up period (T3-T2), the mean change in UAFH for the brachycephalic group was significantly different compared to both the mesocephalic $(\mathrm{p}=0.0876)$ and dolicocephalic $(\mathrm{p}=0.0198)$ groups.

Figure 32. UAFH comparison for the three groups

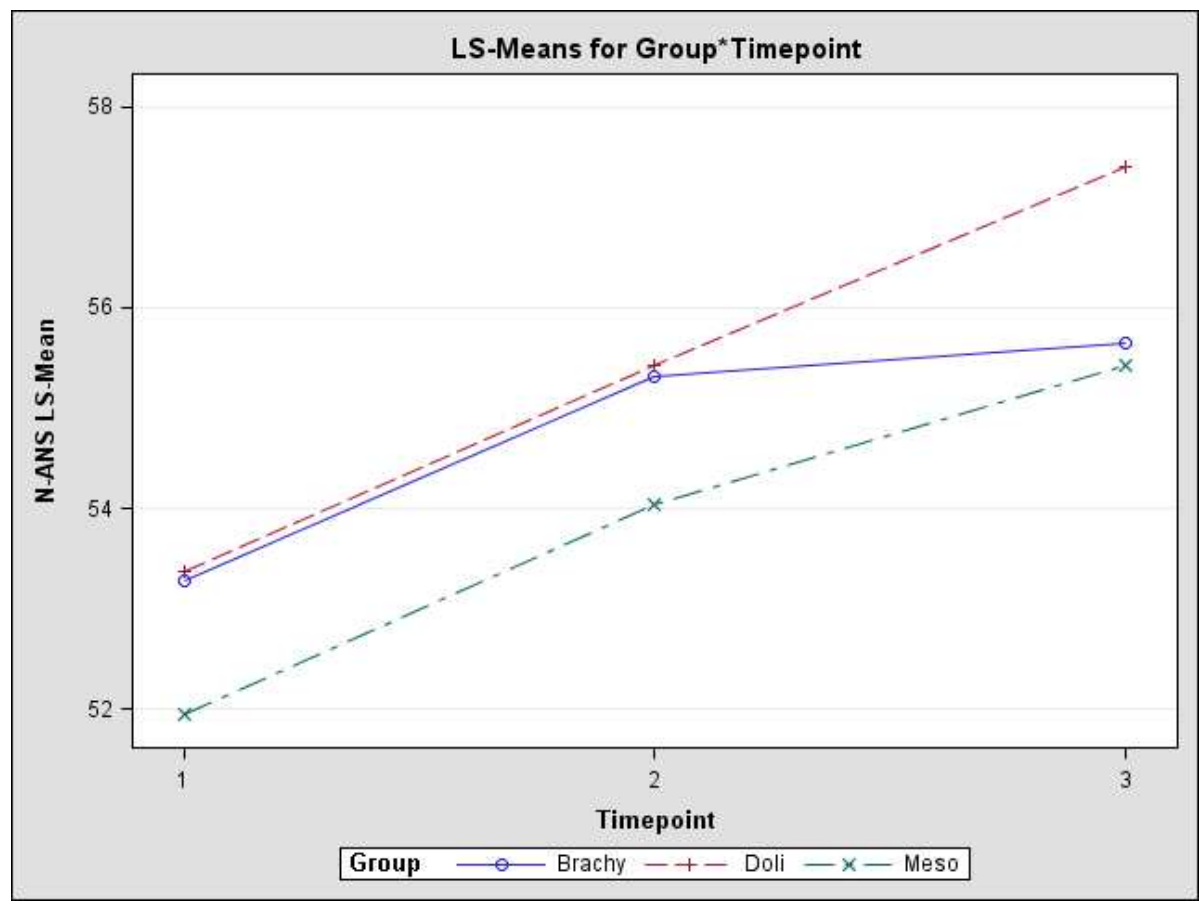




\section{Lower Anterior Face Height (LAFH, ANS-Menton)}

Before orthodontic treatment (T1), the mean LAFH value for the brachycephalic group (61.4 $\mathrm{mm})$ differed significantly from the mean LAFH value for the dolicocephalic (66.1 $\mathrm{mm})$ group $(\mathrm{p}=0.0031)$ with all other comparisons being insignificant. There were no significant differences in LAFH changes between the groups during orthodontic treatment (T2-T1) or during the long-term follow up period $(\mathrm{T} 3-\mathrm{T} 2)(\mathrm{p}>0.05)$.

Figure 33. LAFH comparison for the three groups

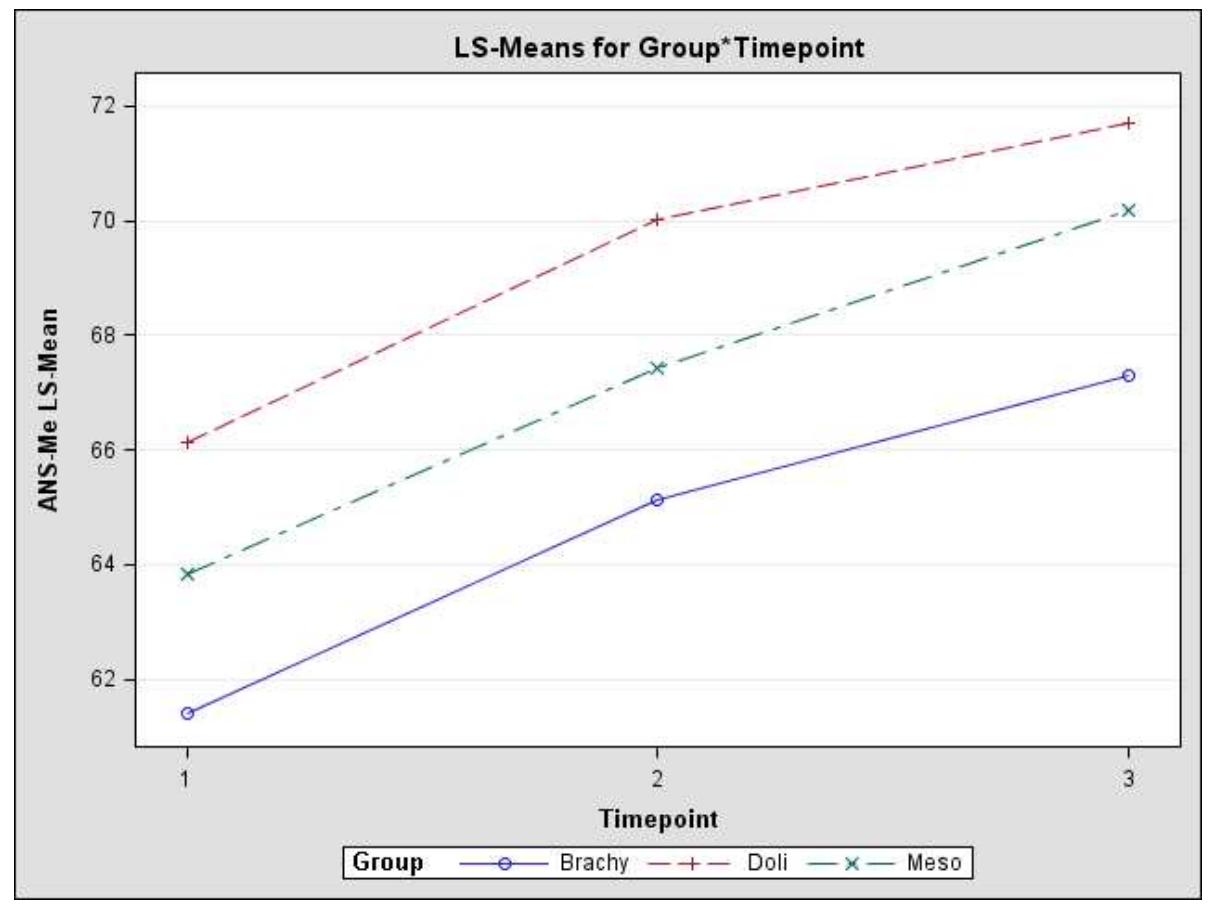




\section{Occlusal Plane Angle (OP-SN)}

Before orthodontic treatment $(\mathrm{T} 1)$, the mean OP-SN angle for the brachycephalic $\left(12.3^{\circ}\right)$, mesocephalic $\left(14.6^{\circ}\right)$, and dolicocephalic $\left(18.9^{\circ}\right)$ groups differed significantly from each other $(\mathrm{p}<0.05)$. There were no significant differences in OP-SN angle changes between the groups during orthodontic treatment (T2-T1) or during the long-term follow up period $(\mathrm{T} 3-\mathrm{T} 2)(\mathrm{p}>0.05)$.

Figure 34. OP-SN comparison for the three groups

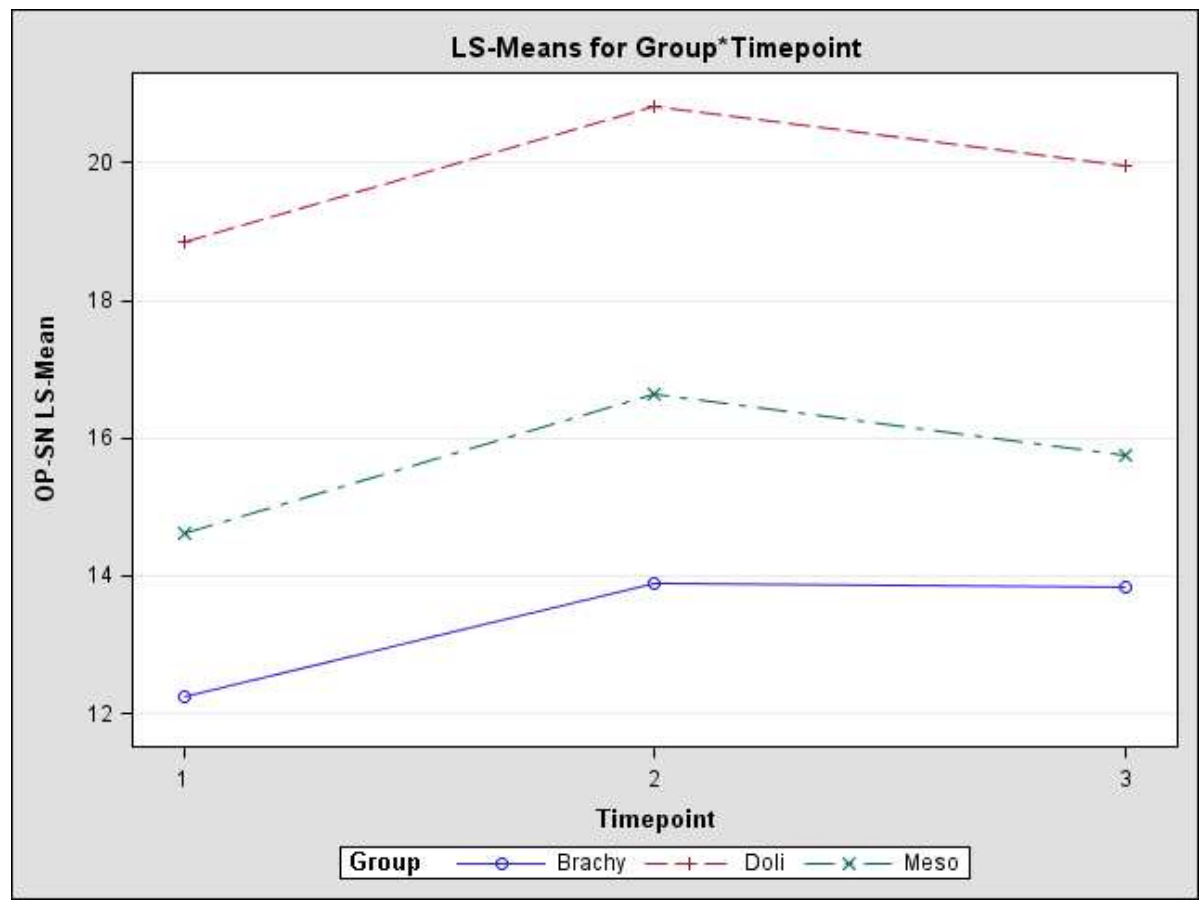




\section{Upper Incisal Angulation (U1-SN)}

Before orthodontic treatment (T1), the mean U1-SN angles for the three groups were not significantly different $(p>0.05)$. There were no significant differences in U1-SN angle changes between the groups during orthodontic treatment (T2-T1) or during the long-term follow up period $(\mathrm{T} 3-\mathrm{T} 2)(\mathrm{p}>0.05)$.

Figure 35. U1-SN comparison for the three groups

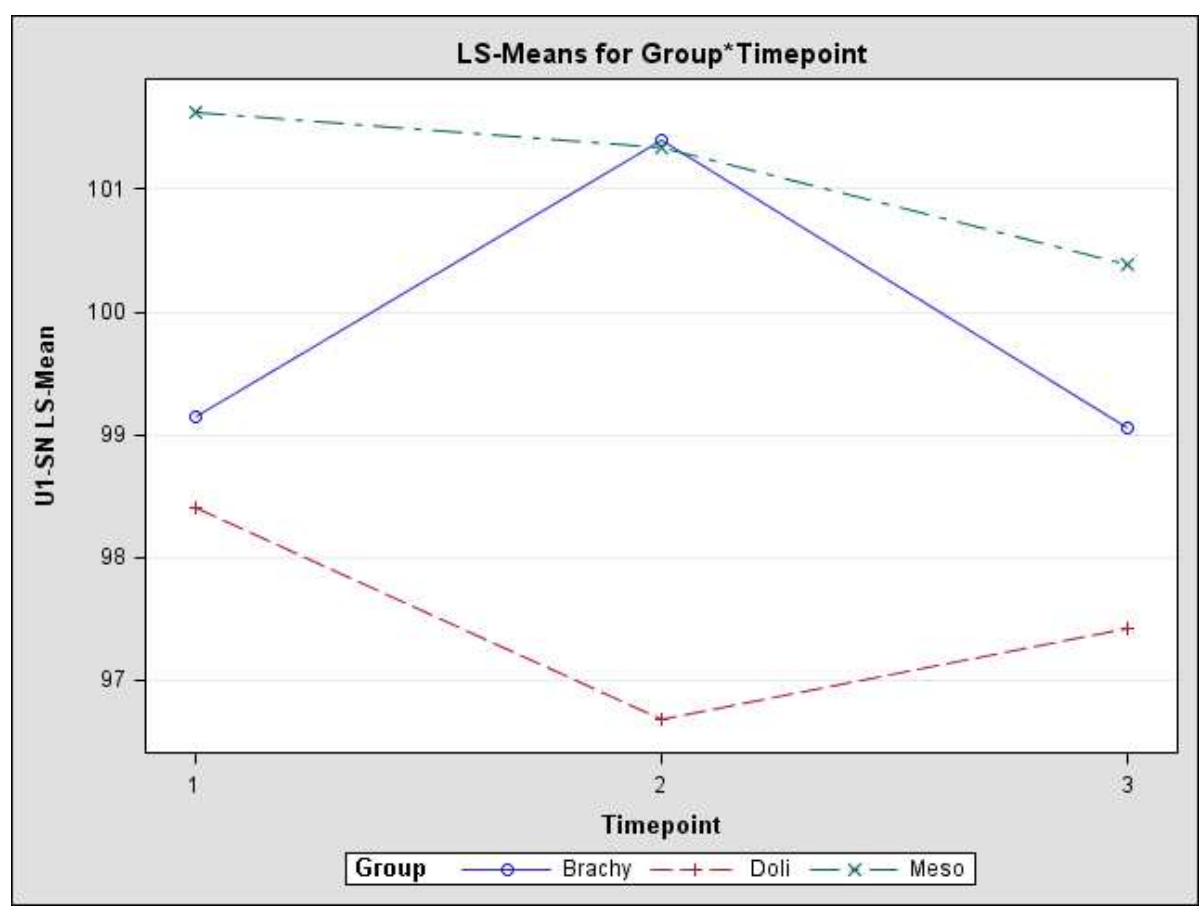




\section{Lower Insical Angulation (L1-MP)}

Before orthodontic treatment (T1), the mean L1-MP angles for the three groups were not significantly different $(\mathrm{p}>0.05)$. There were no significant differences in L1-MP angle changes between the groups during orthodontic treatment $(\mathrm{T} 2-\mathrm{T} 1)(\mathrm{p}>0.05)$. However, during the long-term follow up period (T3-T2), the change in the mean L1-MP for the brachycephalic group was significantly different compared to the dolicocephalic group ( $p$ $=0.0163)$. All other post-retention comparisons were not significant $(\mathrm{p}>0.05)$.

Figure 36. L1-MP comparison for the three groups

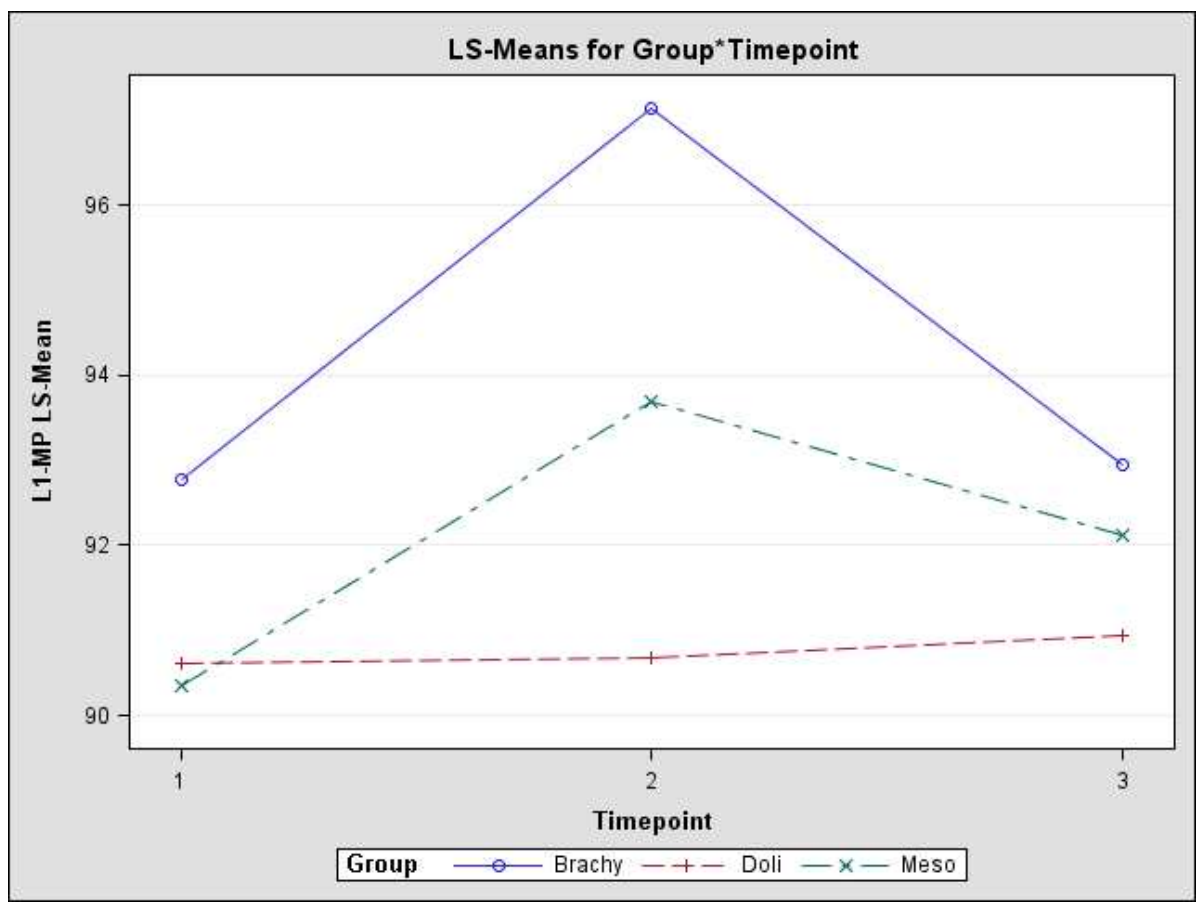




\section{Interincisal Angle (U1-L1)}

Before orthodontic treatment (T1), the mean interincisal angles for the three groups were not significantly different $(\mathrm{p}>0.05)$. There were no significant differences in interincisal angle changes between the groups during orthodontic treatment $(\mathrm{T} 2-\mathrm{T} 1)(\mathrm{p}>0.05)$. However, during the long-term follow up period (T3-T2), the change in the mean interincisal angle for the brachycephalic group was significantly different compared to the dolicocephalic group $(\mathrm{p}=0.0051)$. All other post-retention comparisons were not significant $(\mathrm{p}>0.05)$.

Figure 37. Interincisal Angle comparison for the three groups

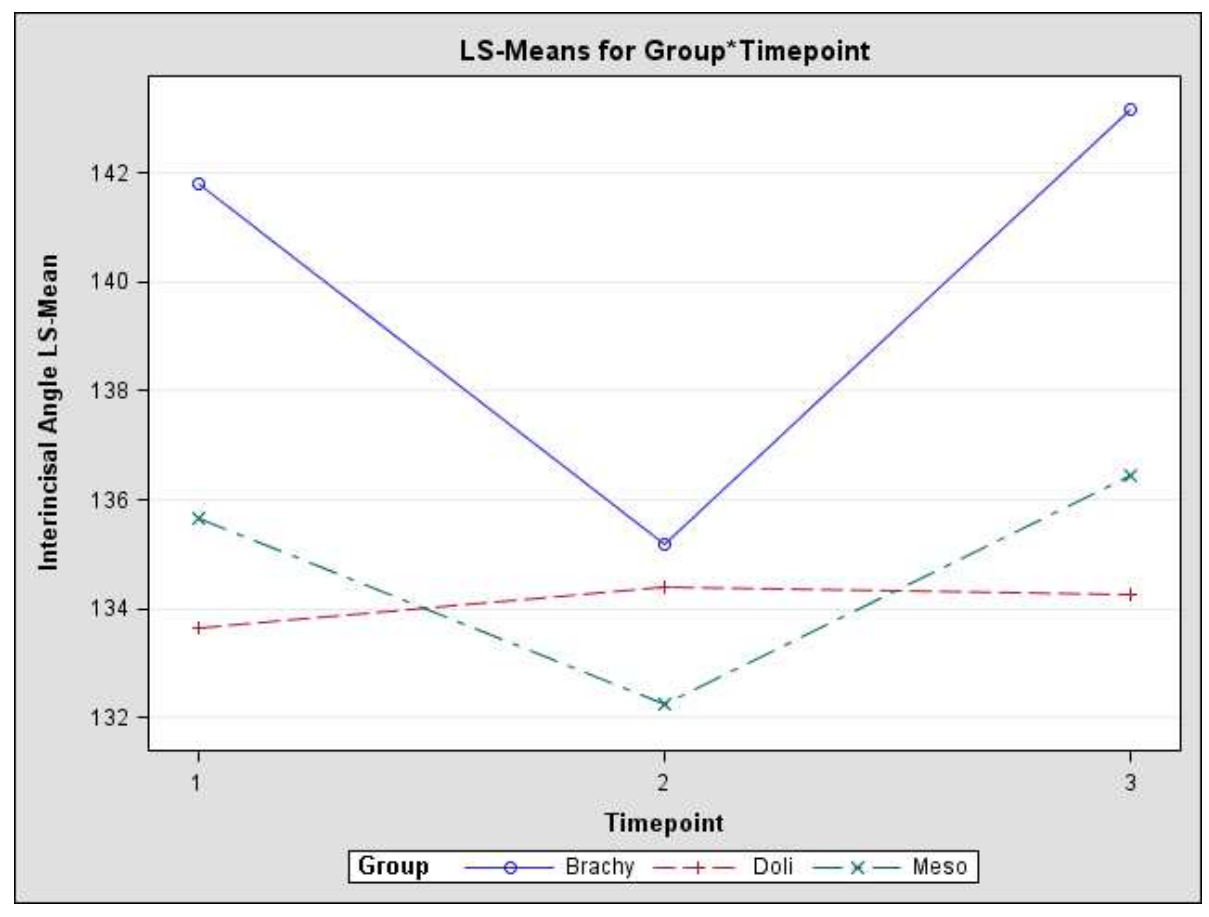




\section{Upper Incisal Position (U1-PP, mm)}

Before orthodontic treatment (T1), the mean U1-PP value for the brachycephalic group $(27.1 \mathrm{~mm})$ differed significantly from the mean U1-PP value for the dolicocephalic (29.0 $\mathrm{mm})$ group $(\mathrm{p}=0.0241)$ with all other comparisons being insignificant. There were no significant differences in U1-PP changes between the groups during orthodontic treatment $(\mathrm{T} 2-\mathrm{T} 1)(\mathrm{p}>0.05)$. However, during the long-term follow up period (T3-T2), the change in the mean U1-PP for the dolicocephalic group was significantly different compared to the mesocephalic group $(\mathrm{p}=0.0417)$. All other post-retention comparisons were not significant $(\mathrm{p}>0.05)$.

Figure 38. U1-PP (mm) comparison for the three groups

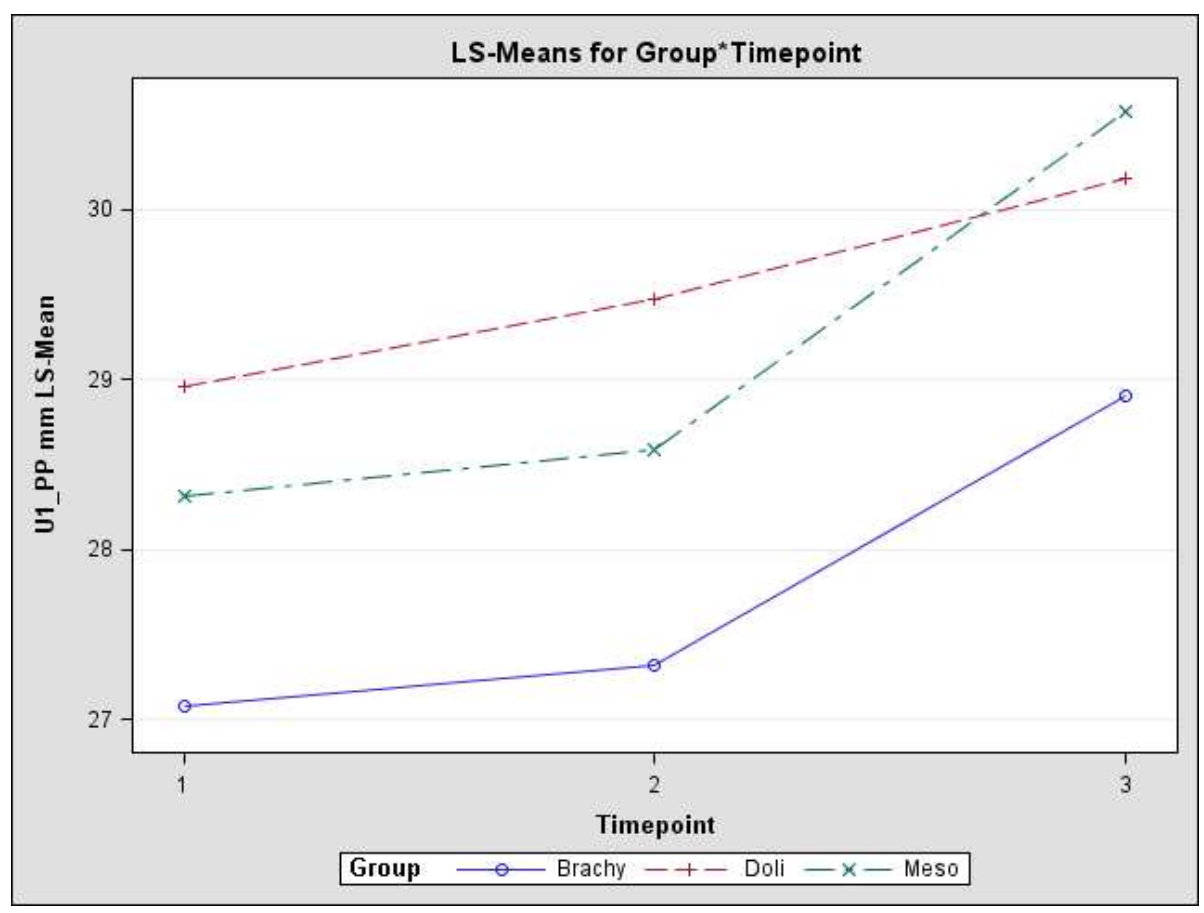




\section{Upper First Premolar Position (U4-PP, mm)}

Before orthodontic treatment (T1), the mean U4-PP values for the three groups were not significantly different $(\mathrm{p}>0.05)$. There were no significant differences in U4-PP changes between the groups during orthodontic treatment (T2-T1) or during the long-term follow up period $(\mathrm{T} 3-\mathrm{T} 2)(\mathrm{p}>0.05)$.

Figure 39. U4-PP (mm) comparison for the three groups

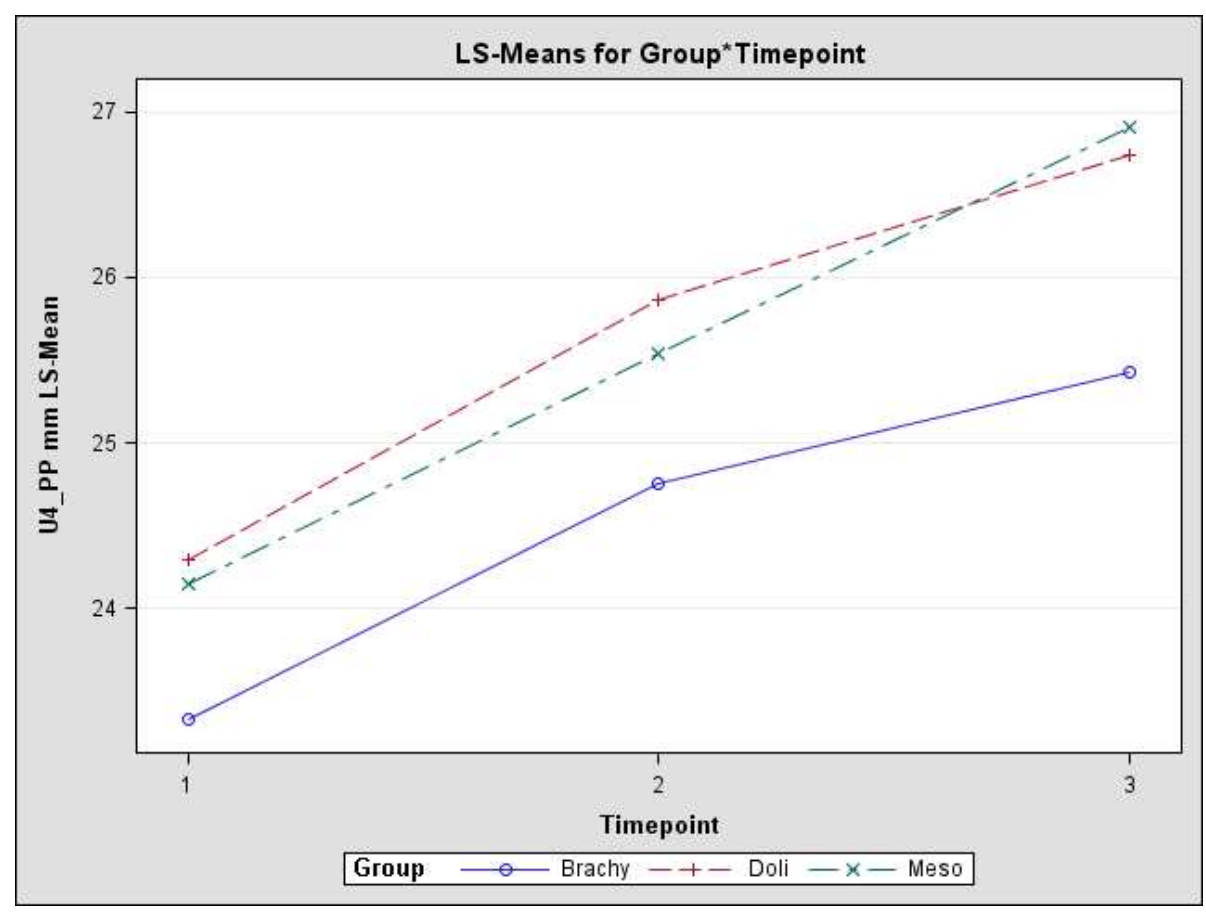




\section{Upper Second Premolar Position (U5-PP, mm)}

Before orthodontic treatment (T1), the mean U5-PP values for the three groups were not significantly different $(\mathrm{p}>0.05)$. There were no significant differences in U5-PP changes between the groups during orthodontic treatment (T2-T1) or during the long-term follow up period $(\mathrm{T} 3-\mathrm{T} 2)(\mathrm{p}>0.05)$.

Figure 40. U5-PP (mm) comparison for the three groups

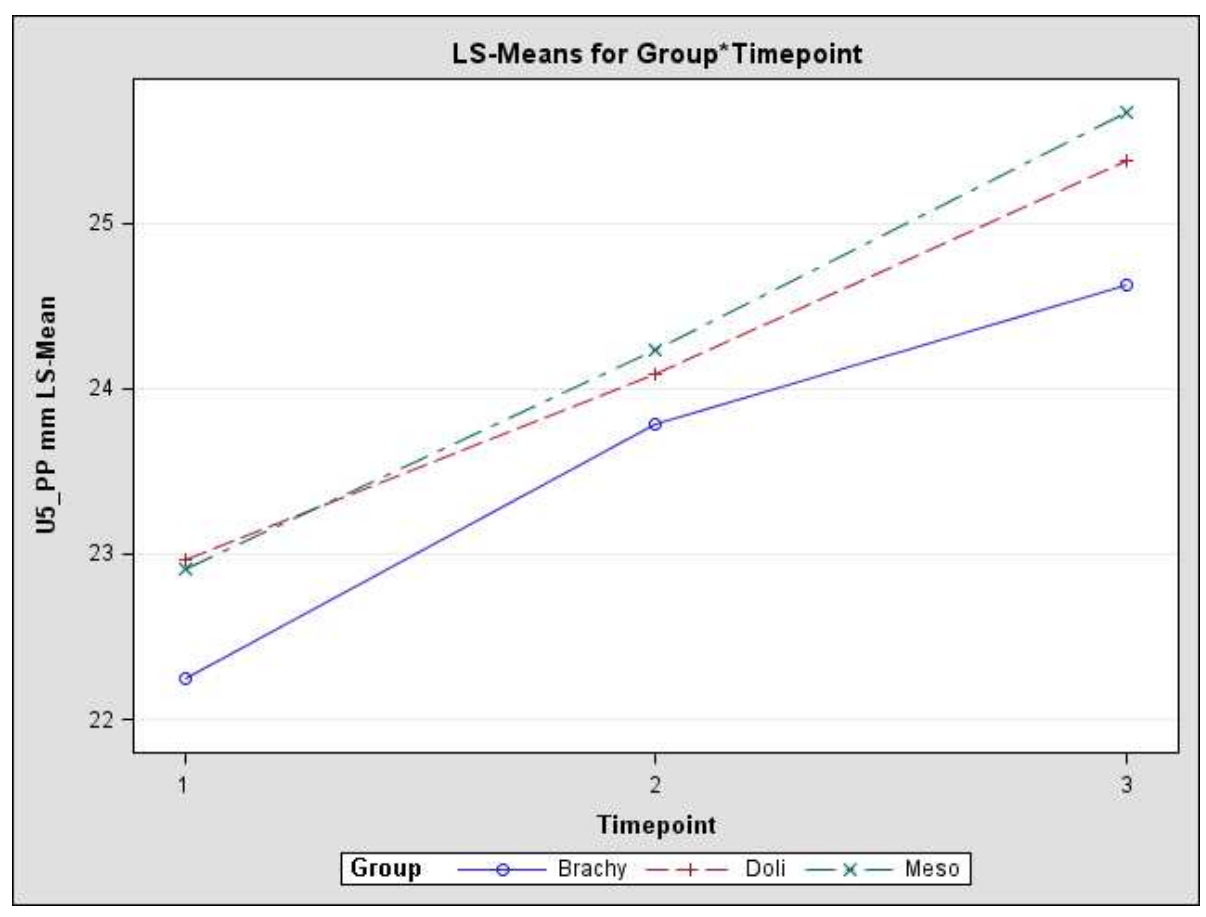




\section{Upper First Molar Position (U6-PP, mm)}

Before orthodontic treatment (T1), the mean U6-PP values for the three groups were not significantly different $(\mathrm{p}>0.05)$. There were no significant differences in U6-PP changes between the groups during orthodontic treatment (T2-T1) or during the long-term follow up period $(\mathrm{T} 3-\mathrm{T} 2)(\mathrm{p}>0.05)$.

Figure 41. U6-PP (mm) comparison for the three groups

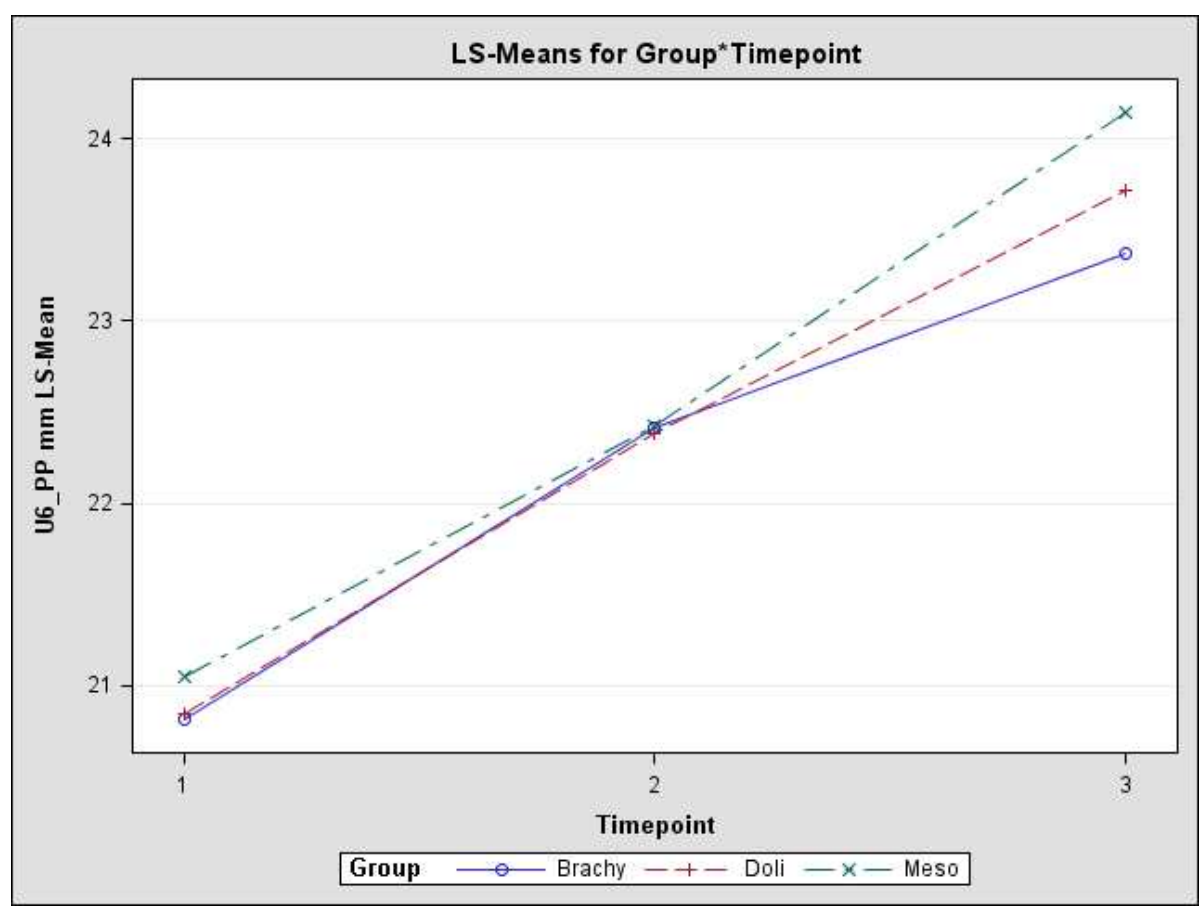




\section{Lower Incisal Position (L1-MP, mm)}

Before orthodontic treatment (T1), the mean L1-MP values for the three groups were not significantly different $(\mathrm{p}>0.05)$. There were no significant differences in L1-MP changes between the groups during orthodontic treatment (T2-T1) or during the long-term follow up period (T3-T2) $(\mathrm{p}>0.05)$.

Figure 42. L1-MP (mm) comparison for the three groups

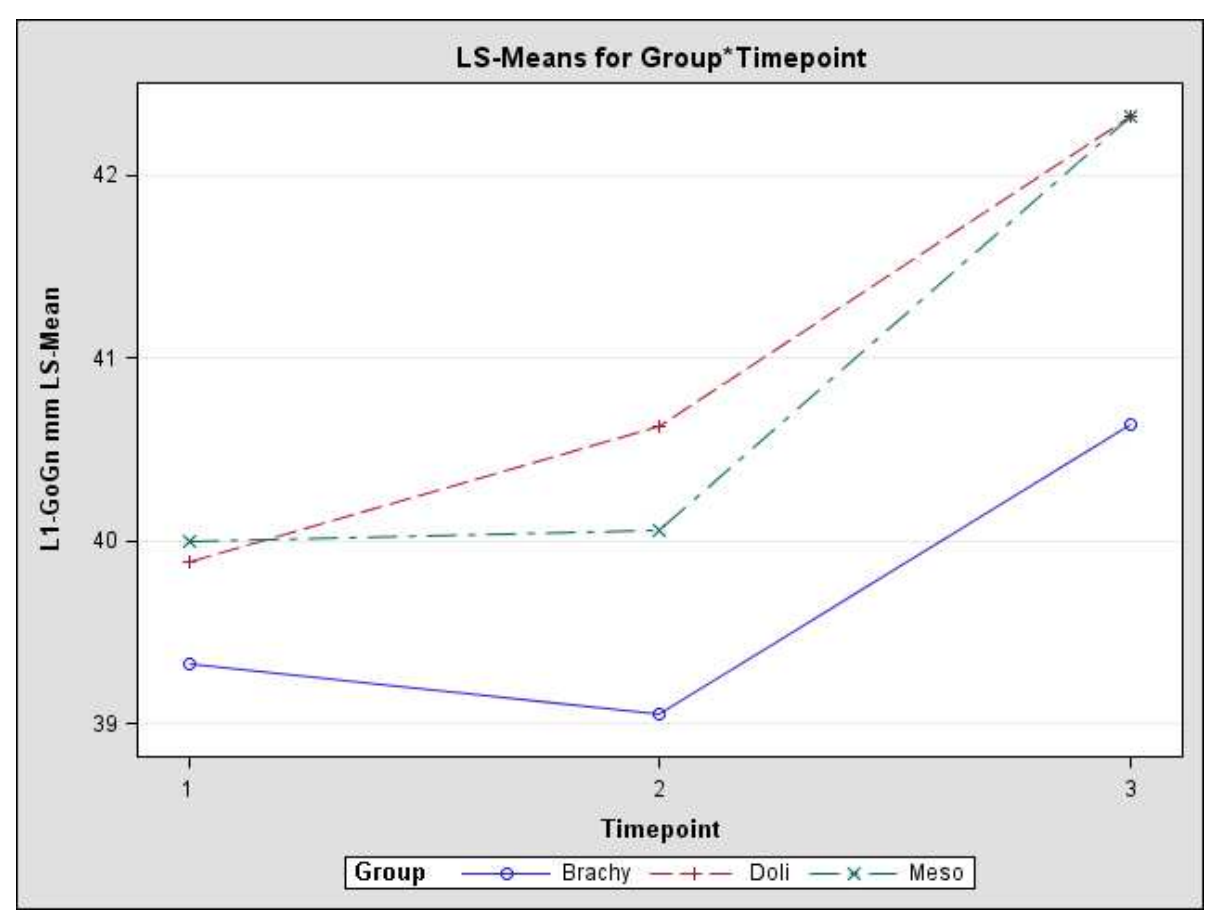




\section{Lower First Premolar Position (L4-MP, mm)}

Before orthodontic treatment (T1), the mean L4-MP values for the three groups were not significantly different $(\mathrm{p}>0.05)$. There were no significant differences in L4-MP changes between the groups during orthodontic treatment (T2-T1) or during the long-term follow up period (T3-T2) $(\mathrm{p}>0.05)$.

Figure 43. L4-MP (mm) comparison for the three groups

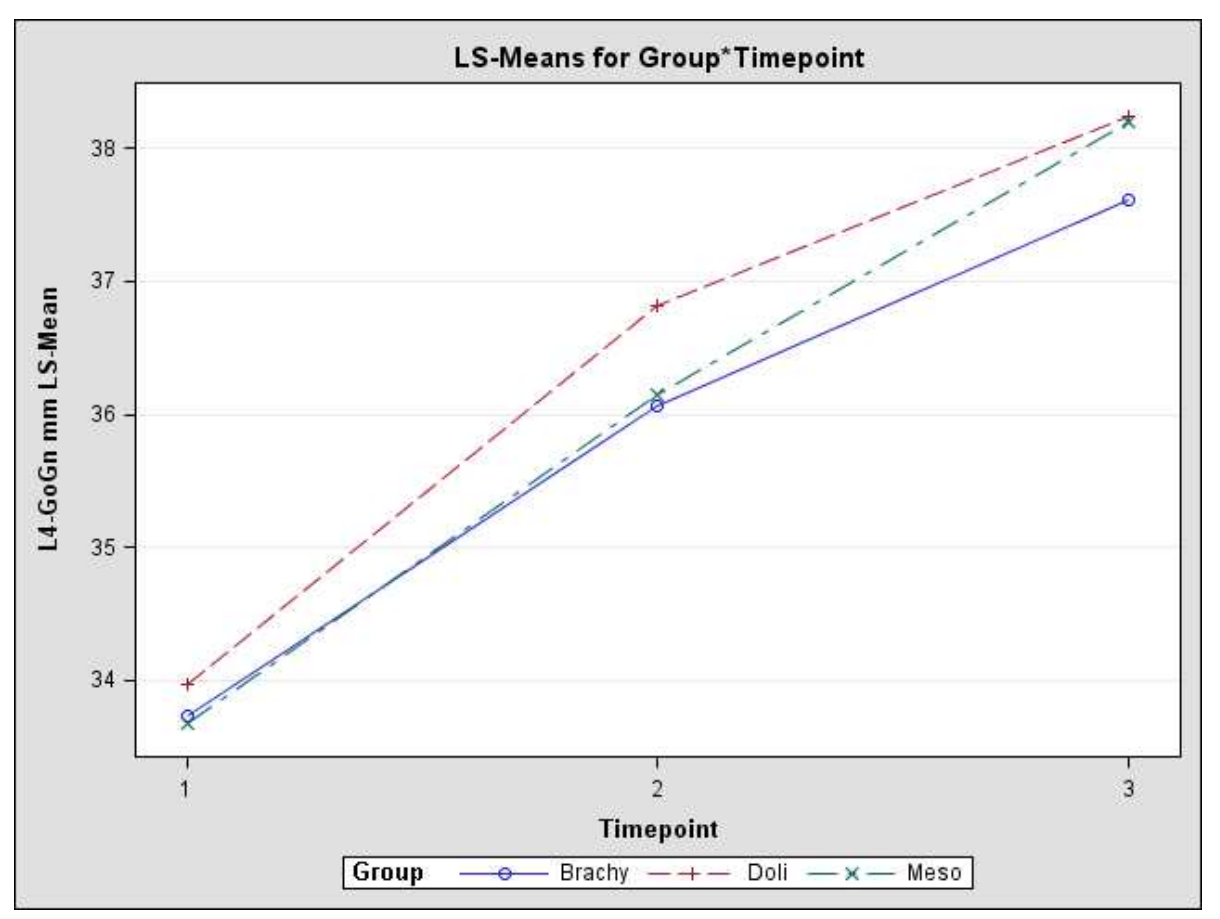




\section{Lower Second Premolar Position (L5-MP, mm)}

Before orthodontic treatment (T1), the mean L5-MP values for the three groups were not significantly different $(\mathrm{p}>0.05)$. There were no significant differences in L5-MP changes between the groups during orthodontic treatment (T2-T1) or during the long-term follow up period (T3-T2) $(\mathrm{p}>0.05)$.

Figure 44. L5-MP (mm) comparison for the three groups

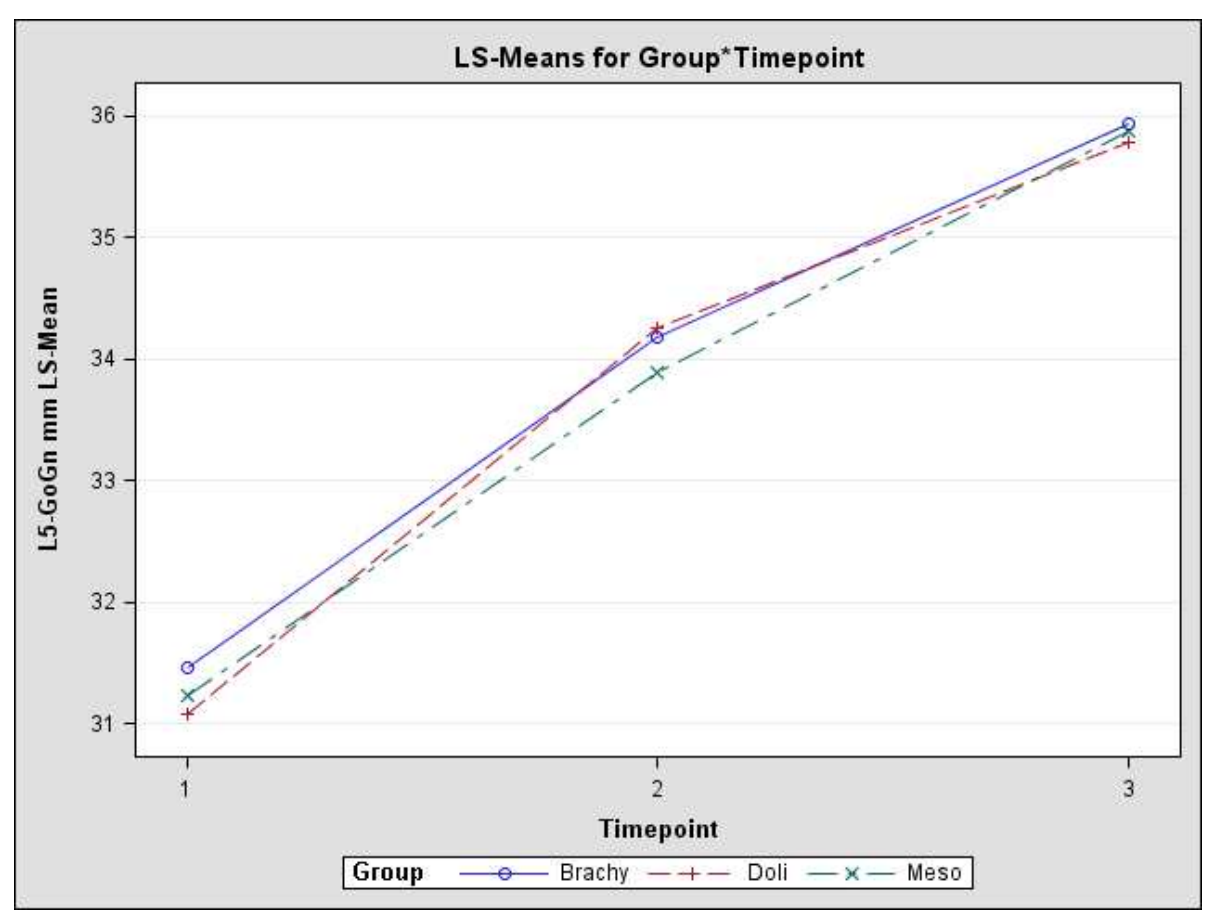




\section{Lower First Molar Position (L6-MP, mm)}

Before orthodontic treatment (T1), the mean L6-MP values for the three groups were not significantly different $(\mathrm{p}>0.05)$. There were no significant differences in L6-MP changes between the groups during orthodontic treatment (T2-T1) or during the long-term follow up period $(\mathrm{T} 3-\mathrm{T} 2)(\mathrm{p}>0.05)$.

Figure 45. L6-MP (mm) comparison for the three groups

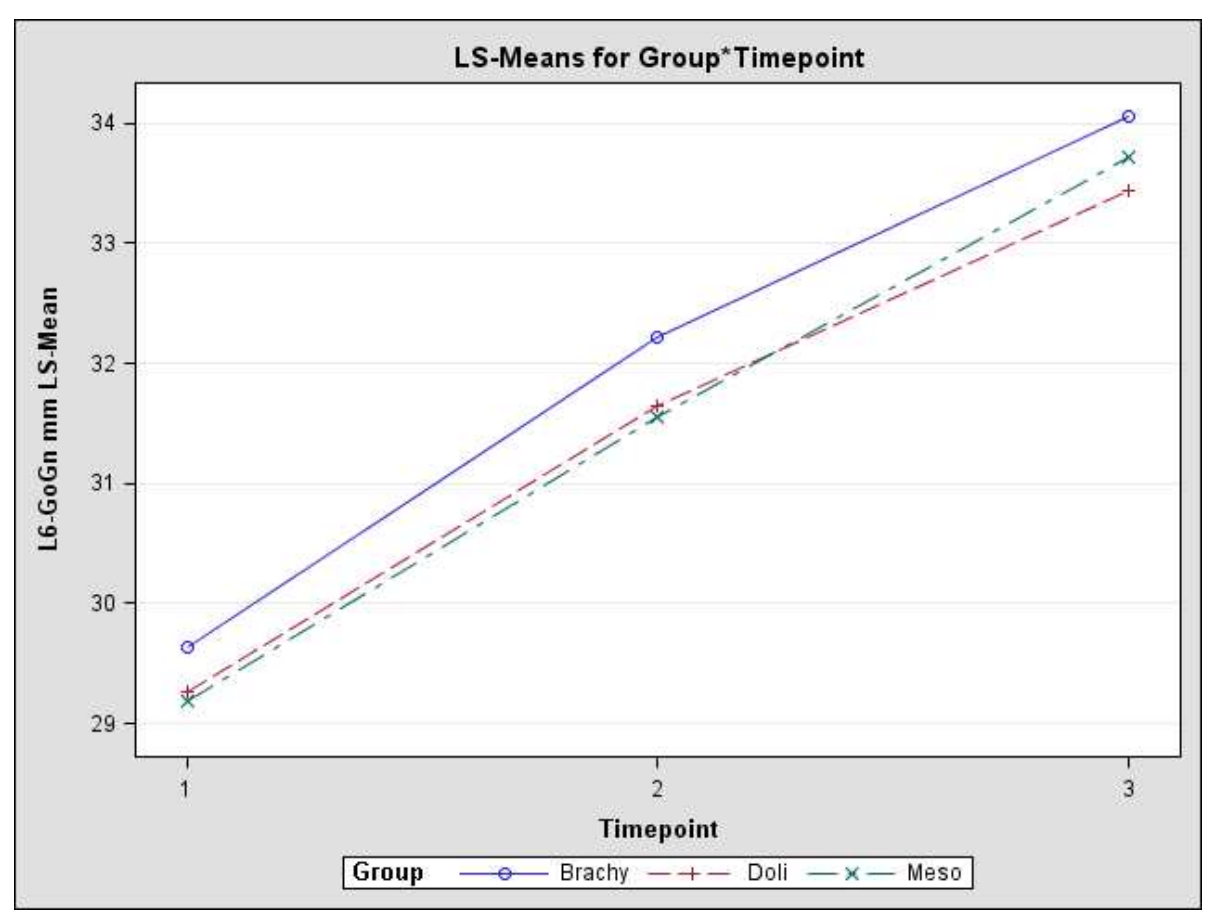




\section{Overjet}

Before orthodontic treatment (T1), the mean overjet values for the three groups were not significantly different $(\mathrm{p}>0.05)$. There were no significant differences in overjet changes between the groups during orthodontic treatment (T2-T1) or during the long-term follow up period (T3-T2) $(\mathrm{p}>0.05)$.

Figure 46. Overjet comparison for the three groups

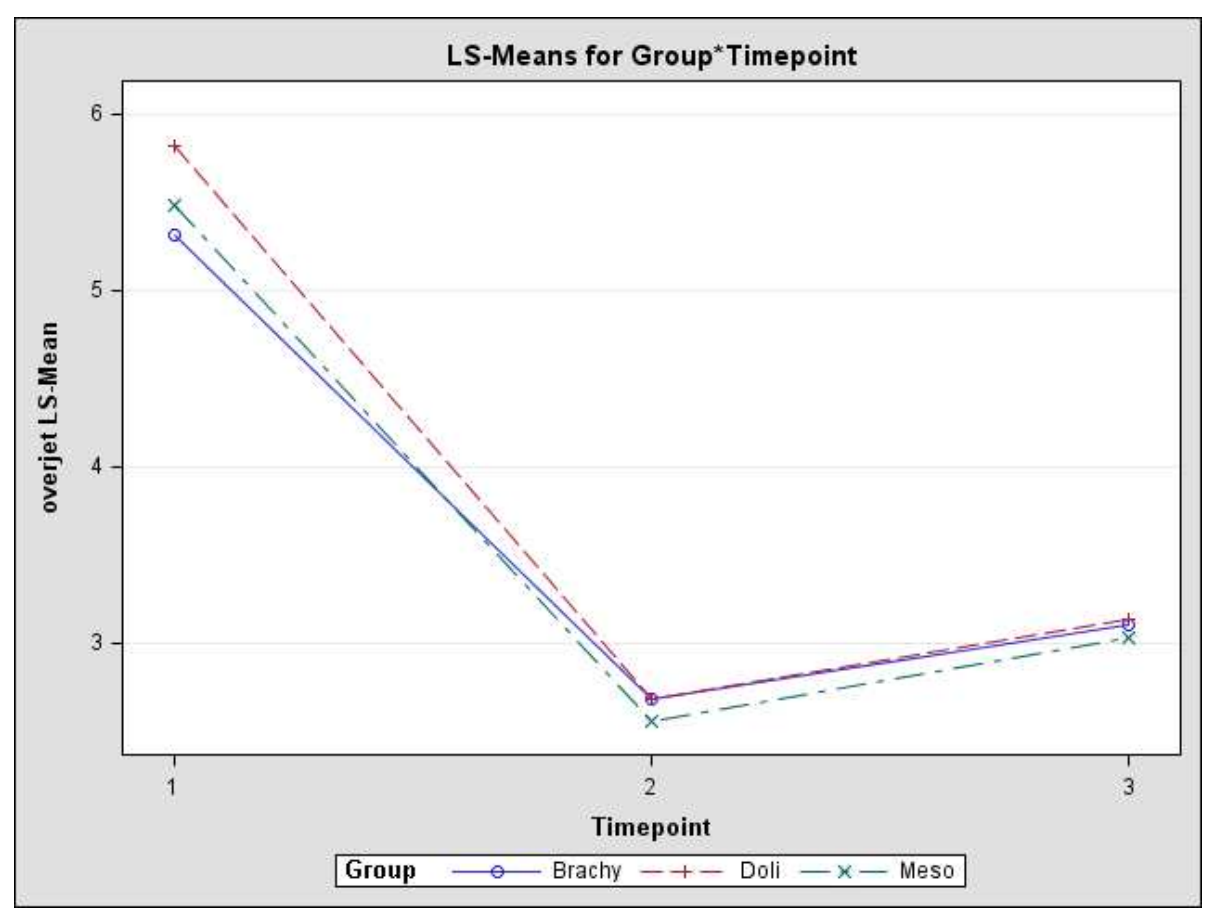




\section{Overbite (mm)}

Before orthodontic treatment (T1), the mean overbite $(\mathrm{mm})$ for the brachycephalic group $(5.8 \mathrm{~mm})$ differed significantly from the mean overbite for the dolicocephalic $(4.7 \mathrm{~mm})$ group ( $\mathrm{p}=0.0332)$ with all other comparisons being insignificant. During orthodontic treatment (T2-T1), the change in the mean overbite for the brachycephalic group was significantly higher compared to the dolicocephalic $(\mathrm{p}=0.0484)$ group. All other comparisons between groups for T2-T1 were not significant $(\mathrm{p}>0.05)$. During the postretention period (T3-T2), the change in the mean overbite for the dolicocephalic group was significantly lower than both the mesocephalic $(\mathrm{p}=0.0008)$ and brachycephalic $(\mathrm{p}=$ 0.0129) groups. The latter two groups' change in overbite did not differ significantly during this time period $(\mathrm{p}>0.05)$.

Figure 47. Overbite (mm) comparison for the three groups

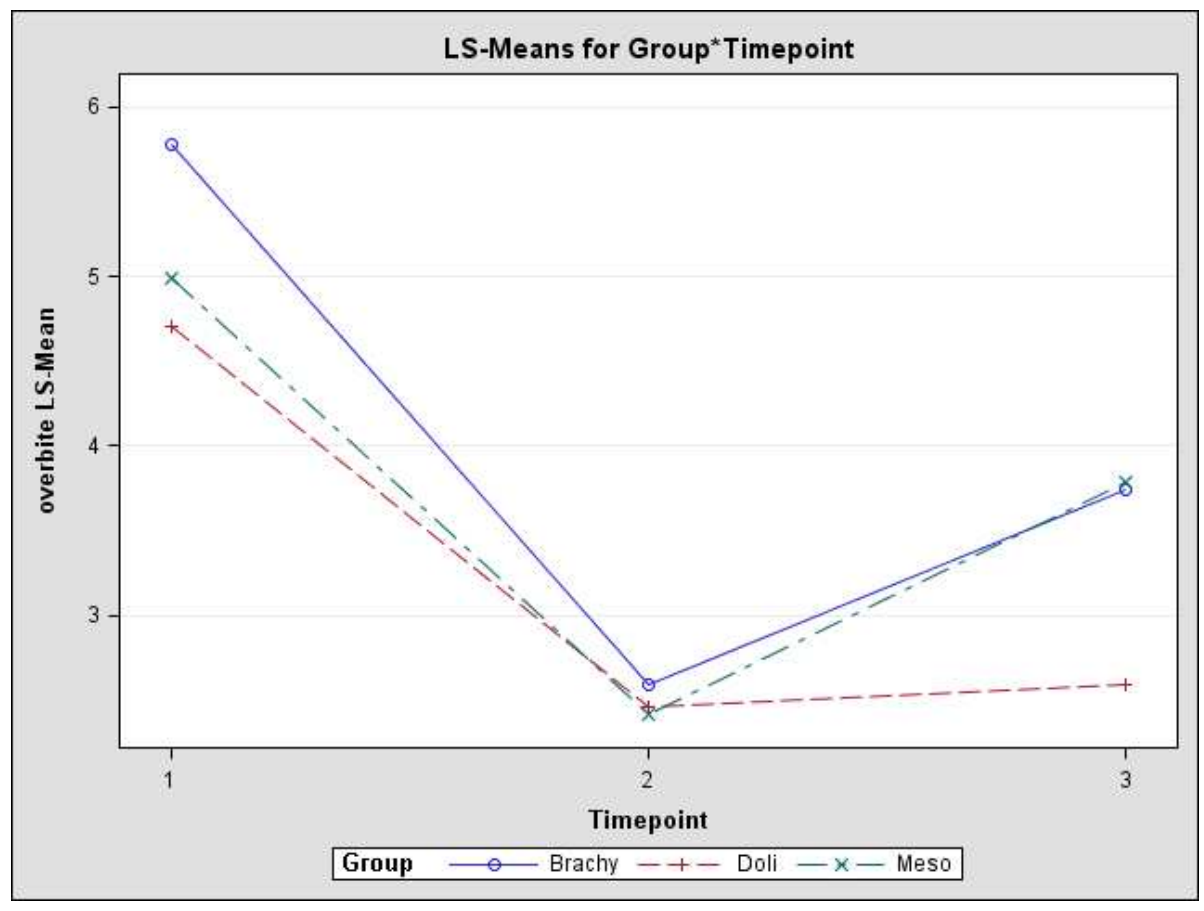




\section{Overbite (\%)}

Before orthodontic treatment (T1), the mean overbite (\%) for the brachycephalic group $(81.0 \%)$ differed significantly from the mean overbite for the dolicocephalic $(64.4 \%)$ group $(\mathrm{p}=0.0264)$ with all other comparisons being insignificant.

Figure 48. Overbite (\%) comparison for the three groups

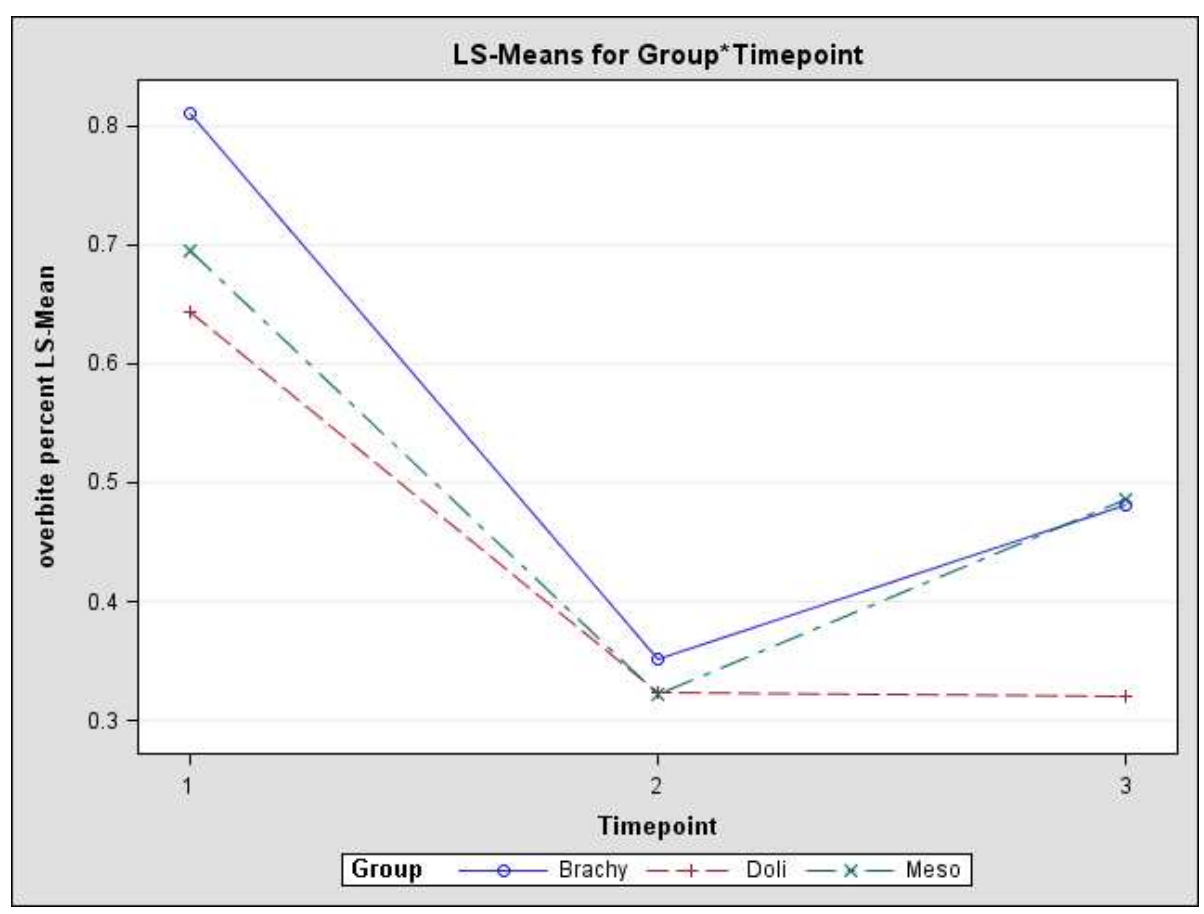




\section{Curve of Spee}

Before orthodontic treatment (T1), the mean Curve of Spee values for the three groups were not significantly different $(p>0.05)$. There were no significant differences in Curve of Spee changes between the groups during orthodontic treatment (T2-T1) or during the long-term follow up period (T3-T2) $(\mathrm{p}>0.05)$.

Figure 49. Curve of Spee comparison for the three groups

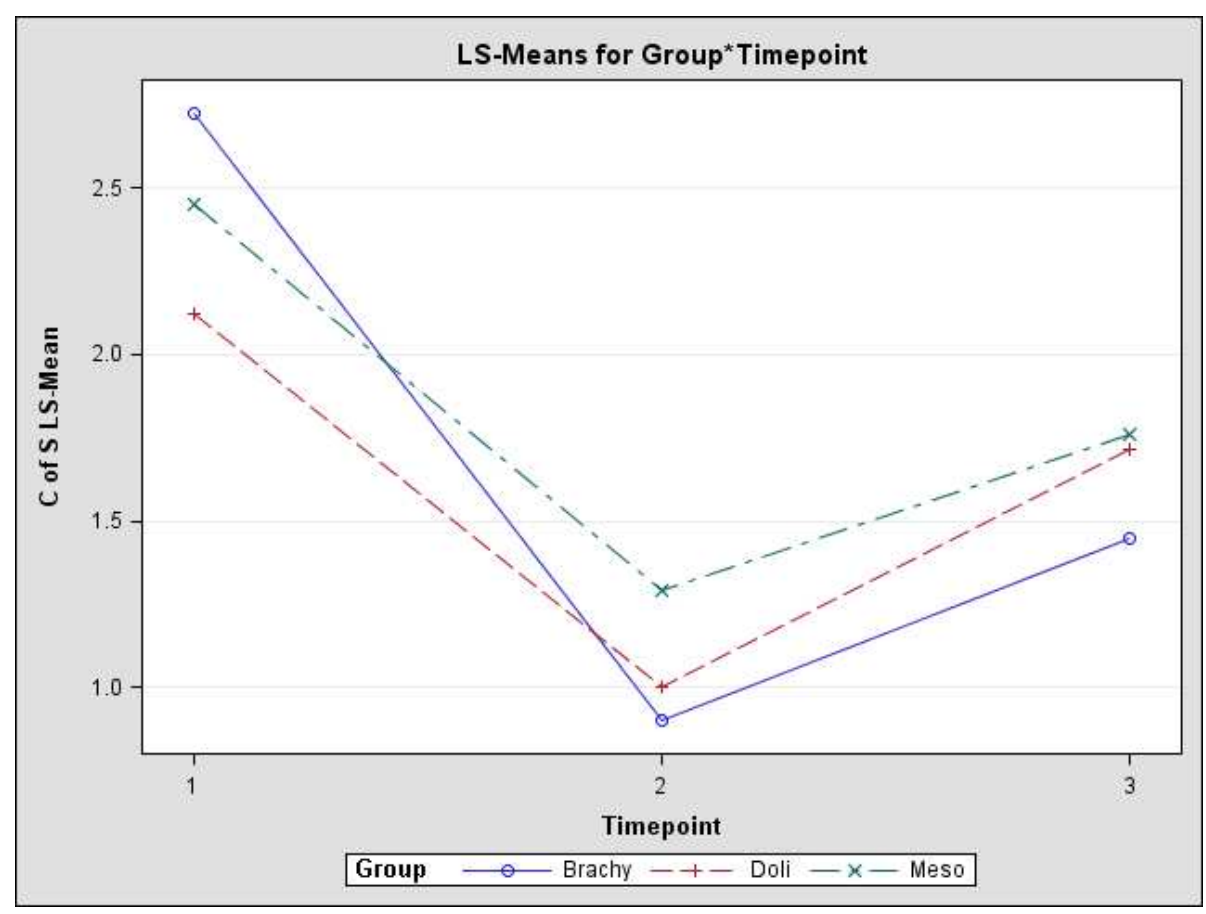




\section{Lower Insicor Irregularity}

Before orthodontic treatment (T1), the mean Lower Incisor Irregularity values for the three groups were not significantly different $(\mathrm{p}>0.05)$. There were no significant differences in Lower Incisor Irregularity changes between the groups during orthodontic treatment $(\mathrm{T} 2-\mathrm{T} 1)$ or during the long-term follow up period $(\mathrm{T} 3-\mathrm{T} 2)(\mathrm{p}>0.05)$.

Figure 50. Lower Incisor Irregularity comparison for the three groups

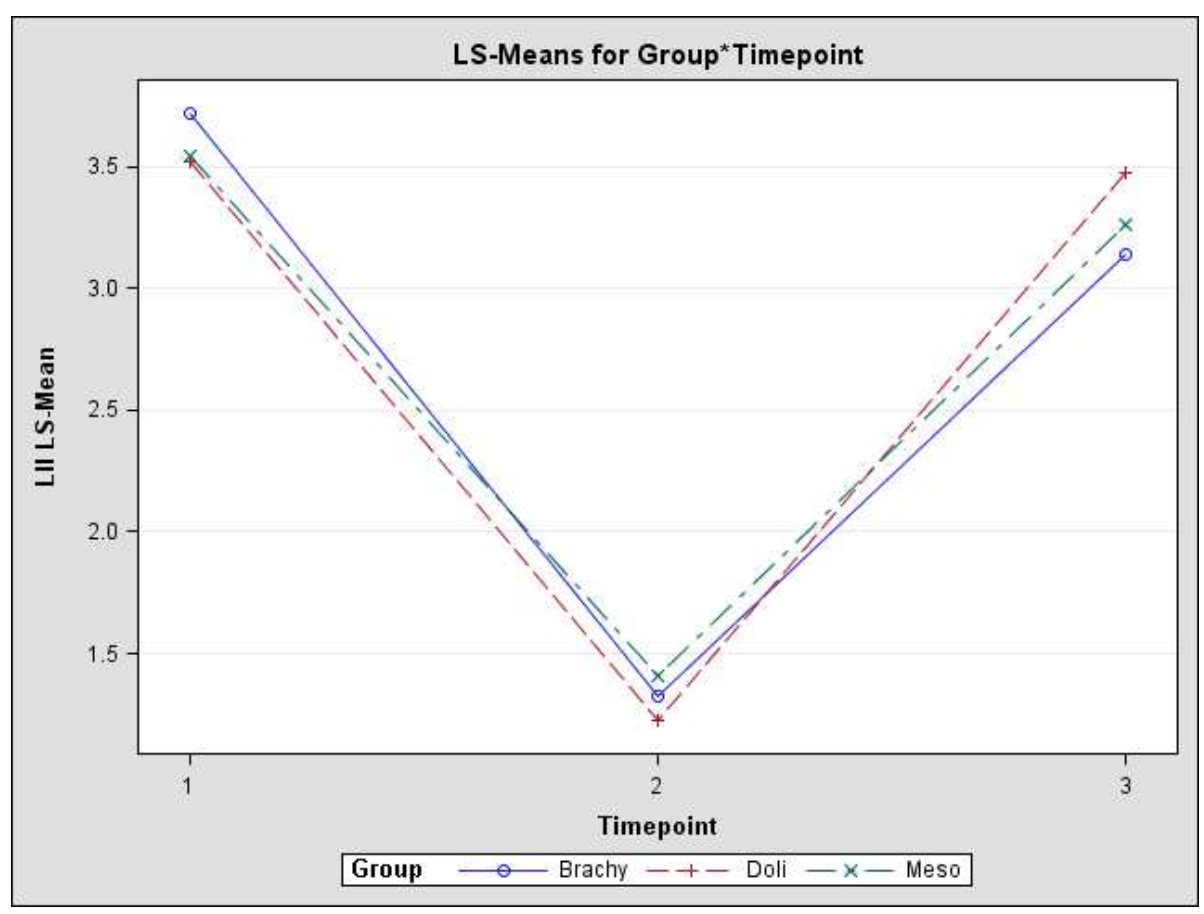




\section{Lower Intercanine Width}

Before orthodontic treatment (T1), the mean Lower Intercanine Width values for the three groups were not significantly different $(\mathrm{p}>0.05)$. There were no significant differences in Lower Intercanine Width changes between the groups during orthodontic treatment (T2T1) or during the long-term follow up period (T3-T2) $(\mathrm{p}>0.05)$.

Figure 51. Lower Intercanine Width comparison for the three groups

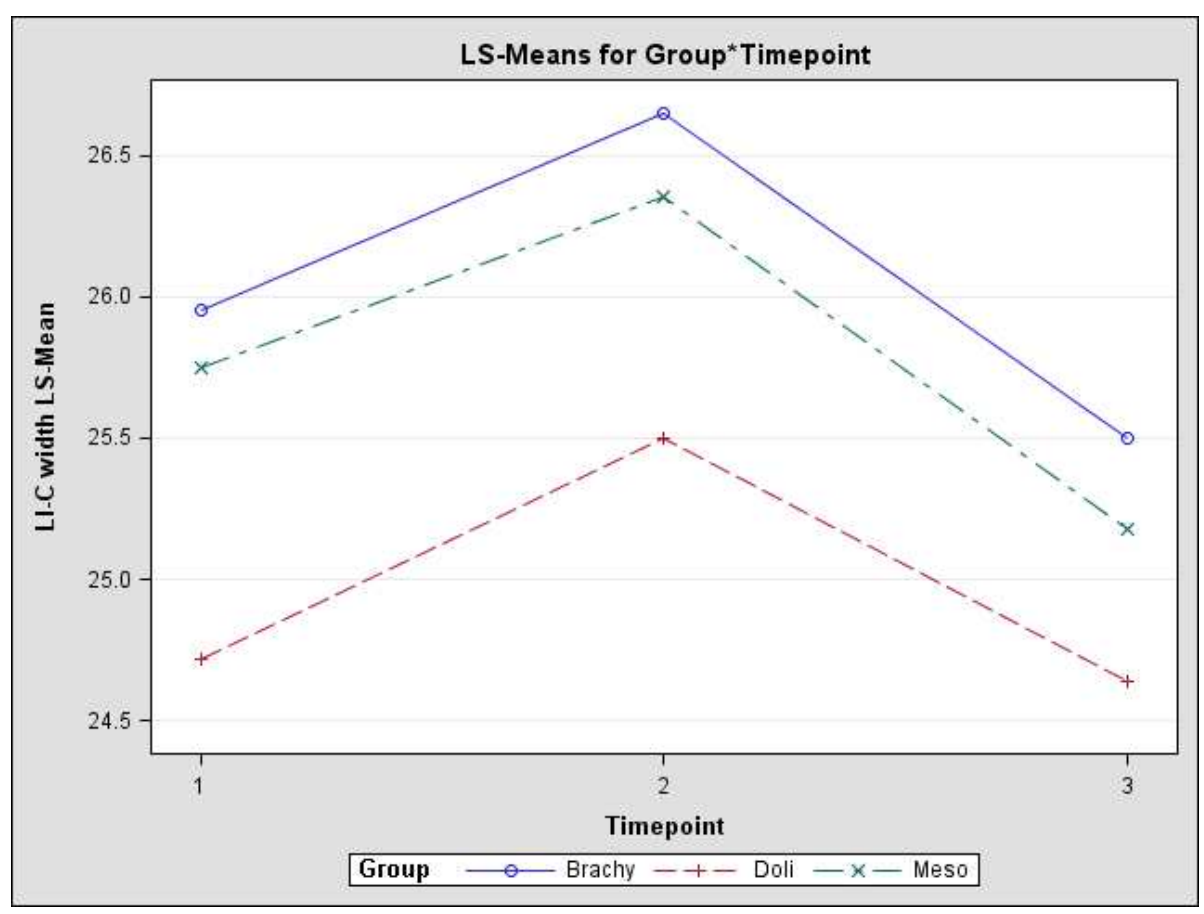




\section{Lower Intermolar Width}

Before orthodontic treatment (T1), the mean Lower Intermolar Width values for the three groups were not significantly different $(\mathrm{p}>0.05)$. There were no significant differences in Lower Intermolar Width changes between the groups during orthodontic treatment (T2T1) or during the long-term follow up period (T3-T2) $(\mathrm{p}>0.05)$.

Figure 52. Lower Intermolar Width comparison for the three groups

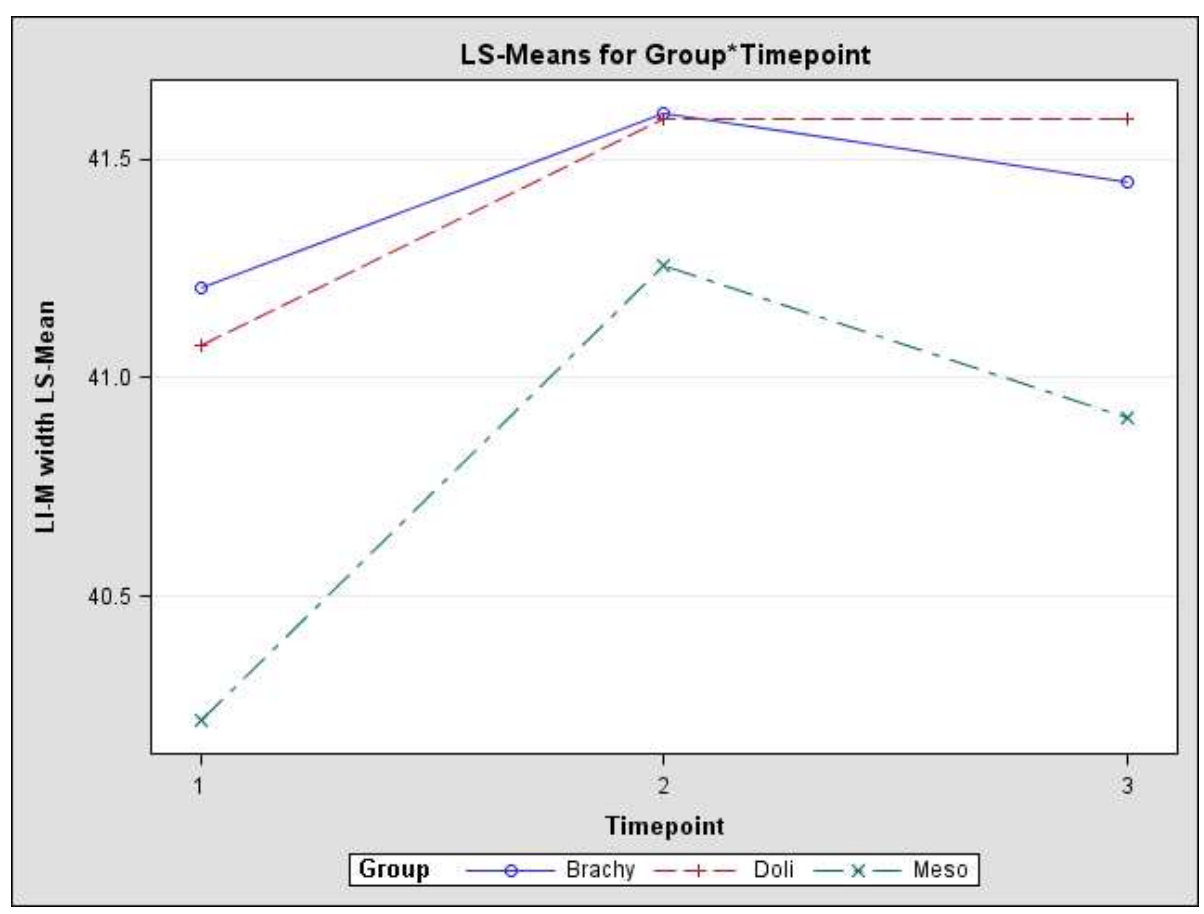




\section{Upper Intercanine Width}

Before orthodontic treatment (T1), the mean Upper Intercanine Width values for the three groups were not significantly different $(\mathrm{p}>0.05)$. There were no significant differences in Upper Intercanine Width changes between the groups during orthodontic treatment (T2$\mathrm{T} 1)$ or during the long-term follow up period (T3-T2) $(\mathrm{p}>0.05)$.

Figure 53. Upper Intercanine Width comparison for the three groups

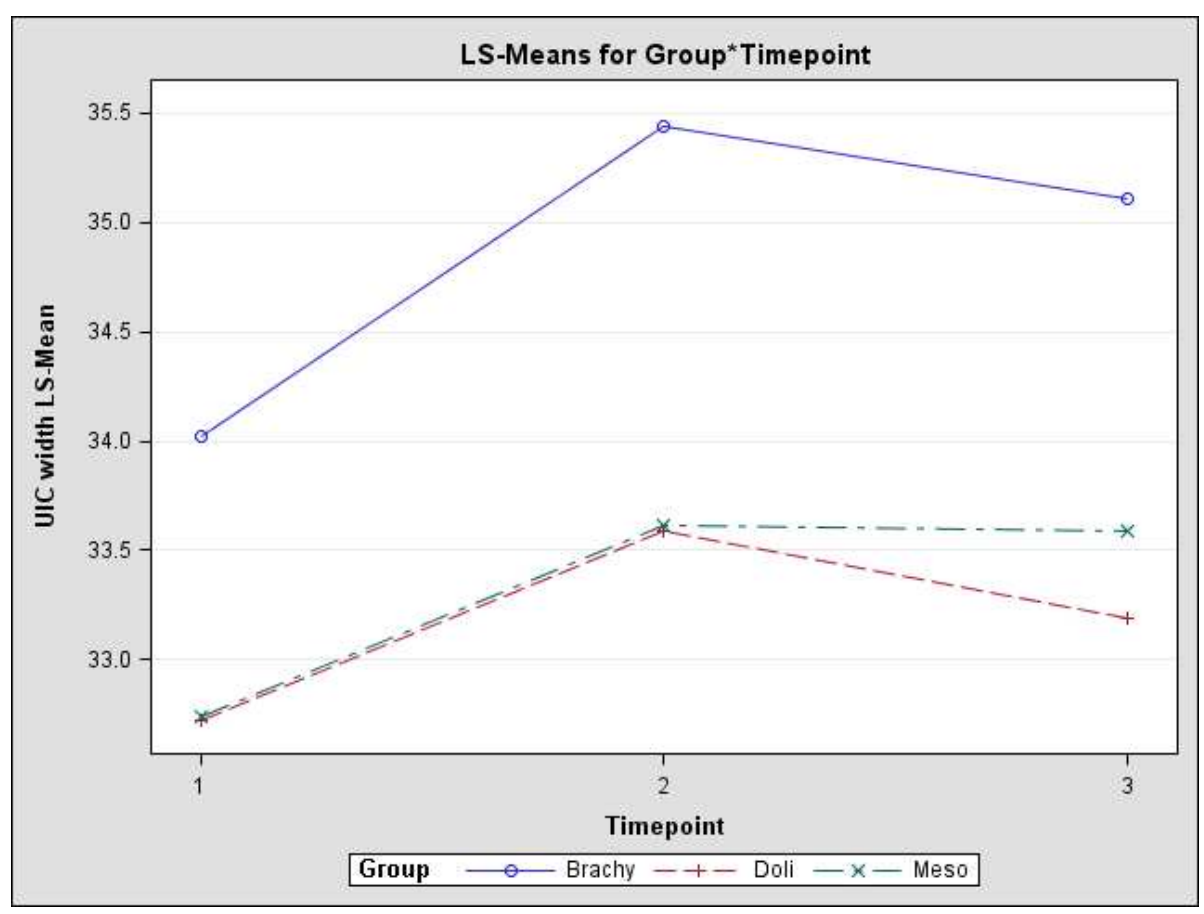




\section{Upper Intermolar Width}

Before orthodontic treatment (T1), the mean Upper Intermolar Width for the brachycephalic group $(46.5 \mathrm{~mm})$ differed significantly from the mean Upper Intermolar Width for the dolicocephalic $(44.9 \mathrm{~mm})$ group $(\mathrm{p}=0.0401)$ with all other comparisons being insignificant. There were no significant differences in Upper Intermolar Width changes between the groups during orthodontic treatment (T2-T1) or during the long-term follow up period (T3-T2) $(\mathrm{p}>0.05)$.

Figure 54. Upper Intermolar Width comparison for the three groups

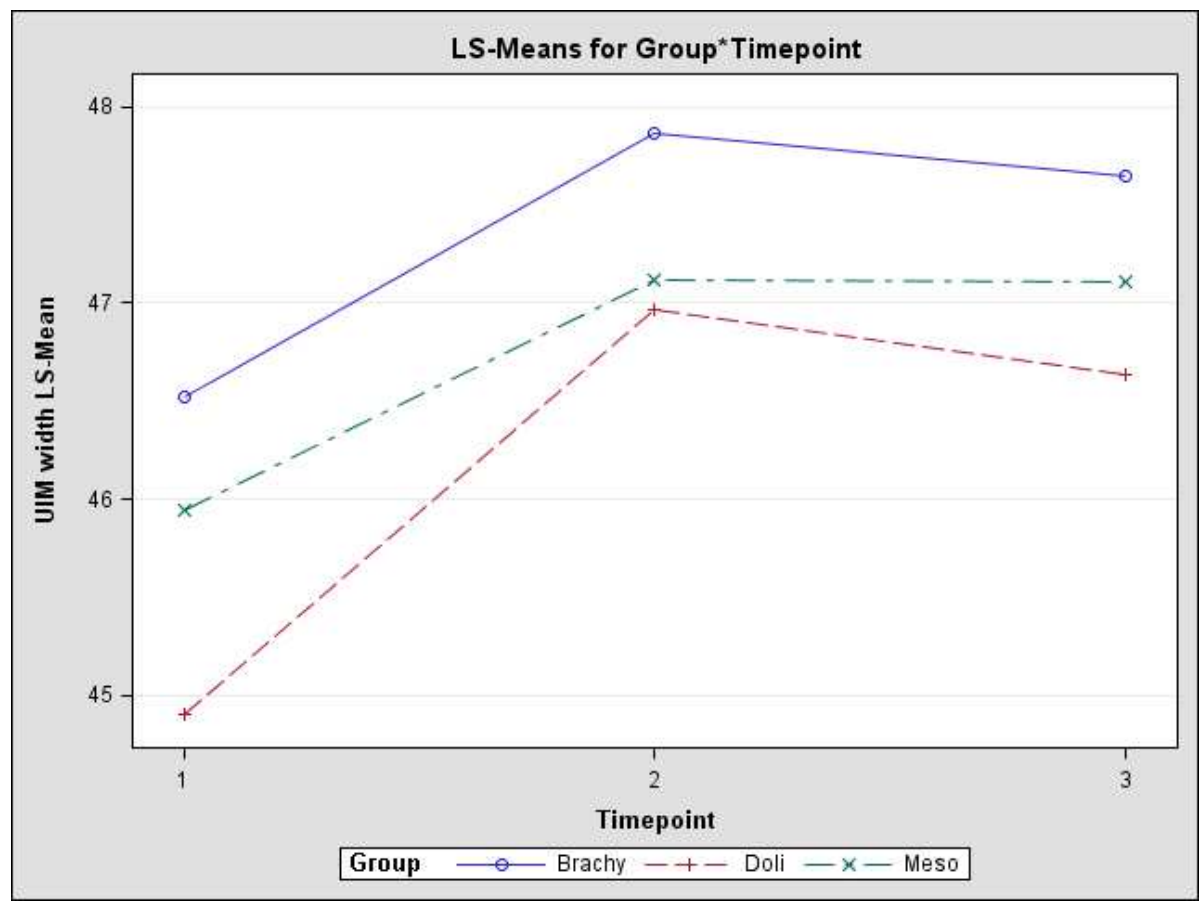




\section{CHAPTER 4}

\section{DISCUSSION}

Page number

4.1 Evaluation of Group Facial Type Characteristics 94

4.2 Evaluation of Overbite Relapse 96

4.3 Possible Reasons for Intergroup Relapse Differences 98

4.3.1 Amount of Deep Bite Correction 98

4.3.2 Incisal Angulation Changes $\quad 99$

$\begin{array}{lll}\text { 4.3.3 Incisal Position Changes } & 102\end{array}$

$\begin{array}{lll}\text { 4.3.4 Growth Pattern } & 104\end{array}$

$\begin{array}{ll}4.4 & \text { Limitations of the Study } \\ & 111\end{array}$ 


\subsection{EVALUATION OF GROUP FACIAL TYPE CHARACTERISTICS}

As mentioned in the Subjects and Methods section, the subjects in this study were grouped according to their initial facial type (mesocephalic, brachycephalic, and dolicocephalic) based on predetermined ranges for MPA, Y-axis, and LFH for each group. The mesocephalic group was chosen to be those with an MPA between $29-35^{\circ}$, Yaxis between $63-69^{\circ}$, and LFH between $44-50^{\circ}$. The dolicocephalic group included those with an MPA greater than $35^{\circ}, \mathrm{Y}$-axis greater than $69^{\circ}$, and $\mathrm{LFH}$ greater than $50^{\circ}$. Finally, the brachycephalic group consisted of those with an MPA less than $29^{\circ}, \mathrm{Y}$-axis less than $63^{\circ}$, and $\mathrm{LFH}$ less than $44^{\circ}$.

After data analysis, the means for MPA, Y-axis, and LFH for each group indicate a fairly good representation of their corresponding facial type. The mesocephalic group had a mean pre-treatment MPA of $32.2^{\circ} \pm 0.4$ and a mean pre-treatment $\mathrm{Y}$-axis of $66.3^{\circ} \pm 0.4$, which are both very close to what is considered to be the normal values for each $\left(32^{\circ}\right.$ for MPA and $66^{\circ}$ for Y-axis). The dolicocephalic group had a mean pre-treatment MPA of $37.8^{\circ} \pm 0.5$ and a mean pre-treatment $\mathrm{Y}$-axis of $70.5^{\circ} \pm 0.5$, which are both greater than

the high end of the normal range for each variable, suggesting the presence of a dolicocephalic pattern. Finally, the brachycephalic group had a mean pre-treatment MPA of $26.3^{\circ} \pm 0.5$, which was less than the low end of the normal range for this variable, suggesting the presence of a brachycephalic pattern. As for the mean pre-treatment $\mathrm{Y}$-axis for the brachycephalic group, it was $64.1^{\circ} \pm 0.5$, which is less than the normal Y-axis value, however it still falls within the lower end of the normal range $\left(66^{\circ} \pm 2\right)$. 
There were also other measurements that differed significantly $(\mathrm{p}<0.05)$ between the groups at $\mathrm{T} 1$ which indicated that all facial types were well represented. For instance, both the mean SNA and SNB values for the dolicocephalic group $\left(77.6^{\circ}\right.$ and $73.4^{\circ}$, respectively) were significantly lower than for both the mesocephalic $\left(82.0^{\circ}\right.$ and $78.0^{\circ}$, respectively) and brachycephalic $\left(82.5^{\circ}\right.$ and $78.7^{\circ}$, respectively) groups $(\mathrm{p}<0.0001)$. In addition, the mean anterior face height for the dolicocephalic group $(118.1 \mathrm{~mm})$ was significantly higher than for both the mesocephalic $(114.3 \mathrm{~mm})$ and brachycephalic $(113.5 \mathrm{~mm})$ groups $(\mathrm{p}<0.05)$. The opposite was true for posterior face height, in which the brachycephalic group $(80.4 \mathrm{~mm})$ had a significantly higher mean value than both the mesocephalic $(74.7 \mathrm{~mm})$ and dolicocephalic $(72.3 \mathrm{~mm})$ groups $(\mathrm{p}<0.001)$. All the above values, as well as the differences between the three facial types, are very similar to the findings of Isaacson, Isaacson, Speidel et al (1971).

The dental characteristics for each group were also indicative of their corresponding facial type. For instance, the mean upper incisor position for the brachycephalic group (27.1 mm) was significantly shorter (less erupted) compared to the dolicocephalic $(29.0$ $\mathrm{mm}$ ) group $(\mathrm{p}=0.0241)$. Isaacson, Isaacson, Speidel et al (1971) also reported this difference between high and low angle patients. The mean Upper Intermolar Width for the brachycephalic group $(46.5 \mathrm{~mm})$ was also significantly wider than for the dolicocephalic $(44.9 \mathrm{~mm})$ group $(\mathrm{p}=0.0401)$. Finally, the mean occlusal plane angles at T1 for the brachycephalic $\left(12.3^{\circ}\right)$, mesocephalic $\left(14.6^{\circ}\right)$, and dolicocephalic $\left(18.9^{\circ}\right)$ groups differed significantly from each other $(\mathrm{p}<0.05)$. 


\subsection{EVALUATION OF OVERBITE RELAPSE}

One of the main objectives of this study was to evaluate and compare the amount of relapse of deep overbite observed in mesocephalic, brachycephalic, and dolicocephalic subjects that were treated by fixed orthodontic appliances. Overall, the mean relapse of the entire sample was $0.98 \pm 1.2 \mathrm{~mm}$, or $11.0 \pm 17.0 \%$ if measured as a percentage of mandibular clinical crown coverage. These results agree with the literature, which reports relapse values that vary from 0.7 to $1.4 \mathrm{~mm}$. For instance, Kim \& Little (1999) used a long post-retention period (mean $=15$ years) and observed an overbite relapse of $1.4 \mathrm{~mm}$. Canut \& Arias (1999) used a slightly shorter post-retention period (mean $=7$ years) and found a mean relapse in overbite of $0.9 \pm 1.2 \mathrm{~mm}$. Al-Buraiki, Sadowsky, \& Schneider (2005) also found that overbite increased by a similar amount $(0.7 \mathrm{~mm}$, or $17 \%)$ during the post-treatment period, which is similar to the $18.8 \%$ observed by Berg (1983) and the $0.8 \mathrm{~mm}$ observed by Schutz-Fransson, Bjerklin, \& Lindsten (2006) after long-term follow-up periods.

In the present study, when subjects were grouped according to facial type, both the brachycephalic $(1.2 \pm 0.9 \mathrm{~mm} ; 13.0 \% \pm 13.2)$ and mesocephalic $(1.4 \pm 1.3 \mathrm{~mm} ; 16.4 \% \pm$ 16.8) groups exhibited a significant amount of overbite relapse after the 10 -year postretention period. In contrast, the dolicocephalic group did not relapse significantly $(0.13 \pm$ $1.1 \mathrm{~mm} ;-0.36 \% \pm 16.2)$. These differing results amongst facial types were similar to what was found in the literature. For instance, Engel, Damerell, McAlpine et al (1980) found that the greatest amount of relapse in treated deep-bite cases was in those with brachycephalic patterns characterized by short lower anterior facial height and low 
mandibular plane angle. The authors also found that patients with a high mandibular arc, an indication of a true brachycephalic pattern, showed the least opening during treatment and the greatest closing after treatment. 


\subsection{POSSIBLE REASONS FOR INTERGROUP RELAPSE DIFFERENCES}

\subsubsection{Amount of Deep Bite Correction}

One obvious reason for the increased relapse seen in the brachycephalic group is that there was a greater amount of deep bite correction during orthodontic treatment in this group compared to the other two. The mean correction for the brachycephalic group was $3.2 \pm 1.5 \mathrm{~mm}(45.9 \% \pm 21.7)$, which differed significantly $(p=0.0484)$ from the $2.2 \pm 1.4$ mm $(32.0 \% \pm 19.4)$ change observed for the dolicocephalic group. Although not statistically significant, the mesocephalic group also had less deep overbite correction (2.6 $\pm \mathrm{mm})$ compared to the brachycephalic group. In a similar study, Simons \& Joondeph (1973) also observed that patients who had a large amount of overbite decrease during treatment also had the greatest amount of relapse or post-retention increase in overbite. This may be due to the fact that, in general, the farther teeth travel during orthodontic treatment, the greater the amount of relapse.

Not only did the brachycephalic group have more deep bite correction, they also started with a deeper bite. Before orthodontic treatment, the mean overbite for the brachycephalic group $(5.8 \mathrm{~mm})$ differed significantly from the mean overbite for the dolicocephalic $(4.7$ $\mathrm{mm}$ ) group $(\mathrm{P}=0.0332)$. This agrees with Kim (1999), who determined that initial overbite was the most important factor in predicting post-retention overbite. 


\subsubsection{Incisal Angulation Changes}

Other than overbite, one of the most dramatic differences between the groups was noted for interincisal angle (U1-L1). The brachycephalic group showed a significant reduction in interincisal angle $\left(-6.6^{\circ}\right)$ during orthodontic treatment due to upper and lower incisor proclination. This relapsed significantly $\left(+8^{\circ}\right)$ post-retention. The mesocephalic group experienced a similar result, but to a lesser extent $\left(-3.4^{\circ}\right.$ reduction with treatment; $+4.2^{\circ}$ relapse). The interincisal angle for these two groups had changes over time that were similar to that observed by Binda, Kuijpers-Jagtman, Maertens et al (1994), who reported a mean reduction in the interincisal angle of $16.2^{\circ}$ during orthodontic treatment followed by a relapse of $6.3^{\circ}$ after five years post-retention. This is also in agreement with Ludwig (1967), who found a positive correlation between overbite change after a post-retention period of two to eight years and interincisal angulation. In contrast, the present study's dolicocephalic group had a mean interincisal angle that did not change significantly from treatment or during the ten year post-retention period. This includes a slight retroclination of the upper incisors during treatment, which is the opposite of what was observed in the brachycephalic group. Considering that brachycephalic patients commonly present with upright maxillary anterior teeth, while dolicocephalic patients are more inclined to present with proclined upper anterior teeth, this result is not surprising.

Lip pressure may also contribute to this finding. Since dolicocephalic patients are more likely to have incompetent lips compared to brachycephalic patients, perhaps this prevents the incisors from being retroclined in the post retention phase. Lapatki, Klatt, Schulte-Monting et al (2004) observed an increased amount of incisal retroclination and 
deep bite relapse in patients whose lip line was not reduced to a maximum of $3 \mathrm{~mm}$ after orthodontic treatment. Similar findings were found by Lapatki, Baustert, Schulte-Monting et al (2006), in which the authors stated that the achievement of physiological relationships between upper incisors and lower lip should be regarded as one of the most important objectives when correcting deep bite.

As mentioned, the brachycephalic group had the greatest amount of change in lower incisor proclination during orthodontic treatment $\left(4.4^{\circ}\right)$. This value is considerably less than the $7.91^{\circ}$ increase observed in a study by Parker, Nanda, \& Currier (1995), although their sample was more homogenous and included only Class II division 2 subjects whereas the present study was a mix. One possible explanation for this observed proclination in the brachycephalic group could be that many of these patients, commonly characterized by short face height, may have been treated with reverse Curve of Spee lower arch wires. Although this would correct the deep bite by posterior extrusion and increase lower anterior face height, it also leads to lower incisor proclination. Since the exact orthodontic mechanics used in each case were not assessed, this is purely speculative.

Although the lower incisor proclination was somewhat of an expected result in the brachycephalic group, its disappearance after the ten year post-retention period was not. This group showed a mean relapse in lower incisor angulation of $4.2^{\circ}$. This contradicts the commonly held belief that brachycephalic patients can tolerate an increased amount of lower incisor proclination because of their commonly associated large chin button and hypodivergent mandibular plane angle. This may have influenced the practitioner's 
decision to allow for more proclination of the lower incisors in brachycephalic subjects during treatment, while attempting to maintain the angulation of the lower anterior teeth in dolicocephalic subjects. This lower incisor collapse back to their original, more retroclined position would definitely result in a deepening of the overbite. In their retrospective study of thirty Class II division 2 subjects, Canut \& Arias (1999) found a statistically significant correlation $(\mathrm{r}=0.52, \mathrm{p}<0.01)$ between post-retention lower crowding and post-retention overbite increase, although this association was weaker than expected. 


\subsubsection{Incisal Position Changes}

In addition to incisor angulation changes, it appears that incisal position might also contribute to deep bite relapse. During orthodontic treatment, both maxillary and mandibular incisor positions, relative to palatal plane and mandibular plane respectively, did not change significantly for all three groups, while the posterior teeth in both arches showed increased eruption. This means that the levelling of the Curve of Spee and the associated correction of the pre-treatment deep bite is due mainly to posterior tooth extrusion and not anterior incisor intrusion. This can be considered relative intrusion since the incisors were held in pre-treatment positions and growth maintained the mandibular plane angle. This was similar to the findings by Bernstein, Preston \& Lampasso (2007), who also observed that most levelling of the Curve of Spee in their sample was accomplished by the extrusion of the premolars, although they noted some incisor intrusion as well. Conversely, Otto, Anholm \& Engel (1980) found that the majority of deep-bite cases treated using the Bioprogressive technique were corrected by a combination of lower incisor intrusion and incisor proclination.

When analyzing tooth eruption patterns at the 10-year follow-up, one major difference arose between the groups. In the brachycephalic and mesocephalic groups, U1-PP and L1-MP increased significantly during this time, indicating that preventing them from eruption during orthodontic treatment was only temporary. This post-treatment extrusion of the upper and lower incisors was slightly higher than the extrusion observed in the posterior teeth, which may be contributable to the relapse in deep overbite. De Praeter, Dermaut, Martens et al (2002) observed a similar result when they determined that the 
highest correlation for the amount of overbite relapse was with the relapse of the Curve of Spee $(r=0.36)$. However, only about $13 \%$ of the relapse of the Curve of Spee could be explained by the deepening of the bite. Conversely, the dolicocephalic group only experienced a significant increase in the lower incisors, while the upper incisors basically maintained their post-treatment position. This lack of vertical incisor eruption may help explain why this group only experienced minimal relapse in overbite. However, Simons \& Jondeph (1973) did not find that the relative vertical position of the maxillary incisors was a factor in overbite relapse in their similar long-term post-retention study.

One possible reason for this finding could be related to the observed retroclination of the mandibular incisors post-retention in the brachycephalic group. This may result in a loss of incisal contact which allows the maxillary anterior teeth to over erupt. This difference could also be attributed to the inclinational changes to the reference planes that were utilized to measure the vertical position of the incisors. Both the mandibular and palatal planes are not stable reference points and, therefore, any angular differences that occur with time could affect all vertical tooth measurements that rely on these planes. 


\subsubsection{Growth Pattern}

Growth pattern is another variable that most likely plays a significant role in the observed difference in deep bite relapse between the facial type groups. It is very important to note here that, since most subjects included in the study were adolescents, the observed changes to each variable are the result of both growth and treatment. Therefore, it is impossible to deduce the contribution of each to the net effects. With that in mind, the dolicocephalic subjects showed a tendency to continue growing in a more vertical direction during orthodontic treatment, with the mean anterior face height $(6.1 \mathrm{~mm})$ increasing considerably more than the mean posterior face height $(3.9 \mathrm{~mm})$. The net result was a mean differential of $2.2 \mathrm{~mm}$. In comparison, the other two groups showed similar increases in anterior and posterior face heights during treatment, with the brachycephalic subjects having a more horizontal pattern (anterior face height increased only $0.8 \mathrm{~mm}$ more than posterior face height) than the mesocephalic group (anterior face height increased $1.2 \mathrm{~mm}$ more than posterior face height).

After ten years post-retention, the observed effects can be thought of as a mixture of growth and orthodontic/orthopaedic relapse. During this period, the dolicocephalic group showed very similar increases of anterior and posterior face heights $(3.7 \mathrm{~mm}$ and $3.6 \mathrm{~mm}$, respectively). On the other hand, the mesocephalic group tended to increase more in the posterior region $(4.8 \mathrm{~mm})$ compared to the anterior $(4.2 \mathrm{~mm})$, but this difference was quite negligible. However, the brachycephalic group demonstrated a considerably larger increase in posterior face height $(3.9 \mathrm{~mm})$ compared to anterior face height $(2.5 \mathrm{~mm})$ 
during this same time period, resulting in a counter clockwise rotation of the mandible that could potentially lead to deep bite relapse.

These vertical measurements are in agreement with the findings of Binda, KuijpersJagtman, Maertens et al (1994), who found that, for their sample of 44 Class II division 2 subjects, the increase in anterior facial height $(6.9 \pm 3.9 \mathrm{~mm})$ exceeded that of posterior facial height $(5.7 \pm 4.2 \mathrm{~mm})$ during orthodontic treatment. During the five year postretention period, the reverse occurred and the increase in posterior facial height $(3.8 \pm 4.3$ $\mathrm{mm})$ was greater than that of anterior facial height $(2.2 \pm 3.1 \mathrm{~mm})$. Harris, Gardner \& Vaden (1999) also observed similar results. In their sample of 28 treated subjects, the anterior vertical height increased more during treatment $(4.80 \mathrm{~mm})$ than the posterior vertical height $(4.13 \mathrm{~mm})$, while after a long-term follow-up (mean $=14.4$ years), the posterior vertical height $(3.47 \mathrm{~mm})$ increase was now greater than in the anterior region (2.13 mm). Considering that these last two studies did not exclude the dolicocephalic subjects, which would undoubtedly be the least common, these results make sense since they closely resemble the mesocephalic and brachycephalic groups in the present study as far as counter clockwise rotation is concerned.

Differences in growth pattern between the three groups were also evident in the changes to the mandibular plane angle over time. Both the brachycephalic and mesocephalic groups showed statistically significant mean decreases in MPA of $1.6^{\circ}$ and $1.5^{\circ}$, respectively during the post-retention period. Binda, Kuijpers-Jagtman, Maertens et al (1994) observed a similar decrease in MPA $\left(1.9^{\circ} \pm 2.7^{\circ}\right)$ in Class II division 2 subjects after a 5-year post-retention period. Also after 5 years without retention, Harris, Gardner 
\& Vaden (1999) reported a similar decrease in MPA $\left(1.63^{\circ} \pm 2.13^{\circ}\right)$ in their sample of 28 subjects. The authors suggested that continued horizontal growth, significant ramus growth, and mandibular border remodelling are the reason for the observed rotation. Payne's (1964) findings agree with this statement as well, after he observed this mandibular rotation in a sample of 41 children that were free of retention from 5 to 12 years. Payne (1964) hypothesized that the post-retention ramus growth with the subsequent increase in posterior face height and forward repositioning of the symphysis could be partially responsible for overbite relapse. Therefore, the direction and amount of mandibular rotation found in the brachycephalic and dolicocephalic groups in the present study could potentially have led to an overclosed situation resulting in the increase in overbite that was observed. Combining this rotation with the relapse of the mandibular incisors as discussed above, one may begin to envision a plausible mechanism for the increase in overbite relapse observed in these subjects. The mandibular anterior teeth are forced lingually at the same time their base is rotated backwards, which inevitably leads to a deepening of the overbite.

One compounding variable that may influence this mechanism that was not accounted for in the present study was the natural rotation of the maxilla first observed by Bjork (1968). A difference in maxillary rotation may exist between subjects with different facial types that potentially could influence the amount of overbite relapse. For instance, a clockwise rotation of the maxilla would tend to deepen the bite, whereas a rotation in the opposite direction would tend to open the bite. No studies in the literature were found to support or refute this potential effect on overbite. 
Unlike the other two groups, the dolicocephalic group did not exhibit a large amount of forward mandibular rotation with time, as the mean mandibular plane angle decreased by only $0.9^{\circ}$ from $\mathrm{T} 2$ to $\mathrm{T} 3$. This was not statistically significant. This lack of forward mandibular rotation and bite closure may help explain why dolicocephalic subjects are less likely to experience significant amounts of overbite relapse post-retention compared to brachycephalic and mesocephalic subjects.

An interesting finding was that, during orthodontic treatment, the change in angle SNB from $\mathrm{T} 1$ to $\mathrm{T} 2$ was significantly greater in the brachycephalic group compared to the other two groups. This was similar to the results found by Woods (2008), who discovered significantly greater forward movements at B Point in both mesocephalic and brachycephalic subjects after deep overbite correction than in dolicocephalic subjects. This might be explained by the fact that many deep bite brachycephalic patients have a Class II division 2 dental malocclusion with associated retroclined upper anterior teeth and a horizontal growth tendency. Although evidence is somewhat limited, many believe that once overjet is created by aligning and proclining the maxillary incisors, this "unlocks" the mandible and enables a more forward direction of mandibular growth. The effect is a more Class I occlusion and a concomitant increase in the SNB angle. This finding, although statistically significant, may not be clinically significant, since the mean increase from $\mathrm{T} 1$ to $\mathrm{T} 2$ was only $0.8^{\circ}$ for the brachycephalic group, whereas the other two groups remained the same. Some of the forward mandibular movement from the theoretical unlocking may have been negated by the downward and backward rotation of the mandible, which is often desired in order to lengthen the face in a short-faced brachycephalic patient. 
Comparing upper to lower face height change during orthodontic treatment, all three groups demonstrated very similar increases. One would have expected the dolicocephalic group to have shown more increase in lower anterior face height due to the tendency toward a long face, but this did not occur. A possible explanation for this may be due to the fact that the orthodontists treating these cases were more aware of this tendency for these patients and, therefore, may have adjusted treatment mechanics to limit the amount of face lengthening. This trend seemed to continue during the ten years post-retention as well, since the mean lower anterior face height for the dolicocephalic subjects only showed a modest $1.7 \mathrm{~mm}$ increase during this time. This was actually lower than the increase observed for the brachycephalic $(2.2 \mathrm{~mm})$ and mesocephalic $(2.7 \mathrm{~mm})$ groups.

Another notable, and somewhat surprising, finding was that upper face height change during the post-retention period was significantly different between the brachycephalic and dolicocephalic groups. The mean increase for the former group was only $0.3 \mathrm{~mm}$, while the latter group increased by a much greater $2.0 \mathrm{~mm}$ (mesocephalic group was in the middle with a mean increase of $1.4 \mathrm{~mm}$ ). It is important to note that both nasion and ANS were two of the most difficult points to identify on the deteriorated cephalometric radiographs, which may help explain the aforementioned result. The difference could also be due to relapse of movement at anterior nasal spine (ANS) from the previous orthodontic treatment and the specific mechanics used. For instance, if one group experienced greater amounts of Class II elastic wear over the other, this has the potential to rotate the occlusal plane in a clockwise direction and also pull ANS downwards. Once the forces are removed, some amount of rebound in both the dentition and in the skeletal 
structures may occur. Since the present study did not assess specific mechanics used for each subject, this can only be speculated. Another possible explanation for the observed difference in upper face height between the two groups could be that it is actually an inherent growth difference between short and long-faced individuals which contributes to their specific facial pattern. No other studies in the literature could confirm this though.

In the transverse dimension, all three groups behaved quite similarly both during orthodontic treatment and after long-term follow-up. In general, maxillary transverse dimensions were increased during treatment, which may have been purposefully or as a by-product of treatment, and this expansion remained relatively stable at the 10 -year postretention follow-up. Although there were no significant differences between the groups in the mean amount of maxillary intermolar expansion achieved during treatment, the dolicocephalic group did experience the most $(2.1 \mathrm{~mm})$, followed by the brachycephalic $(1.3 \mathrm{~mm})$ and mesocephalic $(1.2 \mathrm{~mm})$ groups. This is to be expected, since dolicocephalic patients tend to have weaker facial muscles that can tolerate more dental expansion.

Similarities in the transverse dimension were also observed between the groups in the mandibular arch. The brachycephalic and dolicocephalic groups maintained the mandibular intermolar width from $\mathrm{T} 1$ to $\mathrm{T} 3$, while the mesocephalic group showed a temporary increase during treatment that relapsed post-retention. The only transverse measurement that decreased significantly during the long-term follow-up for all three of the groups was mandibular intercanine width, which was expected considering the vast amount of literature documenting this movement (Little \& Reidel, 1988; Little, 1990). Brachycephalic and mesocephalic groups both had a mean decrease of $1.2 \mathrm{~mm}$, while the 
dolicocephalic group experienced slightly less with a mean of $0.9 \mathrm{~mm}$. The difference between the three groups was not statistically significant therefore this may not be considered as a potential contributor in the difference in overbite relapse observed between the groups.

Although, to this point, this paper has been discussing many dental and skeletal changes through time that differ between the three facial type groups that may explain the observed discrepancy in intergroup overbite relapse, one very important morphological characteristic may be the key to the entire puzzle. This is the variation in facial musculature between the different facial types. An interesting experiment that shows the importance of the mandibular muscles in the determination of facial type and facial growth was performed by Ingervall \& Bitsanis (1987). They analysed 13 long-faced children and got them to chew a tough chewing material daily for one year. Results showed that bite force and muscle activity during maximal bite both increased over the experimental period. More importantly, facial growth was characterized by anterior mandibular rotation in 9 of 12 cases with a mean decrease of $2.5^{\circ}$, a value that is considerably greater than would be expected during normal growth. Another study that supports the claim that facial musculature may play a significant role in overbite was performed by Gedrange, Hietschold, Haase et al (2005). They found that their deep overbite group had significantly higher muscle densities in the medial pterygoid, masseter, and genioglossus muscles in comparison to the open bite group. Therefore, the results of this study showed a correlation between different jaw positions and masticatory muscles. 


\subsection{LIMITATIONS OF THE STUDY}

As mentioned previously, one of the main limitations of the present study is that, because of its retrospective design, the orthodontic treatment mechanics used to treat the deep overbite malocclusions were not reported or standardized. For instance, some may have been treated by incisor intrusion mechanics while others may have been treated by posterior tooth extrusion and associated lengthening of the anterior face height. With the lack of true incisor intrusion observed in any of the three groups in this study, one could speculate that continuous orthodontic mechanics were likely employed to correct the deep overbite malocclusions. Even if mechanics used for each subject were known and grouped accordingly, a study by Parker, Nanda, \& Currier (1995) found that this did not make a difference in treatment outcome. In their sample of 132 deep bite cases, no major differences were found in post-treatment changes of various cephalometric measurements with any of the six treatment modalities studied. It is important to note that this result was for the orthodontic treatment period only and did not assess changes between the different treatment modalities after a long-term, post-retention period. One study that did look at post-retention changes was by Dake \& Sinclair (1989). The researchers concluded that subjects treated by Tweed mechanics demonstrated $0.8 \mathrm{~mm}(20 \%)$ of overbite relapse, compared to $1.4 \mathrm{~mm}$ (34\%) for the Ricketts group. Furthermore, other studies have also shown significant differences in cephalometric variables depending upon which orthodontic mechanics are used (Shudy, 1968; Burstone, 1977) so this remains as a major limitation in the present study. 
Furthermore, molar classification was not considered when forming the three groups. The importance of this is evident in a study by Parker, Nanda, \& Currier (1995), who found that almost all measurements analyzed showed statistically significant changes between the three Angle classifications with orthodontic treatment. Kim \& Little (1999) suggested that inclusion of cases with different Angle classifications may produce samples with wide variations in skeletal relationship, growth pattern, and treatment modalities, making it difficult to obtain clinically useful information about the post-retention overbite change. Therefore, the authors suggested that, to study any specific post-retention overbite change, the sample should comprise the same type of malocclusion and subgroups, with no significant difference in age. The subjects included in this study were carefully selected according to their facial type with similar ages at each time point. Moreover, as far as the skeletal inter-jaw relationships concerned, the mean value of ANB in all three groups were very similar and varied between 3.8 and 4.3 in the beginning of the study.

Finally, the present study did not assess if there were any gender differences between overbite relapse and any of the other variables measured. Although this could very well be the case, it was determined that any differences that may have surfaced might be due to facial type regardless. In other words, since males tend to have a higher predisposition towards a brachycephalic facial type, the expected increase in overbite relapse in this group may have more to do with their facial type and not because they are male. Nevertheless, both Simons \& Joondeph (1973) and Beckmann, Kuitert, Prahl-Andersen et al (1998) did test for gender differences in their post-retention studies on overbite relapse and found no significant differences between males and females. 


\section{CHAPTER 5}

\section{CONCLUSIONS}

In general, the mesocephalic group responded similarly to the dolicocephalic group during orthodontic treatment when comparing the treatment-induced changes in the parameters measured. No significant differences were found between the two. On the other hand, after ten years post-retention, the mesocephalic group tended to act in a way that more closely mimicked the brachycephalic group and no significant differences were now found between these two groups.

The following conclusions can be made from the present study:

- Dolicocephalic subjects tend to relapse less in overbite than brachycephalic and mesocephalic subjects

- The difference in overbite relapse between facial types may be partially due to change in the interincisal angle, SNB angle, lower incisor angulation, and mandibular rotation with time. Considering that relapse of deep bite is thought to be multifactoral, most or all of these can be implicated as causative factors

- A retainer with an anterior bite plane to maintain the overbite correction or overcorrecting by approximately 1 to $1.5 \mathrm{~mm}$ could be considered in brachycephalic and mesocephalic patients

- Dolicocephalic patients are less likely to require a retainer that includes an anterior bite plane or over-correction since relapse will most likely be negligible 


\section{LIST OF REFERENCES}

Al-Buraiki H, Sadowsky C, Schneider B. The effectiveness and long-term stability of overbite correction with incisor intrusion mechanics. Am J Orthod Dentofac Orthop $2005 ; 127: 47-55$.

Baume LJ. Physiological tooth migration and its significance for the development of the occlusion. IV. The biogenesis of overbite. J Dent Res 1950;29:440-47.

Beckmann SH, Kuitert RB, Prahl-Andersen B, Segner D, The RPS, Tuinzing DB. Alveolar and skeletal dimensions associated with overbite. Am J Orthod Dentofac Orthop 1998;113:443-52.

Berg R. Stability of deep overbite correction. Eur J Orthod 1983;5:75-83.

Bergersen EO. A longitudinal study of anterior vertical overbite from eight to twenty years of age. Angle Orthod 1988;58:237-56.

Bernstein RL, Preston CB, Lampasso J. Levelling the curve of Spee with a continuous archwire technique: A long term cephalometric study. Am J Orthod Dentofac Orthop 2007;131:363-71. 
Binda SKR, Kuijpers-Jagtman AM, Maertens JKM, van't Hof MA. A long-term cephalometric evaluation of treated Class II division 2 malocclusions. Eur J Orthod 1994;16:301-8.

Bjork A. Variability and age changes in overjet and overbite. Am J Orthod 1953;39:779801.

Bjork A. The use of metallic implants in the study of facial growth in children: method and application. Am J Phys Anthropol 1968;29:243-54.

Broadbent BH Sr., Broadbent BH Jr., Golden WH. Bolton standards of dentofacial developmental growth. St. Louis: Mosby, 1975.

Brunelle JA, Bhat M, Lipton JA. Prevalence and distribution of selected occlusal characteristics in the US population, 1988-1991. J Dent Res 1996;75 (Spec Iss):706-13.

Burstone CR. Deep overbite correction by intrusion. Am J Orthod 1977;72:1-22.

Canut JA, Arias S. A long-term evaluation of treated Class II division 2 malocclusions: a retrospective study model analysis. Eur J Orthod 1999;21:377-86.

Ceylan I, Eröz B. The effects of overbite on the maxillary and mandibular morphology. Angle Orthod 2001;71:110-15. 
Dake ML, Sinclair PM. A comparison of the Ricketts and Tweed-type arch levelling techniques. Am J Orthod Dentofac Orthop 1989;95:72-8.

Daniels C, Richmond S. The development of the index of complexity, outcome and need (ICON). J Orthod 2000;27:149-62.

De Praeter J, Dermaut L, Martens G, Kuijpers-Jagtman AM. Long-term stability of the levelling of the curve of Spee. Am J Orthod Dentofac Orthop 2002;121:266-72.

Downs WB. Variations in facial relationships: their significance in treatment and prognosis. Am J Orthod 1948;34:812-40.

Engel G, Damerell JM, McAlpine J, Walters R. Treatment of deep-bite cases. Am J Orthod 1980;77:1-13.

Engelman JA. Review of the literature on overbite. J Mo Dent Assoc 1966;46:7-10.

Ferrazzini G. Class II/2 malocclusions: early treatment with removable appliances and stability after 20 years. Schweiz Monatsschr Zahnmed 2008;118:814-9.

Foster TD, Day AJW. A survey of malocclusion and the need for orthodontic treatment in a Shropshire school population. Br J Orthod 1974;1:73-8. 
Gedrange T, Hietschold V, Haase I, Hasse J, Laniado M, Harzer W. Computed tomographic examination of muscle volume, cross-section and density in patients with dysgnathia. Fortschr Rontgenstr 2005;177:204-9.

Harris EH, Gardner RZ, Vaden JL. A longitudinal cephalometric study of postorthodontic craniofacial changes. Am J Orthod Dentofacial Orthop 1999;115:77-82.

Haynes S. The distribution of overjet and overbite in English children aged 11-12 years. Dent Pract Dent Rec 1972;22:380-3.

Hirschfelder U, Fleischer-Peters A. The functional treatment of deep bite - the results of a long-term study. Fortschr Kiefer orthop 1992;53:313-21.

Hirschfelder U, Hertrich K. The treatment of deep bite in adults. Fortschr Kiefer orthop $1990 ; 51: 36-43$.

Ingervall B, Bitsanis E. A pilot study of the effect of masticatory muscle training on facial growth in long-faced children. Eur J Orthod 1987;9:15-23.

Isaacson JR, Isaacson RJ, Speidel TM, Worms FW. Extreme variation in vertical facial growth and associated variation in skeletal and dental relations. Angle Orthod 1971;41:219-29. 
Kim YH. Overbite depth indicator with particular reference to anterior open-bite. Am J Orthod 1974;65:586-611.

Kim T, Little RM. Postretention assessment of deep overbite correction in Class II division 2 malocclusion. Angle Orthod 1999;69:175-86.

Kinaan BK. Overjet and overbite distribution and correlation: A comparative epidemiological English-Iraqi study. Br J Orthod 1986;13:79-86

Lapatki BG, Baustert D, Schulte-Monting J, Frucht S, Jonas IE. Lip-to-incisor relationship and post-orthodontic long-term stability of cover-bite treatment. Angle Orthod 2006;76:942-9.

Lapatki BG, Klatt A, Schulte-Monting J, Stein S, Jonas IE. A retrospective cephalometric study for the quantitative assessment of relapse factors in cover-bite treatment. J Orofacial Orthop 2004;65:475-88.

Lapatki BG, Mager AS, Schulte-Moenting J, Jonas IE. The importance of the level of the lip line and resting lip pressure in Class II, division 2 malocclusion. J Dent Res 2002;81:323-8.

Little RM. The Irregularity Index: a quantitative score of mandibular anterior alignment. Am J Orthod 1975;68:554-63. 
Little RM, Riedel RA, Årtun J. An evaluation of changes in mandibular anterior alignment from 10 to 20 years postretention. Am J Orthod Dentofac Orthop 1988;93:4238.

Little RM. Stability and relapse of dental arch alignment. Br J Orthod 1990;17:235-41.

Liu Y, Xu T, Yang M, Lin J. Preliminary study of treatment mechanism and stability in deep overbite malocclusion with hyperdivergent and hypodivergent skeletal pattern. J Peking Univ 2005;37:425-8.

Lowe AA. Correlations between orofacial muscle activity and craniofacial morphology in a sample of control and anterior open-bite subjects. Am J Orthod 1980;78:89-98.

Ludwig M. A cephalometric analysis of the relationship between facial pattern, interincisal angulation, and anterior overbite changes. Angle Orthod 1967;37:194-204.

Lyotard N, Hans M, Nelson S, Valiathan M. Short-term postorthodontic changes in the absence of retention. Angle Orthod 2010;80:1045-50.

Miao Y, Liu C. Long-term stability of orthodontic treatment out of retention. Zhonghua Kou Qiang Yi Xue Za Zhi 2002;37:216-8.

Moorrees CFA. The dentition of the growing child. A longitudinal study of dental development between 3 and 18 years of age. Cambridge: Harvard University Press, 1959. 
Nahoum HI, Horowitz SL, Benedicto EA. Varieties of anterior open-bite. Am J Orthod 1972;61:486-92.

Neff CW. Tailored occlusion with the anterior coefficient. Am J Orthod 1949;35:309-13.

Otto RL, Anholm JM, Engel GA. A comparative analysis of intrusion of incisor teeth achieved in adults and children according to facial type. Am J Orthod 1980;77:437-46.

Park H, Boley JC, Alexander RA, Buschang PH. Age-related long-term posttreatment occlusal and arch changes. Angle Orthod 2010;80:247-53.

Parker CD, Nanda RS, Currier GF. Skeletal and dental changes associated with the treatment of deep bite malocclusion. Am J Orthod Dentofac Orthop 1995; 107:382-93.

Payne GW. A cephalometric analysis of the effects of growth on certain anatomical facial planes after orthodontic treatment. Thesis. University of Washington, 1964.

Prakash P, Margolis HI. Dento-craniofacial relations in varying degree of overbite. Am J Orthod 1952;38:657-73.

Preston CB, Maggard MB, Lampasso J, Chalabi O. Long-term effectiveness of the continuous and the sectional archwire techniques in levelling the curve of Spee. Am J Orthod Dentofac Orthop 2008;133:550-5. 
Ricketts RM. Perspectives in the clinical application of cephalometrics. Angle Orthod $1981 ; 51: 115-50$.

Riolo ML, Moyers RE, McNamara JA, Hunter WS. An atlas of craniofacial growth. Monograph Number 2. Craniofacial Growth Series. Anne Arbor: Center for Human Growth and Development, University of Michigan, 1974.

Schudy FF. The control of vertical overbite in clinical orthodontics. Angle Orthod 1968;38:19-38.

Schutz-Fransson U, Bjerklin K, Lindsten R. Long-term follow-up of orthodontically treated deep bite patients. Eur J Orthod 2006;28:503-12.

Simons ME, Joondeph DR. Change in overbite: a ten-year postretention study. Am J Orthod 1973;64:349-67.

Strang RHW, Thompson WM. A text-book of orthodontia. Fourth edition. Lea \& Febiger, Philadelphia. 1958.

Woods MG. Sagittal mandibular changes with overbite correction in subjects with different mandibular growth directions: Late mixed- dentition treatment effects. Am J Orthod Dentofac Orthop 2008;133:388-94. 